\title{
Cerebral microembolic signals in cardiac interventions
}

Citation for published version (APA):

Sauren, L. D. C. (2009). Cerebral microembolic signals in cardiac interventions. [Doctoral Thesis, Maastricht University]. Datawyse / Universitaire Pers Maastricht. https://doi.org/10.26481/dis.20091215ls

Document status and date:

Published: 01/01/2009

DOI:

10.26481/dis.20091215ls

Document Version:

Publisher's PDF, also known as Version of record

\section{Please check the document version of this publication:}

- A submitted manuscript is the version of the article upon submission and before peer-review. There can be important differences between the submitted version and the official published version of record.

People interested in the research are advised to contact the author for the final version of the publication, or visit the DOI to the publisher's website.

- The final author version and the galley proof are versions of the publication after peer review.

- The final published version features the final layout of the paper including the volume, issue and page numbers.

Link to publication

\footnotetext{
General rights rights.

- You may freely distribute the URL identifying the publication in the public portal. please follow below link for the End User Agreement:

www.umlib.nl/taverne-license

Take down policy

If you believe that this document breaches copyright please contact us at:

repository@maastrichtuniversity.nl

providing details and we will investigate your claim.
}

Copyright and moral rights for the publications made accessible in the public portal are retained by the authors and/or other copyright owners and it is a condition of accessing publications that users recognise and abide by the legal requirements associated with these

- Users may download and print one copy of any publication from the public portal for the purpose of private study or research.

- You may not further distribute the material or use it for any profit-making activity or commercial gain

If the publication is distributed under the terms of Article $25 \mathrm{fa}$ of the Dutch Copyright Act, indicated by the "Taverne" license above, 
Cerebral microembolic signals in cardiac interventions 
ISBN 9789052788852

C copyright Loes Sauren, Maastricht 2009

Printing: Datawyse / Universitaire Pers Maastricht 


\title{
Cerebral microembolic signals in cardiac interventions
}

\author{
PROEFSCHRIFT \\ Ter verkrijging van de graad van doctor \\ aan de Universiteit Maastricht, \\ op gezag van de Rector Magnificus, \\ Prof. mr. G.P.M.F. Mols, \\ volgens het besluit van de College van Decanen, \\ in het openbaar te verdedigen \\ op dinsdag 15 december 2009 om 16:00 uur \\ door \\ Loes Dorien Christien Sauren
}

$\mathrm{U}_{\mathrm{M}}^{\mathrm{M}}$ 


\section{Promotores}

Prof. dr. J.G. Maessen

Prof. dr. W.H. Mess

\section{Copromotor}

Dr. ir. F.H. van der Veen

\section{Beoordelingscommissie}

Prof. dr. J.L. Waltenberger (voorzitter)

Prof. dr. M. Kaps (Universitätsklinikum Giessen, Duitsland)

Prof. dr. M.A.E. Marcus

Dr. R.J. van Oostenbrugge

Prof. dr. ir. F.N. van de Vosse

Financial support by Stichting Hartsvrienden Rescar and by the Netherlands Heart Foundation for the publication of this thesis is gratefully acknowledged.

Additional support was granted by School of Medical Physics and

Engineering, Eindhoven 


\section{CONTENTS}

$\begin{array}{lll}\text { Chapter } 1 & \text { Introduction } & 7\end{array}$

Chapter 2 Emboli occurrence during coronary artery bypass surgery: $\quad 19$ The influence of a new method of perfusionist blood sampling

Chapter 3 Increased number of cerebral emboli during percutaneous endocardial pulmonary vein isolation versus a thoracoscopic epicardial approach

Chapter 4 Transcranial measurement of cerebral microembolic signals during endocardial pulmonary vein isolation: comparison of three different ablation techniques

Chapter 5 New-ultrasonic-radiation reduces cerebral emboli during extracorporeal circulation

Chapter 6 The EmBlocker ${ }^{\mathrm{TM}}$ : Efficiency and safety of a new ultrasonic embolic protection device adjunctive to heart valve surgery

Chapter 7 Quantification of embolic showers using radio-frequency based TCD analysis

Chapter 8 Discussion

Summary

Samenvatting

Publications

Curriculum vitae 

CHAPTER 1

Introduction 


\section{Scope of the problem}

Every year, worldwide at least one million patients undergo cardiovascular interventions ${ }^{1,2}$. Due to senescence and improvements in patient care, the number of cardiac interventions will grow substantially in the next years. The challenge for the future is twofold: not only an increased quantity of cardiac interventions has to be offered, but also the periprocedural morbidity has to be kept as low as possible. Especially neurological impairment is a major complication after cardiac surgery and cardiological interventions and often undermines the benefit of the intervention. The incidence of postoperative neurological impairment varies depending on the type of procedure and on the definition of "cerebral injury". The most evident cerebral injury is a clinically apparent stroke, which is affecting approximately three percent of coronary artery bypass grafting (CABG) patients ${ }^{2,3}$ and between one and five percent of patients undergoing various cardiological interventions ${ }^{4-6}$. Cognitive deficits are clinically more subtle and can be detected by careful neuropsychological examination in up to 63 percent of CABG patients ${ }^{7,8}$. Diffusion weighted magnetic resonance imaging (DW MRI) scanning is a sensitive imaging method for the detection of cerebral infarctions that are clinically silent. In 31 percent of the CABG patients and in seven to 15 percent of the patients who underwent a cardiologic treatment for atrial fibrillation, DW MRI demonstrated new ischemic lesions postprocedurally ${ }^{9,10}$.

Impaired neurological function after cardiac procedures is associated with substantial increases in mortality, length of hospitalisation, and use of intermediateor long-term care facilities. These put a considerable burden on the health care system. Worldwide, neurological complications after CABG add approximately inhospital costs of $\$ 400$ million extra annually additional to the procedural costs and even up to $\$ 4$ billion if long-term-hospital need is included.

Thus, a significant increase of cardiac surgeries and interventional cardiological procedures can be expected in the nearby future. These procedures are likely to account for neurological impairment postprocedurally in a substantial amount of patients. It is therefore of paramount interest to unravel the mechanisms leading to cerebral injury, which might then allow for developing safer techniques. Besides a temporarily decreased cerebral blood flow, embolism might cause cerebral injury. It could indeed be shown that more than $60 \%$ of all strokes after open heart surgery were of embolic origin 3, 8, 11. Most strokes presented already on the first postoperative day $(40 \%)$, implicating that they are presumably related to intraoperative embolism. These early strokes are associated with a higher inhospital mortality compared to delayed stokes ${ }^{3,11}$. The reduction of early stroke might be accomplished by identification of embolic sources and according to that redesign of clinical protocols or equipment to diminish the amount of emboli. 


\section{Detection of cerebral emboli}

Intraoperatively, Transcranial Doppler (TCD) ultrasonography can be used to identify emboli passing through the cerebral vasculature, usually in the middle cerebral artery (MCA). In 1982 Aaslid and colleagues demonstrated the possible clinical use of TCD ${ }^{12}$. An ultrasound transducer placed over the temporal bone emits a sound wave (typically with a frequency of $2 \mathrm{MHz}$ ), which is scattered back by the intracranial structures and received by the same transducer. If the ultrasound is scattered back by moving blood, the received frequency will according to the wellknown Doppler effect differ from the emitted frequency, whereby the frequency change directly correlates with the speed of the blood. It is hence possible to measure noninvasively the velocity and direction of red blood cells in the cerebral vessels.

Under normal circumstances, the amplitude of the ultrasound received from a vessel is determined by the amount of erythrocytes in the area under measurement (the so-called sample volume). Yet, when a relatively embolus is passing the vessel, the ultrasound signal that is scattered back at that moment is higher as compared to the backscatter of blood alone. Consequently, a short-lasting relative intensity increase in Doppler power is encountered, giving rise to a typical sound, which is easily recognisable to the human ear. Additionally, the signal intensity increase can be made visible in the frequency domain (i.e. the Doppler spectrogram) or in the time domain and is usually measured in decibels. The backscattered signals can be recorded for prolonged periods of time and can be analysed off-line by trained observers to obtain an accurate count of embolic signals (ES) for a given procedure 13-15

In clinical practice, ES are due to emboli consisting of either gas or particulate material ${ }^{16}$.On the average, gaseous emboli give rise to a relatively higher amplitude than do particulate emboli, which can be expressed as a difference of the so-called effective sample volume length ${ }^{17}$. In practice, however, a correct size determination is impeded by several factors, for example the complex relationship between the sample volume properties and the embolus passing by.

Applying advanced Doppler ultrasound instrumentation, Russel and Brucher proposed a new method for the discrimination between the two types of emboli on the basis of their different physical properties when insonated ${ }^{18}$. Yet, their data could not be reproduced by others ${ }^{14,19}$. To summarise, in clinical practice a reliable distinction of an individual embolus with regard to its composition is not feasible at the present moment.

The individual emboli measured during cardiac procedures do not cause an obstruction of one of the main cerebral arteries, resulting in a substantial reduction flow further distally, which might lead to acute cerebral symptomatology. Therefore these emboli are called microemboli (ME) that can be recognised by TCD as microembolic signals (MES). So, an individual ME is commonly regarded to cause no 
symptoms in itself, but functions as an indicator of an ongoing emboligenic process. However, if the number and size of all ME within a given time (the so-called "embolic load") exceed a certain threshold, the asymptomatic nature of ME appears to be relative. This threshold currently is unknown and likely to be different for gaseous and particulate $\mathrm{ME}^{20}$.

The detection of MES in the context of cardiac procedures relies in first instance on aural evaluation of the Doppler signal by a trained observer. Additional information on the presence of an MES can be derived visually either from spectrogram or the time domain signal. This method currently is considered to be the gold standard for counting MES emboli but it is very time-consuming and strenuous for the examiner. In the recent years, therefore, automatic MES detection systems have been developed. Although the reliability of counting relatively small MES stemming from carotid artery plaques has improved considerably, no current system has the required sensitivity and specificity for the use during cardiac interventions ${ }^{13-15,19}$.

\section{Do cerebral emboli matter?}

As outlined above ME can be of either gaseous or particulate nature. The latter are likely to have greater clinical significance than gaseous ME since they will block distal arteries for a relatively longer period and hence cause cerebral ischemia. Nevertheless, both particulate and gaseous ME may cause cerebral inflammation, cerebral oedema and small capillary arteriolar dilatations, which in turn may be responsible for cerebral seizures and cerebral microinfarctions ${ }^{9,21-25}$.

With the use of TCD monitoring during cardiac surgery, several intraoperative events have been identified that contribute to the total cerebral embolic load ${ }^{8,26-28}$. The specific manipulations or interventions which generate emboli are well described However, the total number of detected cerebral emboli during cardiac surgery procedures varies considerably between patients. Figures between 60 emboli ${ }^{29}$ and 2069 emboli have been reported ${ }^{8}$.

Numerous studies demonstrated a correlation between the number of MES and postoperative neurological complications $5,8,24,26,27,30,31$. More specifically, a correlation between the number of cerebral MES and the incidence of the degree of cognitive decline has been demonstrated. Decreasing the number of cerebral MES during cardiopulmonary bypass (CPB) from more than 1.000 to less than 200 reduced the occurrence of a postoperative cognitive decline from $43 \%$ to less than $10 \%$. A reduction to less than 100 cerebral MES per procedure was found to prevent any significant cognitive decline ${ }^{8,24}$. It was also shown that a reduction to half the amount of MES during cardiologic procedures resulted in a reduction of the acute symptomatic neurological complications (transient ischemic attack (TIA)) from $3 \%$ to less than $1 \%^{5,31}$. So, the number of MES during cardiac surgery appears to be 
associated with impaired cerebral function. Hence the determination of the number of MES periprocedurally provides important information on the risk of neurological complications. MES might serve as a surrogate parameter to study the effectiveness of new therapeutic strategies. 


\section{Outline of the thesis}

\section{Awareness of cardiac microemboli}

As has been discussed, TCD monitoring whilst cardiac procedures allows for an estimation of the risk of neurological complications. In order to reduce that risk, it is important to identify the specific moments and sources of ME. On the one hand, different stages of e.g. the CABG procedure are well-known for their emboligenic potential. On the other hand, ME might occur unexpectedly, e.g. due to technical failure. A practical example is the incorrect placement of the venous cannula in the right atrium, resulting in suction of air into the venous line of the CPB. This failure would remain unnoticed without TCD monitoring. However, immediate identification of embolisation by intraoperative TCD monitoring can alert the surgeon, and restoration of airless pump inflow can be accomplished, which will result in a limited number of cerebral MES ${ }^{32}$.

An example for interventions causing ME that can reasonably be expected during $C A B G$ are perfusion interventions, which are known to be a source of bubble introduction in the arterial line ${ }^{28,32}$. These perfusion interventions are inevitable during cardio-pulmonary support, but possibly, adjustments of the equipment or the standard protocol could reduce the number of cerebral ME perioperatively. In chapter one of this thesis two methods of a specific perfusion intervention, which is taking blood samples, are evaluated with respect to the occurrence of ME in the CPB system and in the MCAs.

Pulmonary vein isolation (PVI) has become the treatment of choice for patients with atrial fibrillation (AF) if pharmacological treatment and electrical cardioversion do not have the desired effect. AF is associated with a three-fold increase of stroke risk $^{33}$. So, the mortality, disability, and costs related to cardioembolic stroke are likely to be considerably reduced by advances in treatment of AF. However, PVI itself bears the risk of thromboembolic complications, i.e. also stroke. It has been shown that clinically symptomatic neurological complications (TIA) occur in up to $2.2 \%{ }^{34}$. Additionally, asymptomatic cerebral ischemic lesions are found on diffusion weighted $\mathrm{MRI}$ images in $7 \%{ }^{9}$ of PVI patients. It was demonstrated that ME are generated during PVI procedures and that there is a correlation between these ME and neurological complications ${ }^{5,31}$. Understanding how emboli emerge during PVI and determining the number of $\mathrm{ME}$ are crucial steps to recognise possibly adjustable sources of embolisation and thus being able to find a solution to reduce the amount of ME.

In chapter two we compare the occurrence of cerebral MES during a newly developed epicardial PVI procedure, which is minimally invasive and uses a thoracoscopic epicardial approach, with a standard endocardial method using a radiofrequency (RF) ablation catheter for PVI. It is conceivable that the epicardial 
approach might differ from the endocardial approach with respect to its emboligenicity since no intravascular manipulation is involved. We, therefore, determined the specific moments and mechanisms of embolisation in both the endocardial and epicardial PVI procedure, as well as the amount of cerebral MES which is interpreted as a surrogate marker of the risk for neurological complications.

Since it has been shown that endocardial PVI is accompanied by the occurrence of a large amount of $\mathrm{ME}$, alternative catheter designs and techniques have been developed. A possible candidate for the generation of ME during endocardial PVI is local heating which occurs with most catheters used in clinical practice. Hence, a conventional PVI catheter has been developed allowing for a relatively lower working temperature due to cooling of the tip of the catheter. A second alternative applies a cryo energy source, using temperatures of $-80^{\circ} \mathrm{C}$. Hence local heating is completely absent, which might lower the thrombogenicity of the PVI catheter. Consequently, the risk of post-procedural neurological complications might be favourable as compared to the use of conventional catheter design. In chapter three the rate of embolisation caused by three different catheter designs including the two latter types is examined.

In the first three chapters the occurrence of cerebral MES is studied in cardiac interventions to provide information about embolisation in these procedures. The total number of cerebral MES is used as an indication of the risk of neurological complications of each procedure. After this first step of becoming aware of the sources and the total number of cerebral MES the second step should be to reduce cerebral MES in order to lower the risk of periprocedural neurological impairment.

\section{Reducing cerebral microemboli}

Even if the number of ES can be lowered during cardiac procedures, it is unlikely that a complete elimination will be feasible. For example, during CABG, cannulation of the aorta as well as using CPB will irrevocably be accompanied by ES.

Commercially available devices to reduce cerebral ME during cardiac surgery include arterial line filters, bubble traps in cardiopulmonary bypass systems and intra-aortic filters. The use of arterial filters or bubble traps during open-heart surgery can reduce the gaseous cerebral ME significantly during perfusion interventions ${ }^{35}$, but are not capable of lowering the cerebral microembolisation during aortic manipulations. The intra-aortic filter is a highly invasive method to reduce cerebral ME, however, it is associated with complications ${ }^{36,37}$.

The EmBlocker ${ }^{\mathrm{TM}}$ is a newly developed ultrasonic device that is placed on top of the aortic arch with its ultrasound field directed away from the head. Theoretically, any emerging ME might be directed away from the cerebral vessels by the pressure 
of the ultrasound field. Hence, the number of cerebral ME during cardiac surgery might be reduced.

In chapter 4, we evaluated the safety of this new technology in an animal experiment. Histopathological, haematological and temperature changes were analysed in order to estimate the risk of side effects caused by implementation of the EmBlocker ${ }^{\mathrm{TM}}$. Additionally, to evaluate the efficiency in terms of lowering the number of cerebral ME, known quantities of $\mathrm{ME}$ were injected into the animal systemic circulation with alternating activation of the EmBlocker ${ }^{\mathrm{Tm}}$. Assuming that application of the EmBlocker ${ }^{\mathrm{TM}}$ will indeed reduce cerebral embolism in an animal experiment, it has to be shown that these results can be translated into the human situation. In chapter 5, we describe a clinical pilot study, were the number of cerebral MES was compared between patients in whom the EmBlocker ${ }^{\mathrm{TM}}$ was applied and a control group.

\section{Determination of the correct embolic load}

Several attempts have been described, including those presented in this thesis, to reduce the amount of intraoperatively occurring $M E$ and hence the risk of neurological complications. Assuming that ME and neurological complications are related to each other the most accurate determination of the cerebral embolic load is required if one wants to estimate the neurological risk factor for a given cardiac procedure as reliably as possible. The embolic load depends on the number, the volume, and the composition of the emboli. Previous attempts to determine volume and composition of cerebral ME ${ }^{18,38}$, were not flawless ${ }^{14,19}$. At this moment, there is no method available to reliably estimate the aforementioned parameters in daily practice.

At present, the best possible method of counting the number of cerebral MES is having two human observers evaluating independently the audio signal and either the Doppler spectrogram or the time domain signal. A remarkably high interobserver agreement was found for this approach ${ }^{39}$, equivalent or higher levels of agreement could be reached in MES reading than in CT or MRI reading.

So, counting the number the MES appears to be much more feasible than evaluating size and composition of the embolus. We determined the number of MES according to the abovementioned method in the first five chapters. For single emboli this manual counting in practice is accurate and easily to accomplish. However, during cardiac surgery it is quite common that a large amount of MES pass the MCA in a very short time, giving rise to a so-called cluster or "shower". In this case, MES might even overlap, i.e. stem from different depths simultaneously. When such a cluster enters the Doppler sample volume, it is hardly possible to determine the exact number of $\mathrm{ME}$, neither visually nor acoustically, if one relies on the Doppler signal. This drawback is likely to cause an underestimation of the 
number of cerebral ME which enter the brain during such a shower and thereby the cerebral embolic load during cardiac interventions. So, until now a correct estimation of the embolic load during cardiac surgery is not only hampered by the inability to correctly identify the size and composition of the emboli, but also to accurately count the number of emboli when they occur as a cluster.

An alternative method for evaluating MES does not rely on its velocity characteristics, i.e. the Doppler frequency shift but on its amplitude properties. Moehring et al. could show that the spatial resolution was considerably better, using a multigated system. This so-called power M-mode technology is able to simultaneously provide the Doppler shift, as well as the amplitude of the backscattered ultrasound waves over a wide range of depths ${ }^{40}$. Mess et al demonstrated that emboli can be visualised with an even higher spatial and temporal resolution by using an offline digital postprocessing system based on the analysis of the unprocessed backscattered radiofrequency (RF) ultrasound ${ }^{41}$. So, the latter technology might potentially improve the accuracy of emboli detection, especially during showers. In chapter 6 we present the results of a study where we used the RF-based emboli detection technology in combination with a novel automatic detection algorithm during cardiac surgery.

Finally, the general discussion will not only cover the most essential results of the aforementioned chapters but also elaborate on the usefulness of MES detection in the evaluation of cardiac interventions and their risk of inducing neurological complications. 


\section{References}

1. Association AH. Heart Disease and Stroke 2008 Update At-a-Glance statistics. 2008.

2. Roach GW, Kanchuger M, Mangano CM, Newman M, Nussmeier N, Wolman R, Aggarwal A, Marschall K, Graham SH, Ley C. Adverse cerebral outcomes after coronary bypass surgery. Multicenter Study of Perioperative Ischemia Research Group and the Ischemia Research and Education Foundation Investigators. N Engl J Med. 1996;335(25):1857-1863.

3. Lisle TC, Barrett KM, Gazoni LM, Swenson BR, Scott CD, Kazemi A, Kern JA, Peeler BB, Kron IL, Johnston KC. Timing of stroke after cardiopulmonary bypass determines mortality. Ann Thorac Surg. 2008;85(5):1556-1562; discussion 1562-1553.

4. Earley MJ, Schilling RJ. Catheter and surgical ablation of atrial fibrillation. Heart. 2006;92(2):266-274.

5. Kilicaslan F, Verma A, Saad E, Rossillo A, Davis DA, Prasad SK, Wazni O, Marrouche NF, Raber LN, Cummings JE, Beheiry S, Hao S, Burkhardt JD, Saliba W, Schweikert RA, Martin DO, Natale A. Transcranial Doppler detection of microembolic signals during pulmonary vein antrum isolation: implications for titration of radiofrequency energy. J Cardiovasc Electrophysiol. 2006;17(5):495-501.

6. Kok LC, Mangrum JM, Haines DE, Mounsey JP. Cerebrovascular complication associated with pulmonary vein ablation. J Cardiovasc Electrophysiol. 2002;13(8):764-767.

7. Newman MF, Kirchner JL, Phillips-Bute B, Gaver V, Grocott H, Jones RH, Mark DB, Reves JG, Blumenthal JA. Longitudinal assessment of neurocognitive function after coronary-artery bypass surgery. N Engl J Med. 2001;344(6):395-402.

8. Sylivris S, Levi C, Matalanis G, Rosalion A, Buxton BF, Mitchell A, Fitt G, Harberts DB, Saling MM, Tonkin AM. Pattern and significance of cerebral microemboli during coronary artery bypass grafting. Ann Thorac Surg. 1998;66(5):1674-1678.

9. Lickfett L, Hackenbroch M, Lewalter T, Selbach S, Schwab JO, Yang A, Balta O, Schrickel J, Bitzen A Luderitz B, Sommer T. Cerebral diffusion-weighted magnetic resonance imaging: a tool to monitor the thrombogenicity of left atrial catheter ablation. J Cardiovasc Electrophysiol. 2006;17(1):1-7.

10. Lund C, Nes RB, Ugelstad TP, Due-Tonnessen P, Andersen R, Hol PK, Brucher R, Russell D. Cerebral emboli during left heart catheterization may cause acute brain injury. Eur Heart J. 2005;26(13):12691275.

11. Likosky DS, Marrin CA, Caplan LR, Baribeau YR, Morton JR, Weintraub RM, Hartman GS, Hernandez F, Jr., Braff SP, Charlesworth DC, Malenka DJ, Ross CS, O'Connor GT. Determination of etiologic mechanisms of strokes secondary to coronary artery bypass graft surgery. Stroke. 2003;34(12):28302834.

12. Aaslid R, Markwalder TM, Nornes H. Noninvasive transcranial Doppler ultrasound recording of flow velocity in basal cerebral arteries. J Neurosurg. 1982;57(6):769-774.

13. Markus H. Monitoring embolism in real time. Circulation. 2000;102(8):826-828.

14. Markus HS, Punter M. Can transcranial Doppler discriminate between solid and gaseous microemboli? Assessment of a dual-frequency transducer system. Stroke. 2005;36(8):1731-1734.

15. Ringelstein EB, Droste DW, Babikian VL, Evans DH, Grosset DG, Kaps M, Markus HS, Russell D, Siebler M. Consensus on microembolus detection by TCD. International Consensus Group on Microembolus Detection. Stroke. 1998;29(3):725-729.

16. Mess WH HM. High Intensity Transient Signals. Cerebrovascular Ultrasound; Theory, Practice and Future Developments. Cambridge: Cambridge Univeristy Press; 2001:297-316.

17. Smith JL, Evans DH, Bell PR, Naylor AR. A comparison of four methods for distinguishing Doppler signals from gaseous and particulate emboli. Stroke. 1998;29(6):1133-1138.

18. Russell D, Brucher R. Online automatic discrimination between solid and gaseous cerebral microemboli with the first multifrequency transcranial Doppler. Stroke. 2002;33(8):1975-1980.

19. Evans DH. Embolus differentiation using multifrequency transcranial Doppler. Stroke. 2006;37(7):1641.

20. Chung EM, Hague JP, Evans DH. Revealing the mechanisms underlying embolic stroke using computational modelling. Phys Med Biol. 2007;52(23):7153-7166. 
21. Moody DM, Brown WR, Challa VR, Stump DA, Reboussin DM, Legault C. Brain microemboli associated with cardiopulmonary bypass: a histologic and magnetic resonance imaging study. Ann Thorac Surg. 1995;59(5):1304-1307.

22. Muth CM, Shank ES. Gas embolism. N Engl J Med. 2000;342(7):476-482.

23. Omran $H$, Schmidt $H$, Hackenbroch $M$, Illien $S$, Bernhardt $P$, von der Recke G, Fimmers R, Flacke $S$, Layer G, Pohl C, Luderitz B, Schild H, Sommer T. Silent and apparent cerebral embolism after retrograde catheterisation of the aortic valve in valvular stenosis: a prospective, randomised study. Lancet. 2003;361(9365):1241-1246.

24. Pugsley W, Klinger L, Paschalis C, Treasure T, Harrison M, Newman S. The impact of microemboli during cardiopulmonary bypass on neuropsychological functioning. Stroke. 1994;25(7):1393-1399.

25. Restrepo L, Wityk RJ, Grega MA, Borowicz L, Jr., Barker PB, Jacobs MA, Beauchamp NJ, Hillis AE, McKhann GM. Diffusion- and perfusion-weighted magnetic resonance imaging of the brain before and after coronary artery bypass grafting surgery. Stroke. 2002;33(12):2909-2915.

26. Borger MA, Peniston CM, Weisel RD, Vasiliou M, Green RE, Feindel CM. Neuropsychologic impairment after coronary bypass surgery: effect of gaseous microemboli during perfusionist interventions. J Thorac Cardiovasc Surg. 2001;121(4):743-749.

27. Clark RE, Brillman J, Davis DA, Lovell MR, Price TR, Magovern GJ. Microemboli during coronary artery bypass grafting. Genesis and effect on outcome. J Thorac Cardiovasc Surg. 1995;109(2):249-257; discussion 257-248.

28. Taylor RL, Borger MA, Weisel RD, Fedorko L, Feindel CM. Cerebral microemboli during cardiopulmonary bypass: increased emboli during perfusionist interventions. Ann Thorac Surg 1999;68(1):89-93.

29. Lund C, Hol PK, Lundblad R, Fosse E, Sundet K, Tennoe B, Brucher R, Russell D. Comparison of cerebral embolization during off-pump and on-pump coronary artery bypass surgery. Ann Thorac Surg. 2003;76(3):765-770; discussion 770.

30. Abu-Omar Y, Cifelli A, Matthews PM, Taggart DP. The role of microembolisation in cerebral injury as defined by functional magnetic resonance imaging. Eur J Cardiothorac Surg. 2004;26(3):586-591.

31. Marrouche NF, Martin DO, Wazni O, Gillinov AM, Klein A, Bhargava M, Saad E, Bash D, Yamada H, Jaber W, Schweikert R, Tchou P, Abdul-Karim A, Saliba W, Natale A. Phased-array intracardiac echocardiography monitoring during pulmonary vein isolation in patients with atrial fibrillation: impact on outcome and complications. Circulation. 2003;107(21):2710-2716.

32. Lynch JE, Riley JB. Microemboli detection on extracorporeal bypass circuits. Perfusion. 2008;23(1):23-32

33. Ferro JM. Cardioembolic stroke: an update. Lancet Neurol. 2003;2(3):177-188

34. Wazni OM, Rossillo A, Marrouche NF, Saad EB, Martin DO, Bhargava M, Bash D, Beheiry S, Wexman M, Potenza D, Pisano E, Fanelli R, Bonso A, Themistoclakis S, Erciyes D, Saliba WI, Schweikert RA, Brachmann J, Raviele A, Natale A. Embolic events and char formation during pulmonary vein isolation in patients with atrial fibrillation: impact of different anticoagulation regimens and importance of intracardiac echo imaging. J Cardiovasc Electrophysiol. 2005;16(6):576-581.

35. Martens S, Dietrich M, Pietrzyk R, Graubitz K, Keller H, Moritz A. Elimination of microbubbles from the extracorporeal circuit: dynamic bubble trap versus arterial filter. Int J Artif Organs. 2004;27(1):55-59

36. Gerriets T, Schwarz N, Baehr J, Stolz E, Kluge A, Kaps M, Klovekorn W, Bachman G, Schonburg M. Do filters protect the brain from microembolization during bypass surgery. Paper presented at: Cerebrovasular disease, 2007.

37. Leyh RG, Fischer S, Harringer W, Haverich A. Intraoperative acute type A dissection caused by an intra-aortic filter (EMBOL-X) in a patient undergoing mitral valve re-replacement for acute endocarditis. Eur J Cardiothorac Surg. 2002;21(1):100-101.

38. Barbut D, Yao FS, Lo YW, Silverman R, Hager DN, Trifiletti RR, Gold JP. Determination of size of aortic emboli and embolic load during coronary artery bypass grafting. Ann Thorac Surg. 1997;63(5):12621267 
39. Dittrich R, Ritter MA, Kaps M, Siebler M, Lees K, Larrue V, Nabavi DG, Ringelstein EB, Markus HS, Droste DW. The use of embolic signal detection in multicenter trials to evaluate antiplatelet efficacy: signal analysis and quality control mechanisms in the CARESS (Clopidogrel and Aspirin for Reduction of Emboli in Symptomatic carotid Stenosis) trial. Stroke. 2006;37(4):1065-1069.

40. Moehring MA, Spencer MP. Power M-mode Doppler (PMD) for observing cerebral blood flow and tracking emboli. Ultrasound Med Biol. 2002;28(1):49-57.

41. Mess WH, Willigers JM, Ledoux LA, Ackerstaff RG, Hoeks AP. Microembolic signal description: a reappraisal based on a customized digital postprocessing system. Ultrasound Med Biol. 2002;28(1112):1447-1455. 
CHAPTER 2

\section{Emboli occurrence during coronary artery bypass surgery: The influence of a new method of perfusionist blood sampling}

Published in

Perfusion. 2008 Sep;23(5):261-5

Sauren LD, Mooren E, Severdija E, Weerwind P, Maessen JG. 


\section{Abstract}

Introduction

Perioperative cerebral microemboli in cardiac surgery are associated with postoperative neurological complications cardiopulmonary bypass (CPB) and perfusionist interventions are important contributors of microemboli. In this study, we examined the influence of blood sampling by the perfusionist on MES appearance in an open and closed CPB system.

Methods

Fourteen patients underwent isolated coronary artery bypass grafting (CABG), using either an open or closed CPB system. Patients were monitored with transcranial Doppler (TCD) for the occurrence of microembolic signals (MES) in as well both middle cerebral arteries (MCA) as in the arterial and venous line of the CPB. In the closed systems two sampling methods were used, named "traditional" and "E-line". In the latter a shunt line was applied from the manifold to the cardiotomy reservoir. In the open system one method of blood sampling was used.

Results

Blood sampling in an open system or in a closed system using the E-line resulted in $0.2( \pm 0.56) \mathrm{MES}$, which was significant lower than the traditional method (72 ( \pm 69$)$ MES).

Conclusion

The use of a shunt line reduces MES during blood sampling in closed CPB system. 


\section{Introduction}

Despite impressive improvements in the overall safety of cardiac surgery, cerebral injury remains a major concern after cardiac surgery ${ }^{1-7}$. The two major causative factors for neuropsychological dysfunction after cardiac surgery are global brain hypoperfusion and cerebral emboli, generated by either surgical or perfusion related interventions ${ }^{2,6,8}$. Reducing cerebral emboli to diminish neurological injury emboli should be a major goal in the fields of cardiac anaesthesia, surgery and perfusion ${ }^{2,4-6}$. Since 1990, Transcranial Doppler (TCD) is used to detect cerebral microembolic signals (MES) in the middle cerebral arteries. Studies have shown that total emboli counts on the TCD during CABG can vary from approximately 200 cerebral MES ${ }^{2,9}$ to 2000 cerebral MES per procedure ${ }^{10}$. As CPB and predominantly perfusionist interventions have been shown to be the main source of the cerebral MES, this study has special attention to emboli occurring during perfusion ${ }^{1,} 9$. Installation of the manifold for drug administration and taking blood samples appears to affect the amount of emboli injected into the systemic circulation 2, 9, 11 . In this study, we examined the influence of blood sampling and injection techniques by the perfusionist on MES appearance in an open and closed CPB system.

\section{Methods}

Fourteen patients undergoing isolated CABG or redo CABG were continuously monitored for MES in both middle cerebral arteries with TCD. The used CPB system was randomly chosen, in seven cases an open CPB system was used and in seven a closed CPB system. The exclusion criteria used were: off pump coronary artery bypass grafting (OPCAB), on-pump CABG without aortic cross-clamping, or insufficient acoustic window of the temporal bone to obtain TCD signals.

\section{Cardiopulmonary bypass}

Both open and closed CPB configurations are shown in figure 1. A Sorin-Stöckert S3 roller pump (Sorin S.p.A., Mirandola, Italy) was used in both groups. In both CPB groups a capillary membrane oxygenator with integrated heat exchanger (Capiox 3CXSX18RX), a 40 micron arterial filter (Jostra Leucogard, Jostra Maquet, Hirrlingen Germany), and a hard shell cardiotomy reservoir (Capiox HE-HC 282, Terumo CVS) were used. For the closed systems a soft-shell venous reservoir (Jostra JVR 1900, Maquet) was used. Both CPB circuits were Bioline coated (Jostra, Maquet). For proper de-airing of the arterial cannula during insertion, the vent caps (Edwards Life Sciences) have been used. 


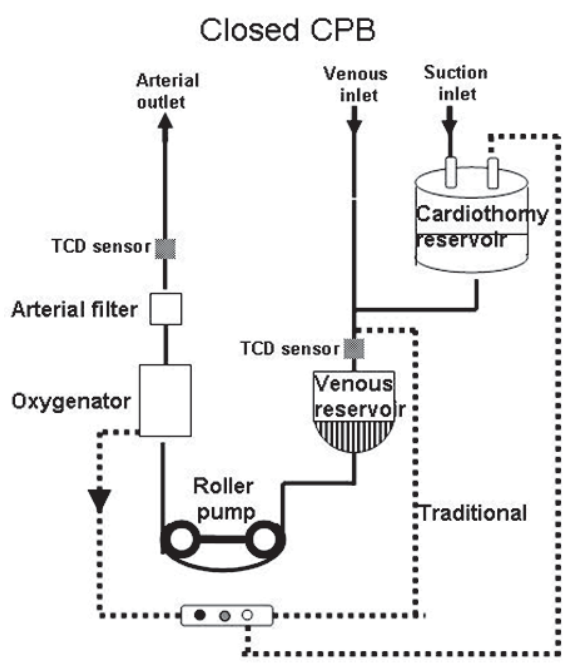

A

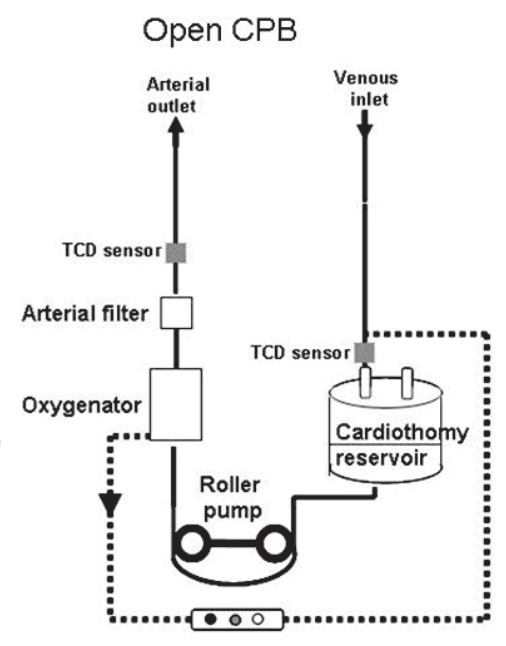

B

Figure 1: A schematic overview of a closed CBP (A) and an open CPB (B).

The open CPB systems is similar in components as the closed CPB except for the absence of a soft shell venous reservoir. The venous line was connected to the top of the hard shell venous reservoir, which in this system also serves as a cardiotomy reservoir. A three-way stopcock manifold served as a port for both injection and blood sampling. For the administration of phenylephrine, an infusion pump was installed to reduce the risk of air injection. The arterial side of the manifold was connected to the arterial line of the CPB circuit through a one-way valve. In the open system, the venous side of the manifold was connected to the venous CPB line at the top inlet of the hard shell venous reservoir. In the closed system the venous line of the manifold was connected to the bottom of the soft shell venous reservoir near the connector by which the venous blood enters the reservoir. Also a shunt line from the manifold to the lure port on top of the cardiotomy reservoir was installed, called the E-line. Through this E-line the blood was returned after a sampling procedure (figure $1 \mathrm{~A}$ ).

In the closed CPB system two methods of blood sampling were used, called "traditional" and "E-line". In the CABG procedures with open CPB system only one sampling method was used and officiates as control. Three methods of blood sampling were compared in this study: i) open, ii) closed traditional, iii) closed Eline.

In the "traditional" way of sampling, the sample syringe $(2.5 \mathrm{ml})$ was flushed into the venous site of the manifold which empties into the venous CPB line. This results in multiple flushes of the syringe before the desirable blood has been collected in the sample syringe. In the "E-line" method a shunt was created to 
deviate flush samples from the manifold to the cardiotomy reservoir. This assures that all blood volume injected during the blood sampling procedure will be emptied into the cardiotomy reservoir. In the closed CPB systems the method of blood sampling was alternated. In a closed CPB CABG procedure, approximately half the samples were taken with the E-line method and half with the traditional method.

\section{Emboli detection and analysis}

Microembolic signal detection was performed with two devices as shown in figure 1. A TCD (Doppler Box, DWL, Compumedics, Singen, Germany) with two $2 \mathrm{MHz}$ probes was used to monitor both middle cerebral arteries. The cerebral TCD recording was started at the beginning of sternotomy until closure of the sternum. Additionally, another $2 \mathrm{MHz}$ TCD device (Spencer PMD 100, Spencer Technologies, Seattle, WA, USA) was used to monitor microembolic signals in the arterial and venous CPB lines (figure 1). Special probe connectors were clamped on the lines to keep the transducers in fixed positions. In all cases the arterial probe was placed downstream the arterial filter. The venous probe was set just behind the connector that connects the venous line of the perfusionist manifold to the venous CPB line. The arterial and venous TCD recordings were started at the moment of cannulation, and continued until two minutes after decannulation. The TCD recordings were divided in 2 time frames: 1 . bypass time (time on CPB) and 2. cross-clamp time. The cross-clamp time is the period in which the detected cerebral MES have their origin only from the CPB.

Perfusionist interventions were defined as the time period from the start of the intervention till 2 minutes after the intervention. If another perfusion intervention of surgical interventions occurred in the 2 minutes time frame, the perfusionist interventions were considered a drop out for data analysis.

Computer software from DWL (QL 1.5.1) was used to review the data from the middle cerebral arteries. The Spencer PMD 100 contained on-board software to review the recordings of the arterial and venous line. The complete procedure was recorded on both TCD and analysed offline. Two trained, blinded physicians independently manually counted according to the established consensus criteria ${ }^{12-}$

${ }^{14}$. All data was analysed using the statistical software package SPSS ${ }^{\circledR}$ version 12.0 (SPSS Inc., Chicago, IL). P values of $<0.05$ were considered statistically significant.

\section{Results}

A total of 14 patients were included. Table 1 lists the group characteristics. There was no significant difference between the two groups regarding age, height, body 
surface area, body mass index, mean pump flow, bypass time, aortic cross-clamp time or the number of perfusionist interventions.

Table 1: Patient characteristics in the closed CPB and in the open CPB group

\begin{tabular}{llll}
\hline & $\begin{array}{l}\text { Closed CPB } \\
\mathrm{n}=7\end{array}$ & $\begin{array}{l}\text { Open CPB } \\
\mathrm{n}=7\end{array}$ & p-value \\
& Mean (SD) & mean (SD) & \\
\hline Male : Female & $2: 5$ & $3: 4$ & - \\
Age & $61(6)$ & $71(10)$ & 0.090 \\
Height & $168(7)$ & $168(7)$ & 0.898 \\
BW (kg) & $74(11)$ & $76(8)$ & 0.385 \\
BSA (m2) & $1.85(0.2)$ & $1.88(0.1)$ & 0.274 \\
BMI & $26(3)$ & $27(3)$ & 0.53 \\
Mean flow during CPB (ml) & $4471(449)$ & $4514(333)$ & 0.593 \\
Bypass time in minutes & $79(23)$ & $79(21)$ & 0.899 \\
Cross-clamp time in minutes & $51(13)$ & $40(15)$ & 0.695 \\
Perfusionist interventions & $9(6)$ & $7(3)$ & 0.113
\end{tabular}

CPB: Cardiopulmonary bypass system; SD: Standard deviation; BSA: body surface area; BI: body mass index

The total number of micro embolic signals (MES) during each procedure was counted. Table 2 shows the average emboli counts during the whole procedure of both groups. No significant difference was demonstrated between the total number of cerebral MES in the closed CPB and open CPB groups. In both groups, most cerebral MES were detected while the patient was on bypass. In the open CPB procedure, $91 \%$ and, in the closed CPB procedures, $72 \%$ of the total amount of cerebral MES were detected in the bypass period.

Table 2: Average number of cerebral MES during three different time periods.

\begin{tabular}{llll}
\hline & Closed CPB & Open CPB & p-value \\
& $\mathrm{n}=7$ & $\mathrm{n}=7$ & \\
& Mean (SD) & Mean (SD) & \\
\hline Complete procedure & $416(505)$ & $246(167)$ & 0.104 \\
Bypass time & $377(494)$ & $177(159)$ & 0.080 \\
Cross-clamp time & $204(368)$ & $89(136)$ & 0.199 \\
\hline
\end{tabular}

MES: micro embolic signals; CPB: cardiopulmonary bypass system; SD: standard deviation

Table 3: Average number of arterial line and cerebral MES per blood sample.

\begin{tabular}{llll}
\hline & \multicolumn{3}{c}{ Sampling method } \\
\cline { 2 - 4 } & "Open" & "Traditional" & "E-line" \\
& $\mathrm{n}=42$ & $\mathrm{n}=31$ & $\mathrm{n}=29$ \\
& Mean (SD) & Mean (SD) & Mean (SD) \\
\hline In arterial CPB line & $0.36(14)$ & $496(361) *$ & $0.33(43) \#$ \\
On TCD & $0.2(0.56)$ & $72(69) *$ & $0.22(0.67) \#$ \\
\hline
\end{tabular}

* = Significant difference to "Open", \# = Significant difference to "Traditional" 
A comparison of the different sampling methods is listed in table 3 . In the open CPB system group, 42 blood samples were used for data analysis. In the closed CPB system group, 60 blood samples were analysed; 31 of the traditional sampling method and 29 in the E-line sampling method. A blood sample in an open system produced an average of 0.4 MES in the arterial CPB line, and 0.2 MES in the MCAs. In a closed system using the E-line an average emboli count of 0.3 MES in the arterial CPB line and 0.2 MES in the MCA's were observed. Sampling in an open system and in a closed system with the "E-line" method both generated significant less MES as compared to the 496 MES in the arterial line, and the 72 MES in the MCAs using the "traditional" sampling method.

\section{Discussion}

During heart surgery, several studies examined the number of cerebral MES which manifested in a variation in total number of cerebral MES; ranking from 200 cerebral MES ${ }^{2,9}$ to 2000 cerebral MES ${ }^{10,15}$. Although factors such as peripheral vascular disease, the incidence of cross-clamp placement and manipulation of the ascending aorta are of importance in generating perioperative emboli and could cause various numbers of cerebral MES, they are not examined in this study ${ }^{2,8}$. Another factor which could play an essential role in the documented differences in number of perioperative cerebral MES, could be the method in which perfusion interventions are performed, as suggested by the in-vitro study of Myers et al ${ }^{11}$. Their study showed significant differences between the sampling methods. This can be confirmed by our clinical study, which demonstrated fewer MES in the arterial CPB line and in the cerebral vessels when taking blood samples in an open CPB system or in a closed system using the "E-line" compared to the "traditional" sampling method.

\section{TCD measurements}

During the entire CABG procedures, no significant differences in the total amount of cerebral MES between the open and closed CPB systems were found. This could be due to alternating the "E-line" and the "traditional" sampling method in the closed CPB group. The E-line method of sampling generated significantly less MES as compared to the traditional sampling method as demonstrated in table 3. A possible higher number of cerebral MES during bypass in the closed CPB group could be measured when only the traditional method of sampling was used. Although in this study no difference in the total number of cerebral MES could be determined between the open and closed CPB system, there is a significant difference in filtering capability between the two CPB systems used. A certain amount of air 
entering the venous line by sampling is inevitable, but in the open system no arterial MES were detected. This was in contrast to the 596 arterial MES which were observed when using the traditional sampling method in the closed system. This difference suggests a higher filtering capability of the open CPB system than that of the closed CPB system. The use of a softshell venous reservoir in the closed CPB system could be the reason for a reduced filtering capacity as suggested by Taylor et al. ${ }^{9}$. Air bubbles may be able to rise more efficiently to the top of the reservoir in hard shell reservoirs. The E-line in the closed CPB system proved a reasonable resemblance to the micro emboli-eliminating capacity of the open CPB system during blood sampling.

\section{Clinical relevance}

Microembolic load during CPB is associated with neuropsychological deficits. An overall reduction of the amount of microemboli may improve cognitive outcome of patients undergoing $\mathrm{CABG}$ using $\mathrm{CPB}{ }^{1,4-6}$. Therefore, we suggest the use of the $\mathrm{E}$ line for acquiring blood samples in all closed systems to reduce the amount of MES in the circulation.

\section{Limitations}

This study included 14 patients. In the 7 patients a closed CPB system was used and two sampling methods were used alternately in each patient. The two sampling methods show significant differences in the number of MES per blood sample, which could result in a difference in the total number of cerebral MES when using only one method of sampling in the closed CPB. Therefore, due to the alternate use of two sampling methods in each patient, it could not be determined in this study whether using the E-line sampling method reduces the overall number of cerebral MES. This flaw could be an explanation for the lack of significant difference between the total number of cerebral MES in the open CPB group and the total number of cerebral MES in closed CPB group. This could be an important aspect for future studies on this subject.

The reliability of the "golden standard" counting method decreases when the number of MES rises above approximately 10 MES per second. Empirically, we found it impossible to quantify high density embolic showers with an emboli interspacing of less than 50 ms with aural evaluation. Commercial automatic MES detection algorithms fail here as well, since their temporal resolution is limited by a refractory period in the order of 0.1 seconds ${ }^{16}$. A newly developed algorithm could not be implemented yet, due to a maximum recording period of 3 seconds ${ }^{17}$. In high density showers the number of MES per second is too large for an accurate estimation, and the amount of emboli can only be approximated. 


\section{Conclusion}

In this study, we have demonstrated that different methods of perfusionist blood sampling are responsible for differences in the generation of cerebral microemboli. A nil amount of emboli enters the systemic circulation when acquiring blood samples in an open CPB system as compared to a closed system using a traditional sampling method. When a blood sample is taken using a shunt line (E-line) from the manifold to the cardiotomy reservoir in a closed CPB system, no MES occur in the arterial line or cerebral vessels. The E-line method for acquiring blood samples in all closed systems is expected to reduce the amount of MES in the circulation and, therefore, is recommended. 


\section{References}

1. Borger MA, Peniston CM, Weisel RD, Vasiliou M, Green RE, Feindel CM. Neuropsychologic impairment after coronary bypass surgery: effect of gaseous microemboli during perfusionist interventions. J Thorac Cardiovasc Surg. 2001;121(4):743-749.

2. Clark RE, Brillman J, Davis DA, Lovell MR, Price TR, Magovern GJ. Microemboli during coronary artery bypass grafting. Genesis and effect on outcome. J Thorac Cardiovasc Surg. 1995;109(2):249-257; discussion 257-248.

3. Fearn SJ, Pole R, Wesnes K, Faragher EB, Hooper TL, McCollum CN. Cerebral injury during cardiopulmonary bypass: emboli impair memory. J Thorac Cardiovasc Surg. 2001;121(6):1150-1160.

4. Pugsley W, Klinger L, Paschalis C, Treasure T, Harrison M, Newman S. The impact of microemboli during cardiopulmonary bypass on neuropsychological functioning. Stroke. 1994;25(7):1393-1399.

5. Sylivris S, Levi C, Matalanis G, Rosalion A, Buxton BF, Mitchell A, Fitt G, Harberts DB, Saling MM, Tonkin AM. Pattern and significance of cerebral microemboli during coronary artery bypass grafting. Ann Thorac Surg. 1998;66(5):1674-1678.

6. Hammon JW, Stump DA, Butterworth JB, Moody DM. Approaches to reduce neurologic complications during cardiac surgery. Semin Thorac Cardiovasc Surg. 2001;13(2):184-191.

7. Bierbach B, Meier M, Kasper-Konig W, Heimann A, Alessandri B, Horstick G, Oelert H, Kempski O. Emboli formation rather than inflammatory mediators are responsible for increased cerebral water content after conventional and assisted beating-heart myocardial revascularization in a porcine model. Stroke. 2008;39(1):213-219.

8. van Dijk D, Moons KG, Keizer AM, Jansen EW, Hijman R, Diephuis JC, Borst C, de Jaegere PP, Grobbee $\mathrm{DE}$, Kalkman CJ. Association between early and three month cognitive outcome after off-pump and on-pump coronary bypass surgery. Heart. 2004;90(4):431-434.

9. Taylor RL, Borger MA, Weisel RD, Fedorko L, Feindel CM. Cerebral microemboli during cardiopulmonary bypass: increased emboli during perfusionist interventions. Ann Thorac Surg. 1999;68(1):89-93

10. Rodriguez RA, Rubens F, Rodriguez CD, Nathan HJ. Sources of variability in the detection of cerebral emboli with transcranial Doppler during cardiac surgery. J Neuroimaging. 2006;16(2):126-132.

11. Myers GJ. Preventing gaseous microemboli during blood sampling and drug administration: an in vitro investigation. J Extra Corpor Technol. 2007;39(3):192-198.

12. Mess WH, Titulaer BM, Ackerstaff RG. A new algorithm for off-line automated emboli detection based on the pseudo-wigner power distribution and the dual gate TCD technique. Ultrasound Med Biol. 2000;26(3):413-418.

13. Van Zuilen EV, Mess WH, Jansen C, Van der Tweel I, Van Gijn J, Ackerstaff GA. Automatic embolus detection compared with human experts. A Doppler ultrasound study. Stroke. 1996;27(10):18401843.

14. Ringelstein EB, Droste DW, Babikian VL, Evans DH, Grosset DG, Kaps M, Markus HS, Russell D, Siebler $\mathrm{M}$. Consensus on microembolus detection by TCD. International Consensus Group on Microembolus Detection. Stroke. 1998;29(3):725-729.

15. Liebold A, Khosravi A, Westphal B, Skrabal C, Choi YH, Stamm C, Kaminski A, Alms A, Birken T, Zurakowski D, Steinhoff G. Effect of closed minimized cardiopulmonary bypass on cerebral tissue oxygenation and microembolization. J Thorac Cardiovasc Surg. 2006;131(2):268-276.

16. Cullinane M, Reid G, Dittrich R, Kaposzta Z, Ackerstaff R, Babikian V, Droste DW, Grossett D, Siebler M, Valton L, Markus HS. Evaluation of new online automated embolic signal detection algorithm, including comparison with panel of international experts. Stroke. 2000;31(6):1335-1341.

17. Lipperts MG, Sauren LD, Maessen JG, Hoeks AP, Mess WH. Quantification of Embolic Showers Using Radio-Frequency Based TCD Analysis. Ultrasound Med Biol. 2008. 


\title{
CHAPTER 3
}

\author{
Increased number of cerebral \\ emboli during percutaneous \\ endocardial pulmonary vein \\ isolation versus a thoracoscopic \\ epicardial approach
}

Published in

Eur J Cardiothorac Surg. 2009 Nov;36(5):833-7

Sauren LD, la Meir M, de Roy L, Pison L, van der Veen FH, Mess WH, Crijns HJ, Maessen JG. 


\section{Abstract}

Introduction

Isolation of the pulmonary veins (PVI) using ablation energy appears an effective treatment for atrial fibrillation (AF) with a success rate of approximately $80 \%$. However, postprocedural neurological complications still occur in $0.5 \%-10 \%$ of all patients undergoing PVI, presumably due to embolism. Therefore, we investigated the occurrence of cerebral microembolic signals (MES) as a surrogate marker for the risk of neurological impairment of two different PVI methods: (1) percutaneous endocardial radiofrequency (RF) ablation and (2) thoracoscopic epicardial ablation using RF energy.

Methods

Ten patients ( 8 persistent AF and 2 paroxysmal AF) underwent a minimally invasive thoracoscopic epicardial RF ablation (EPI) and ten patients (1 persistent AF and 9 paroxysmal AF) underwent a percutaneous endocardial isolation (ENDO). Transcranial Doppler (TCD) was used to detect MES in the middle cerebral arteries.

Results

An average of $5( \pm 6)$ MES were detected during epicardial PVI procedure versus $3908( \pm 2816)$ MES during percutaneous endocardial PVI procedure. Respectively $1( \pm 1)$ and $2566( \pm 2296)$ cerebral MES were detected during the ablation application period.

Conclusions

Cerebral microemboli during epicardial ablation are almost absent when compared to the thousands of emboli measured during percutaneous endocardial ablation. 


\section{Introduction}

Atrial fibrillation (AF) is a common, potentially disabling disease, with an increasing incidence as the population ages and an incremental risk factor for death and stroke ${ }^{1}$. Standard treatment options for AF are antiarrhythmic drugs and pulmonary veins isolation (PVI). The PVI procedure has become a routine treatment for AF whereby an ablation energy source can be applied endocardially or epicardially around the pulmonary veins by a percutaneous or surgical approach ${ }^{2,3}$. Catheter endocardial $\mathrm{PVI}$ procedures are efficacious providing a $\pm 80 \%$ success rate in terms of $\mathrm{AF}$ treatment with multiple procedures. One of the complications of PVI however, is the occurrence of cerebro-embolic events, which occurs in $0.5 \%-10 \%$ of the catheter endocardial PVI patients ${ }^{2,4-9}$. The occurrence of emboli in the cerebral vessels is the main cause of these complications. Although a single intravascular measured microembolic signal (MES) in itself is not accompanied by clinically relevant symptoms, several publications suggest a correlation between the number of cerebral MES and neurological impairment or even stroke ${ }^{4,10-12}$. We examined the number of cerebral MES as a surrogate marker for the risk of neurological complications during commonly used (1) catheter-based percutaneous endocardial (ENDO) PVI procedure and (2) a recently developed minimal invasive video-assisted thoracoscopic epicardial (EPI) PVI approach on a beating heart. The latter procedure uses a bipolar radiofrequency (RF) ablation device, which can reliably create bilateral lesions around the atrial cuff of the right and left pulmonary veins. The purpose of this study is to compare both PVI methods concerning cerebral MES. A different frequency of cerebral MES in the PVI procedure might indicate a different risk of neurological complications.

\section{Methods}

\section{Patients}

Between August 2007 and February 2008, 21 patients suffering from paroxysmal or persistent AF undergoing PVI were included. All patients were assigned for PVI by their attending physician after unsuccessful treatment with antiarrhythmic drugs. If a focal isolation seemed sufficient a percutaneous endocardial PVI (ENDO group) was performed. If more ablation lines were likely to be required, a minimal invasive thoracoscopic epicardial PVI (EPI group) was chosen. Exclusion criteria consisted of the presence of thrombus in the left atrial appendage (LAA) and a left ventricular ejection fraction $<30 \%$. The present study did not influence the decision which ablation technique was used in a given patient. 


\section{Procedure}

The investigation was approved by the Human Research and Ethics Committee of the University Hospital Maastricht, the Netherlands.

\section{ENDO PVI approach}

All patients started taking oral anticoagulants for a minimum of 4 weeks until 2 days before the start of the procedure, followed by subcutaneous fractionated heparin until the day of the procedure. Trans-oesophageal echocardiography (TEE) was performed 24-48 hours before the procedure to rule out the presence of intracardiac thrombus and to identify the possible presence of a patent foramen ovale (PFO). All ENDO PVIs were performed under local anaesthesia. Two diagnostic catheters were positioned via the femoral veins into the coronary sinus and at the His-bundle region respectively as a reference for the ENSITE system (St. Jude medical, Minnetonka, MN, USA). One steerable multiplex electrophysiologic LASSO $(12 \mathrm{~mm}-15 \mathrm{~mm}-20 \mathrm{~mm})$ catheter (Biosense Webster, Diamond bar, CA, USA) and a RF ablation catheter (Safire $4 \mathrm{~mm}$ bi-directional (St.jude medical, Minnetonka, MN, USA) were positioned at the orifice of the different veins. Placement in the left atrium was performed by means of a transseptal puncture. If a PFO was present no transseptal puncture was required. The introducers were continuously flushed to prevent the formation of thrombi on the tip of the catheter. At this stage, heparin was injected and the activated clotting time (ACT) was kept above $350 \mathrm{~s}$ during the remaining procedure. Ablation was performed at the atrio-venous junction at sites showing the earliest PV potentials. The maximum power and temperature limit for $\mathrm{RF}$ ablation was set on $30 \mathrm{~W}$ and $55^{\circ} \mathrm{C}-60^{\circ} \mathrm{C}$. RF energy applications were repeated to achieve total elimination of $\mathrm{PV}$ potentials. All patients underwent 24-hour Holter monitoring at their 3-, and 6-month follow-up.

\section{EPI PVI approach}

Oral anticoagulation was halted in all patients 3 days before ablation followed by subcutaneous fractionated heparin until the procedure. All epicardial ablation procedures were performed by means of a minimal invasive thoracoscopic approach on a beating heart by the same cardiac surgeon (MLM) ${ }^{13}$. The EPI intervention was performed under complete anaesthesia using three right-sided thoracoscopic ports. This procedure has been described extensively elsewhere ${ }^{8,9}$. In short, the procedure is conducted after achievement of general anaesthesia administered with a double-lumen endotracheal tube. TEE is performed in the operating room to verify the absence of a left atrial thrombus before the start of the procedure and adequacy of LAA excision at the end of the procedure. The right pulmonary veins are accessed first by an articulated lighted dissector (AtriCure, Inc, Cincinnati, $\mathrm{OH}, \mathrm{USA})$. Next, the bipolar clamp is introduced through the port incision. This bipolar RF clamp (Isolator, AtriCure Inc, Cincinnati, OH, USA) is used to 
achieve linear, transmural ablation lesions. Bipolar RF energy is applied to electrically isolate the pulmonary veins; 3 overlapping lesions are created to ensure isolation. When the conductance of the tissue decreases to less than $0.0025 \mathrm{~S}$, typically after $8 \mathrm{~s}$, an audible signal is automatically generated to indicate transmurality of the lesion. The technique is repeated on the left side with the addition of division of the ligament of Marshall. As on the right side, the bipolar clamp is positioned into place to ablate the left atrial cuff adjacent to the left pulmonary veins. After completion of the energy applications, electrical isolation was checked by pacing on the left atrium near the right superior pulmonary vein. All patients underwent 24-hour holter monitoring at their 3-, and 6-month follow-up

\section{Transcranial Doppler (TCD) monitoring}

TCD is the standard non-invasive monitoring technique for the detection of MES in the cerebral circulation. TCD (PMD 100, Spencer Technologies, Seattle, USA) was used to monitor both middle cerebral arteries (MCAs) through the temporal bone windows for MES using two $2 \mathrm{MHz}$ probes, fixed with a headband (Marc 600, Spencer technologies, Seattle, USA). The probes were installed after the patient was positioned for the PVI procedure. Patients were monitored continuously from 30 minutes before the procedure until termination of the procedure. TCD recordings were stored for later offline analysis. In our study, the detection of cerebral MES was performed by a blinded trained physician according to the guidelines of the consensus committee ${ }^{14}$.

\section{Statistics}

Mann-Whitney U tests (SPSS, version 12.0, SPSS Inc., Chicago, IL, USA) were used to compare the EPI group $(n=10$,$) with the ENDO group (n=10)$. A $p$-value $<0.05$ was considered statistically significant. Data are expressed as mean +/- SD unless stated otherwise.

\section{Results}

Table 1 represents pre- and postoperative patient's characteristics of both the groups. In Table 2 the amount of detected cerebral MES of both the PVI groups are shown. No cerebral vascular attacks (CVAs) were observed peri-and postprocedurally. One patient was excluded from this study, because no TCD monitoring was possible. 


\section{ENDO PVI approach}

In the 10 patients, an average of $34( \pm 14)$ applications with a mean of $33( \pm 5)$ seconds per application resulted in $22( \pm 10)$ minutes of actual ablation time in this patient group. The total procedural time was $257( \pm 72)$ minutes.

\section{EPI PVI approach}

In all 10 patients an average of $6( \pm 2)$ RF energy deliveries, with an average of 15 seconds, was performed. The total procedural time was $135( \pm 42)$ minutes.

Table 1: Patient's characteristics in the EPI group and in the ENDO group

\begin{tabular}{lll}
\hline & EPI & ENDO \\
\hline $\mathrm{N}$ & & \\
Male $(\mathrm{n})$ & 10 & 10 \\
Age $( \pm \mathrm{SD})$ & 7 & 9 \\
PAF/PersistentAF & $53( \pm 11)$ & $54( \pm 13)$ \\
PFO & $2 / 8$ & $9 / 1$ \\
Previous TIA & 1 & 3 \\
Previous percutaneous ablation & 1 & - \\
Post operatively (months) & 4 & 2 \\
Post in Sinus Rhythm & $6( \pm 2)$ & $7( \pm 2)$ \\
Post in PAF & 10 & 9 \\
Post in persistent AF & 0 & 1 \\
\hline PAF: paroxysmal atrialfibrillation, PFO pathen & 0 & 0 \\
\hline
\end{tabular}

PAF: paroxysmal atrial fibrillation, $\mathrm{PFO}=$ patent foramen ovale, TIA: transient ischemic attack.

\section{Number of emboli}

A total number of $5( \pm 6)$ cerebral MES were detected during the EPI procedure. The average number of cerebral MES during manipulation was $4( \pm 5)$ and during the total duration of ablation applications $1( \pm 1)$. A total number of $3908( \pm 2816)$ cerebral MES were detected during the ENDO procedure of which the most of them occurred during the RF ablation applications $2566( \pm 2296)$ as shown in table 2. 
Table 2: Number of microembolic signals in the EPI group and in the ENDO group

\begin{tabular}{|c|c|c|c|c|c|c|c|c|c|}
\hline & \multicolumn{4}{|c|}{$\operatorname{EPI}(n=10)$} & \multicolumn{4}{|c|}{ ENDO $(n=10)$} & \\
\hline & \multirow{2}{*}{$\begin{array}{l}\text { PAF } \\
(n=2)\end{array}$} & \multirow{2}{*}{$\begin{array}{l}\text { Persistent } \\
(n=8)\end{array}$} & \multicolumn{2}{|c|}{ Total Epi } & \multirow{2}{*}{$\begin{array}{l}\text { PAF } \\
(n=2)\end{array}$} & \multirow{2}{*}{$\begin{array}{l}\text { Persistent } \\
\quad(n=8)\end{array}$} & \multicolumn{2}{|c|}{ Total ENDO } & \\
\hline & & & Mean & SD & & & Mean & SD & \\
\hline $\begin{array}{l}\text { Total number of cerebral } \\
\text { MES }\end{array}$ & 10 & 7 & 8 & \pm 6 & 4128 & 1925 & 3908 & $\begin{array}{c} \pm 2816 \\
(872-9971)\end{array}$ & * \\
\hline $\begin{array}{l}\text { Number of cerebral MES } \\
\text { prior to energy application }\end{array}$ & 9 & 5 & 6 & \pm 5 & 336 & 296 & 332 & $\begin{array}{c} \pm 193 \\
(41-773)\end{array}$ & * \\
\hline $\begin{array}{l}\text { Number of cerebral MES } \\
\text { during energy applications }\end{array}$ & 1 & 2 & 2 & \pm 1 & 2804 & 426 & 2566 & $\begin{array}{c} \pm 2296 \\
(184-7931)\end{array}$ & * \\
\hline
\end{tabular}

\section{Discussion}

Both epicardial and percutaneous endocardial PVI procedures generate emboli. However, the number of cerebral MES detected during both PVI procedures differs significantly (Table 2). The EPI procedure induces scarcely cerebral microembolic signals compared to the abundant MES during the ENDO procedure.

\section{Causes of emboli}

Several interventions or manipulations can be identified which may explain the cause and the differences in occurrence of cerebral MES during the EPI and ENDO PVI method.

\section{ENDO PVI method}

During the ENDO PVI approach air can enter the systemic circulation during insertion, manipulation and flushing of introducers or catheters. In this study 332 $( \pm 193$ ) cerebral MES were detected prior to the first energy application, which represents $8 \%$ of all the MES detected during the whole ENDO procedure, as shown in table 2. When applying ablation energy on the endocardial wall of the ostia of the $\mathrm{PV}$, the cardiac endothelium is damaged which may lead to platelet adhesion and activation, resulting in clot formation ${ }^{15}$. Another cause of emboli during the applications could be linked to high temperatures. To accomplish PV isolation interface temperatures can rise up to $100^{\circ} \mathrm{C}^{16,17}$. This high temperature may cause denaturation of proteins and formation of thrombi in the blood and can also cause electrolytic phenomena creating gaseous emboli into the systemic circulation ${ }^{16,17}$. The generation of thrombi and gas bubbles during the ablation applications are known to be associated with endocardial ablation procedures. Thrombus formation on the surface of catheters (i.e., char formation) is another possible source of 
emboli ${ }^{18}$. These emboli can be released from the catheter surface during manipulation.

\section{EPI PVI method.}

In the EPI PVI approach there is no invasion of major blood vessels and the ablation catheter is positioned epicardially around the pulmonary veins. No intravascular emboli can be injected into the systemic circulation. Nevertheless, the positioning procedure of the RF clamp could theoretically release small parts of atheroma due to palpation of the heart ${ }^{19}$. The few cerebral MES detected during this period could be induced by the positioning procedure; however, AF by itself could be responsible for generation and migration of thrombi ${ }^{1,20}$.

During the energy applications the blood temperature during the EPI PVI ablation is not likely to increase significantly, as no direct contact between the ablation catheter and the blood occurs. Although accomplishment of transmurality by epicardial ablation could activate a cascade of clotting mechanisms, the damage instigated to the endothelium will be less than that created by the ENDO PVI approach $^{21}$ and will most likely be not sufficient to generate microemboli. No thrombus has been observed on the endocardial surface of the ablation line in animals. ${ }^{8}$.

\section{Clinical relevance}

The number of periprocedural cerebral emboli is correlated with neurological complications like stroke, cerebral vascular attack, transient ischemic attack (TIA) and cognitive decline ${ }^{4,10-12}$. Although solid emboli are assumed to cause more (or more permanent) brain injury compared to gaseous emboli, both solid and gaseous emboli are associated with postoperative neurological impairment ${ }^{4,11,12}$. Therefore, the composition of the cerebral emboli should be considered when assigning neurological risk, as suggested by Padanilam ${ }^{22}$. The possible causes and thereby the possible nature of the emboli found in both ablation techniques are mentioned earlier. Because there is no invasion in the blood vessels during the EPI PVI approach, no air can enter the systemic circulation and all emboli detected in this procedure will most likely be solid, due to manipulation or possible intravascular overheating. The composition of the emboli detected during ENDO PVI could be different depending on the various phases of the procedure. The period of flushing the catheters will most likely be responsible for introduction of gaseous emboli. The nature of emboli recorded during energy application (66\% of the total number of cerebral MES), and manipulation between the applications in the ENDO PVI ( $26 \%$ of the total cerebral MES), are not completely understood. Both thrombus ${ }^{15,18}$ as gaseous formation ${ }^{16,17}$ could occur in both phases. Lickfett et al ${ }^{6}$ demonstrated with diffusion-weighted (DW)-MRI that $10 \%$ of the patients treated by a 
percutaneous endocardial ablation method, had cerebral embolic lesions postprocedurally. Kilicislan et al ${ }^{4}$ showed that, by reducing cerebral emboli during percutaneous ablation a reduction of neurological complications could be achieved, suggesting that even without the knowledge of their constitution, the detected emboli during percutaneous ablation are responsible for neurological complications.

The correlation between the number of cerebral emboli during a cardiac procedure and neurological complications is well documented ${ }^{4,10-12}$. A reduction of the periprocedural number of cerebral emboli results in a reduction of postprocedural neurological complications ${ }^{4,10,12}$. Marrouche et al ${ }^{10}$ and Kilicislan et al ${ }^{4}$ demonstrated a similar correlation between cerebral microemboli and postprocedural neurological complications during ENDO PVI procedures. Our study showed that during the EPI PVI procedure the number of cerebral MES originated can be abolished compared to the abundant number of cerebral MES detected during the ENDO PVI procedure, indicating that patients undergoing an EPI PVI are potentially less likely to develop neurological complications.

Furthermore, the two PVI approaches in this study are relatively different in procedural aspects. The applied anaesthesia and the use of radiographs are examples, which could be of importance for the choice of treatment. The efficiency of isolation of the pulmonary veins is evidently the main goal of PVI procedures. The success rate of both ENDO and EPI PVI procedures was not the main focus of this study. The success rates found in this study seem to resemble the success rates found in literature. For the RF bilateral epicardial approach, the previous studies have shown a success rate of $91 \%^{7,8}$, all the 10 patients treated with the EPI PVI approach in this study had sinus rhythm after a 5 month follow-up. The success rate of the ENDO PVI method in paroxysmal AF patients in this study is $90 \%$, which is consistent with previous studies in paroxysmal endocardial catheter approach PVI $(75 \%-95 \%)^{2}$.

\section{Study limitations}

The EPI group mainly exists of patients with persistent AF and the ENDO group of patients with paroxysmal AF. The success rate of both groups is not comparable due to the difference in AF patients, but emboli generation is not influenced by the type of $\mathrm{AF}$ and will therefore not influence the result of this study.

Results of this study should be interpreted with caution since the sample size is small. Nevertheless, the difference in number of cerebral MES between both groups is very large.

Only one percutaneous endocardial ablation catheters were examined in this study. The percutaneous endocardial RF ablation catheter used in this study was the standard catheter used in the Academic Hospital Maastricht. Other catheters could generate a different number of cerebral microemboli. 
With the current available TCD systems, the nature (gaseous or solid) and size of cerebral emboli cannot be reliably determined. In theory, the relative intensity of the reflected signal of gaseous as compared to solid emboli differs when insonated by different emitting ultrasound frequencies ${ }^{23}$. Yet, the existing dual-frequency transducer can not accurately discriminate between solid and gaseous emboli ${ }^{24}$. Therefore, no discrimination of emboli was possible in this study. Similarly, no indication of size of emboli can be given due to the fact that a small gaseous embolus could reflect the same level of ultrasound as big solid emboli.

This study examined cerebral MES as a surrogate marker of the risk of neurological complications. Clinical outcome was not investigated in this study. Although correlation between the number of cerebral MES and neurological complications has been reported in previous studies, future studies should focus on the clinical impact of the demonstrated difference in cerebral MES in the two examined PVI procedures. In this respect, pre- and postprocedural cognitive examination and/or cerebral MRI scans in a multicenter study is recommended to define the clinical impact of the findings of this study.

\section{Conclusions}

The number of cerebral MES signals detected during thorasocopic epicardial PVI can be neglected compared to the abundant number of cerebral MES occurring during percutaneous endocardial PVI. Taking into account the other procedural aspects, and the reported success rate in $\mathrm{AF}$, the minimal invasive thoracoscopic epicardial $\mathrm{PVI}$ approach might become a feasible alternative to endocardial catheter PVI procedures. 


\section{References}

1. Wolf PA, Abbott RD, Kannel WB. Atrial fibrillation as an independent risk factor for stroke: the Framingham Study. Stroke. 1991;22(8):983-988.

2. Cappato R, Calkins H, Chen SA, Davies W, lesaka Y, Kalman J, Kim YH, Klein G, Packer D, Skanes A. Worldwide survey on the methods, efficacy, and safety of catheter ablation for human atrial fibrillation. Circulation. 2005;111(9):1100-1105.

3. Garrido MJ, Williams M, Argenziano M. Minimally invasive surgery for atrial fibrillation: toward a totally endoscopic, beating heart approach. J Card Surg. 2004;19(3):216-220.

4. Kilicaslan F, Verma A, Saad E, Rossillo A, Davis DA, Prasad SK, Wazni O, Marrouche NF, Raber LN, Cummings JE, Beheiry S, Hao S, Burkhardt JD, Saliba W, Schweikert RA, Martin DO, Natale A. Transcranial Doppler detection of microembolic signals during pulmonary vein antrum isolation: implications for titration of radiofrequency energy. J Cardiovasc Electrophysiol. 2006;17(5):495-501.

5. Zhou L, Keane D, Reed G, Ruskin J. Thromboembolic complications of cardiac radiofrequency catheter ablation: a review of the reported incidence, pathogenesis and current research directions. J Cardiovasc Electrophysiol. 1999;10(4):611-620.

6. Lickfett L, Hackenbroch M, Lewalter T, Selbach S, Schwab JO, Yang A, Balta O, Schrickel J, Bitzen A, Luderitz B, Sommer T. Cerebral diffusion-weighted magnetic resonance imaging: a tool to monitor the thrombogenicity of left atrial catheter ablation. J Cardiovasc Electrophysiol. 2006;17(1):1-7.

7. Gaynor SL, Diodato MD, Prasad SM, Ishii Y, Schuessler RB, Bailey MS, Damiano NR, Bloch JB, Moon MR, Damiano RJ, Jr. A prospective, single-center clinical trial of a modified Cox maze procedure with bipolar radiofrequency ablation. J Thorac Cardiovasc Surg. 2004;128(4):535-542.

8. Wolf RK, Schneeberger EW, Osterday R, Miller D, Merrill W, Flege JB, Jr., Gillinov AM. Video-assisted bilateral pulmonary vein isolation and left atrial appendage exclusion for atrial fibrillation. J Thorac Cardiovasc Surg. 2005;130(3):797-802.

9. Yilmaz A, Van Putte BP, Van Boven WJ. Completely thoracoscopic bilateral pulmonary vein isolation and left atrial appendage exclusion for atrial fibrillation. J Thorac Cardiovasc Surg. 2008;136(2):521522.

10. Marrouche NF, Martin DO, Wazni O, Gillinov AM, Klein A, Bhargava M, Saad E, Bash D, Yamada H, Jaber W, Schweikert R, Tchou P, Abdul-Karim A, Saliba W, Natale A. Phased-array intracardiac echocardiography monitoring during pulmonary vein isolation in patients with atrial fibrillation: impact on outcome and complications. Circulation. 2003;107(21):2710-2716.

11. Muth CM, Shank ES. Gas embolism. N Engl J Med. 2000;342(7):476-482.

12. Pugsley $W$, Klinger L, Paschalis C, Treasure $T$, Harrison $M$, Newman S. The impact of microemboli during cardiopulmonary bypass on neuropsychological functioning. Stroke. 1994;25(7):1393-1399.

13. La Meir M, De Roy L, Blommaert D, Buche M. Treatment of lone atrial fibrillation with a right thoracoscopic approach. Ann Thorac Surg. 2007;83(6):2244-2245.

14. Ringelstein EB, Droste DW, Babikian VL, Evans DH, Grosset DG, Kaps M, Markus HS, Russell D, Siebler M. Consensus on microembolus detection by TCD. International Consensus Group on Microembolus Detection. Stroke. 1998;29(3):725-729.

15. van Oeveren W, Crijns HJ, Korteling BJ, Wegereef EW, Haan J, Tigchelaar I, Hoekstra A. Blood damage, platelet and clotting activation during application of radiofrequency or cryoablation catheters: a comparative in vitro study. J Med Eng Technol. 1999;23(1):20-25.

16. Bruce GK, Bunch TJ, Milton MA, Sarabanda A, Johnson SB, Packer DL. Discrepancies between catheter tip and tissue temperature in cooled-tip ablation: relevance to guiding left atrial ablation. Circulation. 2005;112(7):954-960.

17. Wood MA, Shaffer KM, Ellenbogen AL, Ownby ED. Microbubbles during radiofrequency catheter ablation: composition and formation. Heart Rhythm. 2005;2(4):397-403.

18. Demolin JM, Eick OJ, Munch K, Koullick E, Nakagawa H, Wittkampf FH. Soft thrombus formation in radiofrequency catheter ablation. Pacing Clin Electrophysiol. 2002;25(8):1219-1222. 
19. Sylivris S, Levi C, Matalanis G, Rosalion A, Buxton BF, Mitchell A, Fitt G, Harberts DB, Saling MM, Tonkin AM. Pattern and significance of cerebral microemboli during coronary artery bypass grafting. Ann Thorac Surg. 1998;66(5):1674-1678.

20. Sohara H, Amitani S, Kurose M, Miyahara K. Atrial fibrillation activates platelets and coagulation in a time-dependent manner: a study in patients with paroxysmal atrial fibrillation. J Am Coll Cardiol. 1997;29(1):106-112.

21. Santiago T, Melo JQ, Gouveia RH, Martins AP. Intra-atrial temperatures in radiofrequency endocardial ablation: histologic evaluation of lesions. Ann Thorac Surg. 2003;75(5):1495-1501.

22. Padanilam BJ. Cerebral microembolism during AF ablation: an innocent bystander or an accessory to brain injury? J Cardiovasc Electrophysiol. 2006;17(5):502-503.

23. Russell D, Brucher R. Online automatic discrimination between solid and gaseous cerebra microemboli with the first multifrequency transcranial Doppler. Stroke. 2002;33(8):1975-1980.

24. Markus HS, Punter M. Can transcranial Doppler discriminate between solid and gaseous microemboli? Assessment of a dual-frequency transducer system. Stroke. 2005;36(8):1731-1734. 


\title{
CHAPTER 4
}

\author{
Transcranial measurement of \\ cerebral microembolic signals \\ during endocardial pulmonary \\ vein isolation: comparison of \\ three different ablation \\ techniques
}

Published in

J Cardiovasc Electrophysiol. 2009 Oct 1;20(10):1102-1107

Sauren LD, van Belle Y, de Roy L, Pison L, la Meir M, van der Veen FH, Crijns HJ, Jordaens L, Mess WH, Maessen JG. 


\section{Abstract}

Introduction

Isolation of the pulmonary veins (PVI) using high ablation energy is an effective treatment for atrial fibrillation (AF) with a success rate of $50-95 \%$; however, postoperative neurological complications still occur in $0.5 \%-10 \%$. In this study the incidence of cerebral microembolic signals (MES) as a risk factor for neurological complications is examined during three percutaneous endocardial ablation procedure strategies: segmental PVI using a conventional radiofrequency (RF) ablation catheter, segmental PVI using a an irrigated RF tip catheter and circumferential PVI with a cryoballoon catheter (CB).

Methods

Thirty patients underwent percutaneous endocardial pulmonary vein isolation. Ostial isolation was performed in 10 patients with a conventional $4 \mathrm{~mm}$ RF catheter (CRF) and in 10 patients with a $4 \mathrm{~mm}$ irrigated RF catheter (IRF). A circumferential PVI was performed in 10 patients with a CB. Transcranial Doppler (TCD) monitoring was used to detect MES in the middle cerebral arties.

Results

The total number of cerebral MES differs significantly between the 3 PVI groups; 3908 cerebral MES were measured with use of the CRF catheter, 1404 cerebral MES with use of the IRF catheter and 935 cerebral MES with use of the CB catheter.

Conclusion

This study demonstrates a significant difference in cerebral MES during PVI with 3 different ablation procedures. The use of an irrigated RF and a cryoballoon procedures significantly fewer cerebral MES than the use of conventional RF for a PVI procedure. Suggesting a higher risk for neurologic complications using conventional RF energy during a percutaneous PVI procedure. 


\section{Introduction}

Atrial fibrillation (AF) is a highly prevalent cardiac arrhythmia, with an agedependent increase in incidence. It is an independent risk factor for death and stroke ${ }^{1}$. Antiarrhythmic drug treatment and pulmonary vein isolation (PVI) are standard treatment options. PVI has become a mainstream treatment for AF whereby ablation energy is applied to electrically isolate the pulmonary veins ${ }^{2,3}$. Catheter PVI procedures are efficacious with success rates approximating $80 \%$. However, one of the complications of PVI procedure however is the occurrence of cerebroembolic complications in $0.5 \%-10 \%$ of the patients ${ }^{2,4,5}$. Several publications support an association between the number of cerebral MES and neurological impairment and stroke ${ }^{4,6-9}$. Therefore in this study, the number of cerebral MES was considered as a risk factor of neurological complications and examined during three different catheter-based PVI approaches: (1) segmental isolation with a conventional radiofrequency (RF) ablation catheter (CRF), (2) segmental isolation with an irrigated RF tip ablation catheter (IRF), and (3) circumferential isolation with a cryoballoon catheter (CB).

\section{Methods}

\section{Patients}

A total of 30 consecutive patients suffering from drug-refractory and symptomatic AF undergoing a PVI were included in this study. We compared three separate cohorts in three different centres: Academic Hospital Maastricht (the Netherlands), Cliniques Universitaires de Mont-Godinne, Yvoir (Belgium) and Erasmus Medical Centre, Rotterdam (the Netherlands). Three groups were defined according to the ablation catheter used in each centre: (1) conventional RF catheter (CRF), (2) irrigated RF tip catheter (IRF), (3) cryoballoon catheter (CB).

\section{Procedures}

The investigation was approved by the Human Research and Ethics Committee of the Academic Hospital Maastricht (the Netherlands), Cliniques Universitaires de Mont-Godinne, Yvoir (Belgium) and Erasmus Medical Centre, Rotterdam (the Netherlands).

\section{Segmental PVI}

These procedures were performed under local anaesthesia and with femoral vein punctures. Two echo guided transseptal punctures were preformed and a steerable 
circular electrophysiologic catheter (Lasso ${ }^{\circledR}$, Biosense Webster, Diamond bar, CA, USA) was positioned at the orifice of the targeted veins. Ablation was performed at the atrio-venous junction at sites showing the earliest PV potentials. The introducers were continuously flushed to prevent the formation of thrombi on the catheter. Details about the segmental ablation have been published earlier ${ }^{3}$.

The ablation catheter used for the conventional RF ablation was a 4-mm bidirectional RF ablation catheter (Saphire ${ }^{\circledR}$, St.jude medical, Minnetonka, MN, USA). The maximum power limit for the RF ablation was set on $25 \mathrm{~W}$ to $30 \mathrm{~W}$, with a maximum temperature limit of $55^{\circ} \mathrm{C}$ to $60^{\circ} \mathrm{C}$.

The ablation catheter used for the irrigated tip RF ablation was a 4-mm externally irrigated tip catheter (Celius Thermo-cool ${ }^{\circledR}$, Biosense Webster, Diamond bar, CA, USA). The maximum power limit for the RF ablation was set on $25 \mathrm{~W}$, with a maximum temperature limit of $48^{\circ} \mathrm{C}$.

\section{Circumferential cryoballoon procedure}

The procedure was performed with femoral access and through a single transseptal puncture, guided by intracardiac echocardiography. The ablation was performed with a 28-mm double-lumen balloon catheter (Arctic front ${ }^{\circledR}$, Cryocath, Montreal, Quebec, Canada), through a $14 \mathrm{~F}$ transseptal sheath and positioned over an exchange wire to occlude the ostium of each PV. The introducers were continuously flushed to prevent the formation of thrombi on the catheter. Cryoenergy was given for 5 minutes per application of $-80^{\circ} \mathrm{C}$, with a minimum of 2 applications per vein. After ablation, a circular 20-polar catheter was positioned at the ostium of every vein to check for PV potentials. The procedural endpoint was the absence of pulmonary vein potentials in all of the targeted veins. If isolation could not be achieved with the cryoballoon, an additional segmental isolation was performed with an $8 \mathrm{~mm}$ tip cryocatheter (Freezor Max ${ }^{\circledR}$, Cryocath, Montreal, Quebec, Canada). Details on this approach have been published previously ${ }^{10,11}$.

\section{Periprocedural anticoagulation management}

All patients of all three groups were on oral anticoagulation for a minimum of 1 month before the procedure. This was stopped 2 to 3 days before the ablation. Transesophageal echocardiography was performed 24-48 hours before the procedure to rule out presence of intracardiac thrombi. The activated clotting time (ACT) was kept above 350 seconds during the entire procedure in the CRF procedures, between 200 seconds and 250 seconds in the IRF procedures, and an ACT of 350 seconds was maintained in the cryoballoon procedures. After the procedure, oral anticoagulation was resumed with a target international normalized ratio between 2 and 3 . 


\section{Transcranial Doppler (TCD) monitoring}

TCD, (PMD 100, Spencer Technologies, Seattle, WA, USA) was used to monitor both middle cerebral arteries through the temporal windows for microemboli using two 2.0 $\mathrm{MHz}$ probes, fixed with a headband (Marc 600, Spencer technologies). The probes were by an experienced physician installed after the patient was positioned for both PVI procedures. Patients were monitored continuously starting from 30 minutes before the procedure until termination of the procedure. TCD recordings were stored for later offline analysis. In our study the detection of cerebral MES was performed by a blinded trained physician according the guidelines of the consensus committee ${ }^{12}$. The TCD analyses were divided into different periods. The period from transseptal puncture until the first ablation was considered the placement period (placement period). The period during which ablation energy was delivered was classified as the ablation period. Due to the delay between emboli generation in the pulmonary veins and arrival of these emboli in the cerebral vessels, a 10-s period after the end of ablation was included in the ablation period in all of the different methods (ablation period). The period from the first ablation, until the end of the procedure, minus the ablation periods was considerate the manipulation period (manipulation period).

\section{Data analysis}

The different patterns of cerebral MES were categorized according to previously defined criteria ${ }^{4,13,14}$. Type I embolic showers were defined as 1 to 10 cerebral MES in 1 minute of ablation. Type II embolic showers were defined as 11 to 60 cerebral MES in 1 minute of ablation. Type III embolic showers were defined as more than 61 cerebral MES in 1 minute of ablation. Figure 1 demonstrates the 3 mentioned types of embolic showers.

\section{Statistical method}

All data was analysed using the statistical software package SPSS ${ }^{\circledR}$ version 12.0 (SPSS Inc., Chicago, IL, USA). A Mann-Whitney $U$ test was used to compare the 3 different types of embolic showers in the different ablation groups. A p-value of $<0.05$ was considered statistically significant. 


\section{Results}

\section{Patient characteristics}

A total of 30 patients were enrolled in this study. Table 1 presents patients' characteristics of the three PVI groups. There were no significant differences in the baseline characteristics.

Table 1: Patient's characteristics in the irrigated RF group, the conventional RF group and the cryoballoon group

\begin{tabular}{llll}
\hline & Conventional RF & Irrigated RF & Cryo balloon \\
\hline $\mathrm{N}$ & 10 & 10 & 10 \\
Male & 9 & 10 & 7 \\
Age (SD) & $50(11)$ & $53(14)$ & $58(11)$ \\
PAF/CAF & $9 / 1$ & $9 / 1$ & $10 / 0$ \\
PFO & 2 & 1 & 1 \\
Previous TIA & 0 & 0 & 1 \\
Previous percutaneous & 3 & 1 & 2
\end{tabular}

ablation

PAF: paroxysmal atrial fibrillation, CAF: consistent atrial fibrillation, PFO= patent foramen ovale, TIA: transient ischemic stroke.

\section{PVI procedures}

A total of 741 energy applications were delivered in 30 patients: in the CRF group 318 applications, in the IRF group 314 applications, and in the CB group 109 applications. The CRF and IRF procedures had a significantly shorter total ablation time than the $C B$ procedures $(P=0.01)$ (Table 2$)$. The total procedural time was significantly longer in the CRF group (274 min) versus IRF and CB group (185 min $\mathrm{P}=$ 0.032 and $178 \mathrm{~min} P<0.0001)$. The ACT levels in the IRF group were significantly lower $(A C T=210)$ than in the $C R F(A C T=371, P=0.017)$ and the $C B$ groups $(A C T=$ $364, \mathrm{P}=0.05)$.

Table 2: Procedure characteristics in the Conventional RF group, the irrigated RF group and in the cryo balloon group.

\begin{tabular}{llllllllll}
\hline & CRF & \multicolumn{3}{c}{ IRF } & & \multicolumn{7}{c}{ CB } & & \\
& Mean & SD & Mean & SD & CRF vs. IRF & Mean & SD & CB vs. CRF & CB vs. IRF \\
\hline Ablation time (min) & 24 & 10 & 16 & 9 & $\mathrm{p}=0.347$ & 79 & 42 & $\mathrm{P}<0.0001$ & $\mathrm{P}=0.01$ \\
Time per ablation (sec) & 45 & 15 & 34 & 17 & $\mathrm{p}=0.008$ & 300 & 0 & $\mathrm{P}<0.0001$ & $\mathrm{P}<0.0001$ \\
Procedural time (min) & 274 & 92 & 185 & 49 & $\mathrm{p}=0.032$ & 178 & 57 & $\mathrm{P}<0.0001$ & $\mathrm{P}=0.711$ \\
ACT $(\mathrm{sec})$ & 371 & 106 & 210 & 33 & $\mathrm{p}=0.017$ & 364 & 90 & $\mathrm{P}=0.909$ & $\mathrm{P}=0.05$ \\
Impedance $(\Omega)$ & 200 & 10 & 115 & 14 & $\mathrm{p}=0.04$ & & & & \\
Power $(\mathrm{W})$ & 24 & 6 & 24 & 2 & $\mathrm{p}=0.906$ & & & & \\
Temperature $\left({ }^{\circ} \mathrm{C}\right)$ & 49 & 5 & 36 & 2 & $\mathrm{p}=0.01$ & & & & \\
& & & & & & & & & \\
\hline
\end{tabular}


Embolic shower Type I

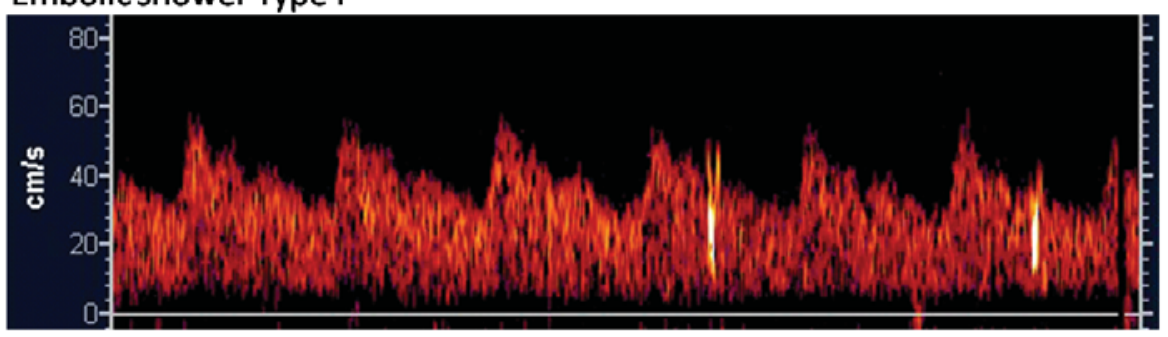

Embolic shower Type II

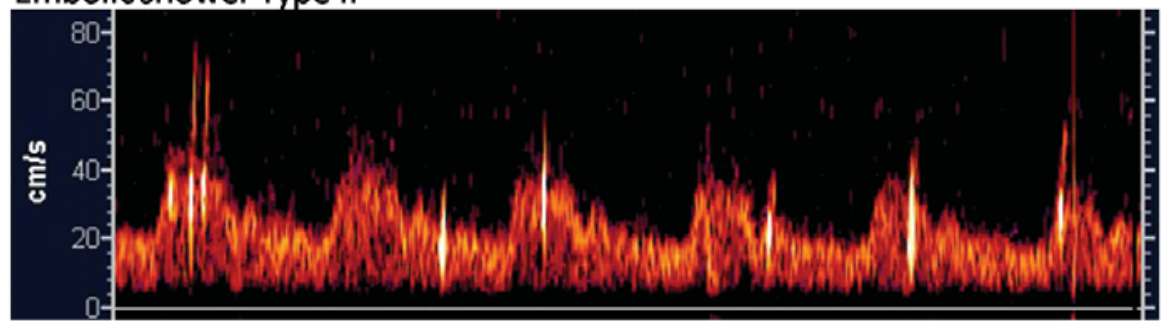

Embolic shower Type III

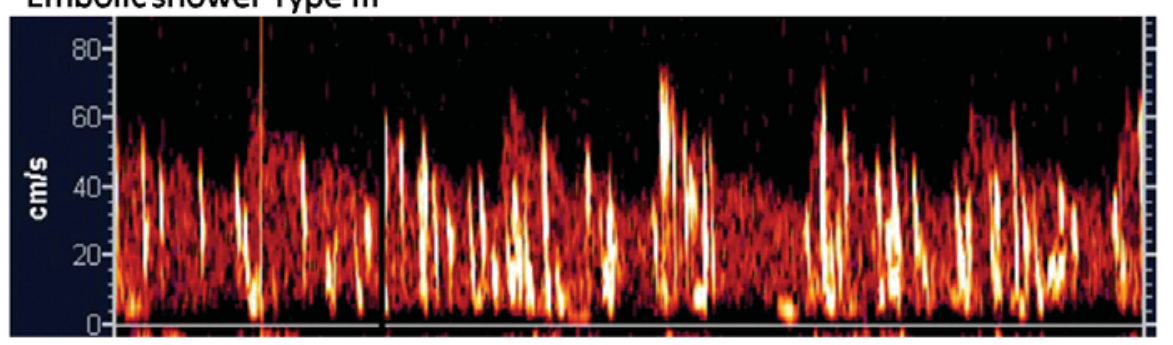

Figure 1: Examples of the 3 types of showers in the velocity spectrum of the Transcranial Doppler (TCD) screen

\section{Total number of cerebral MES}

The numbers of cerebral MES in the three procedures are represented in Table 3.

Table 3: Number of microembolic signals in the conventional RF group, the irrigated tip RF and the cryo balloon group.

\begin{tabular}{lllllllllll}
\hline & CRF & \multicolumn{3}{c}{ IRF } & \multicolumn{3}{c}{ IRF vs. CRF CB } & & CB vs. CRF & CB vs. IRF \\
& Mean & SD & Mean & SD & & Mean & SD & & \\
\hline MES total & 3908 & 2816 & 1404 & 981 & $p=0.019$ & 935 & 463 & $p=0.001$ & $p=0.186$ \\
MES placement period & 332 & 193 & 745 & 467 & $p=0.015$ & 377 & 297 & $p=0.624$ & $p=0.03$ \\
MES ablation period & 2566 & 2296 & 105 & 71 & $p=0.01$ & 163 & 91 & $p=0.001$ & $p=0.266$ \\
$\begin{array}{l}\text { MES manipulation } \\
\text { period }\end{array}$ & 1010 & 733 & 554 & 601 & $p=0.143$ & 395 & 186 & $p=0.027$ & $p=0.874$ \\
$\begin{array}{l}\text { MES per 1 minute of } \\
\text { ablation }\end{array}$ & 92 & 144 & 7 & 20 & $p<0.0001$ & 3 & 5 & $p<0.0001$ & $p=0.03$ \\
\hline
\end{tabular}


The total number of cerebral MES differs significantly among the 3 groups. The number of cerebral MES detected during the entire PVI procedure was significantly lower in the IRF group (1404 MES) and in the CB group (935 MES), compared to the CRF group (3908 MES, respectively $P=0.0019, P=0.001$ ). The number of cerebral MES during the placement period was significantly higher in the IRF group (745 cerebral MES) compared to the other two groups $(C B=377$ cerebral MES, $P=0.03$; and $C R F=332$ cerebral MES, $P=0.015)$. During the ablation period, less cerebral MES were generated in the IRF group (105 MES) and in the CB group (163 MES) compared to the CRF group (2566 MES, respectively, $P=0.01, P=0.0001$ ). When considering the number of MES per minute of ablation, the $\mathrm{CB}$ group demonstrated the lowest number of three cerebral MES per minute of ablation compared to both the other procedures. (CRF $=92 \mathrm{MES}, \mathrm{P}<0.0001 ; \mathrm{IRF}=7 \mathrm{MES}, \mathrm{P}=0.03)$.

\section{MES in the $C B$ procedures}

The number of MES during contrast injections and single point ablation in the $\mathrm{CB}$ group were analysed separately. On average $13 \pm 2$ cerebral MES were observed during each contrast injections in the CB procedure, resulting in an average of $132 \pm$ 37 MES per procedure caused by contrast injections. Single segmental ablations with the freezer max did not contribute significantly to the total number of cerebral MES, as only $2 \pm 1$ cerebral MES were observed in the complete segmental ablation period, consisting of 8 applications.

Ablation characteristics and type of embolic showers in CRF procedures

Type I showers occurred during the CRF procedure at an average ablation application time of 41 seconds ( \pm 16 ), with an average temperature per ablation of $47^{\circ} \mathrm{C}\left( \pm 4^{\circ} \mathrm{C}\right)$. Type II showers occurred at an average similar ablation application duration ( 44 seconds \pm 16 ) but with a significant higher temperature of $49^{\circ} \mathrm{C}\left( \pm 5^{\circ} \mathrm{C}\right)$ $(P=0.025)$. Type III showers occurred at significant higher ablation application time of 52 seconds $( \pm 11)$ than both type I and type II embolic showers $(P<0.0001)$ and at significant higher temperatures of $52^{\circ} \mathrm{C}\left( \pm 5^{\circ} \mathrm{C}\right)$ than both other types of showers $(\mathrm{P}<$ 0.0001).

\section{Discussion}

This study demonstrates that cerebral MES are generated in patients undergoing catheter-based PV ablation procedures. However, the number of cerebral MES generated during PVI procedures is dependent on the type of the ablation catheter. The CB generates a lower number of cerebral MES during the ablation application than methods involving RF-based ablation catheters. When comparing the irrigated tip RF catheter and the conventional RF catheter, the former generates the lowest 
number of cerebral MES. The duration and temperature of each ablation application could play a role in the difference in generation of emboli when RF energy is used. It has been proven that cerebral MES are an indicator of systemic and cerebral embolization, and are associated with a significant risk of neurologic damage ${ }^{4,6-9,15}$, ${ }^{16}$. Lickfett et al ${ }^{5}$ demonstrated with diffusion-weighted magnetic resonance imaging that $10 \%$ of patients undergoing PVI with a RF catheter had cerebral embolic lesions postprocedurally. Kilicislan et al and Marrouche et al ${ }^{4}$ have shown that patients with cerebroembolic events had significantly higher numbers of cerebral MES, suggesting that without the knowledge of the constitution of those emboli, the cerebral emboli during catheter RF ablation are responsible for neurological complications. The method of detecting cerebral emboli cannot provide information of the composition of the observed emboli, but the moment of occurrence can provide an indication about the nature of the observed emboli. In cryoballoon ablation, a majority of MES are observed during the placement and manipulation phase and at end of each ablation. Since placement of a $14 \mathrm{Fr}$ transseptal sheath and contrast injections during placement of the cryoballoon are involved in the placement and manipulation phases, it seems a reasonable hypothesis that the observed MES during these phases are mainly caused by iatrogenic gas injection. At the end of the ablation phase, however, the balloon that occluded the PV ostium (trapping injected contrast inside the PV) is deflated. The cerebral MES detected at that moment could be the release of ice chips formed at the balloon-PV interface or the release of thrombi formed in the trapped blood column behind the occluding balloon. But it could also be the release of trapped contrast including some injected air which could be responsible for MES formation. Although the nature of the detected emboli in the CB procedures cannot be determined with certainty, it is clear from this study that a lower number of MES are detected during the $\mathrm{CB}$ procedure compared to the methods involving RF. The observed low number of MES during cryoenergy delivery with the cryoballoon and the absence of MES during with cryothermal segmental ablations confirms the previously proven low thrombogenity of cryoablation ${ }^{17-20}$.

Both RF groups show a higher number of observed MES compared to the $\mathrm{CB}$ procedure during the ablation phase. It has been shown that RF energy is not only highly thrombogenic ${ }^{17-19,21,22}$, but also causes the gaseous emboli to emerge due to tissue disruption and temperature rises ${ }^{13,14,23}$. Since this study confirms the significant correlation between increasing number of cerebral MES with higher power, duration and temperatures of the RF ablation, it confirms that the emboli are correlated with the energy delivery. In the CRF ablations the type III cerebral embolic showers may be prevented by reducing the duration of each ablation. It also shows that reducing the catheter tip temperatures by irrigated cooling is an effective means for reduction of cerebral MES, probably through prevention of thrombus formation as was suggested earlier ${ }^{22,24}$. This shows that when using RF- 
energy for PVI, with a high number of ablation lesions in the left atrium, an irrigated tip catheter is preferable to a conventional RF catheter since systemic embolization can have devastating consequences and is a frequently occurring complication ${ }^{5,6,20 \text {, }}$ 25 .

\section{Study limitations}

The activated clotting times during the ablation was not entirely uniform in all groups. The CRF and IRF maintained lower anticoagulation levels than the CB group which may pose a serious bias in this study. However, in the IRF group, although being the least anticoagulated, a significant lower MES were observed than in the CRF group, indicating the major determinant of MES was the method of power delivery, and not the anticoagulation level during the procedure.

The standard MES evaluation is the off-line evaluation of a recorded TCD signal by a human expert ${ }^{12}$; and although the agreement rates of MES detection by TCD are higher than the agreement rates for interpretation of computed tomography or magnetic resonance imaging ${ }^{26,27}$, a human dependency factor remains present by MES evaluation.

This study did not include a neurological examination of the patients. No observations were made of postprocedural neurological complications. However due to reports which have demonstrated a correlation between cerebral emboli and brain damage ${ }^{4-6,8,9,15,16,28}$, a lower incidence of neurological complications in the cryoablation and the irrigated RF treated patients can be expected.

\section{Conclusion}

This study demonstrates that the generated cerebral MES during a PVI procedure are significant lower with the use of a CB catheter and an IRF catheter compared to the use of a CRF catheter. The risk of postprocedural neurological complications can therefore be expected to be higher with the use of a CRF catheter during a PVI procedure. 


\section{References}

1. Wolf PA, Abbott RD, Kannel WB. Atrial fibrillation as an independent risk factor for stroke: the Framingham Study. Stroke. 1991;22(8):983-988.

2. Cappato R, Calkins H, Chen SA, Davies W, lesaka Y, Kalman J, Kim YH, Klein G, Packer D, Skanes A. Worldwide survey on the methods, efficacy, and safety of catheter ablation for human atrial fibrillation. Circulation. 2005;111(9):1100-1105.

3. Haissaguerre M, Jais P, Shah DC, Takahashi A, Hocini M, Quiniou G, Garrigue S, Le Mouroux A, Le Metayer $P$, Clementy J. Spontaneous initiation of atrial fibrillation by ectopic beats originating in the pulmonary veins. N Engl J Med. 1998;339(10):659-666.

4. Kilicaslan F, Verma A, Saad E, Rossillo A, Davis DA, Prasad SK, Wazni O, Marrouche NF, Raber LN, Cummings JE, Beheiry S, Hao S, Burkhardt JD, Saliba W, Schweikert RA, Martin DO, Natale A. Transcranial Doppler detection of microembolic signals during pulmonary vein antrum isolation: implications for titration of radiofrequency energy. J Cardiovasc Electrophysiol. 2006;17(5):495-501.

5. Lickfett L, Hackenbroch M, Lewalter T, Selbach S, Schwab JO, Yang A, Balta O, Schrickel J, Bitzen A, Luderitz B, Sommer T. Cerebral diffusion-weighted magnetic resonance imaging: a tool to monitor the thrombogenicity of left atrial catheter ablation. J Cardiovasc Electrophysiol. 2006;17(1):1-7.

6. Marrouche NF, Martin DO, Wazni O, Gillinov AM, Klein A, Bhargava M, Saad E, Bash D, Yamada H, Jaber W, Schweikert R, Tchou P, Abdul-Karim A, Saliba W, Natale A. Phased-array intracardiac echocardiography monitoring during pulmonary vein isolation in patients with atrial fibrillation: impact on outcome and complications. Circulation. 2003;107(21):2710-2716.

7. Muth CM, Shank ES. Gas embolism. N Engl J Med. 2000;342(7):476-482.

8. Pugsley W, Klinger L, Paschalis C, Treasure T, Harrison M, Newman S. The impact of microemboli during cardiopulmonary bypass on neuropsychological functioning. Stroke. 1994;25(7):1393-1399.

9. Clark RE, Brillman J, Davis DA, Lovell MR, Price TR, Magovern GJ. Microemboli during coronary artery bypass grafting. Genesis and effect on outcome. J Thorac Cardiovasc Surg. 1995;109(2):249-257; discussion 257-248.

10. Van Belle Y, Janse P, Rivero-Ayerza MJ, Thornton AS, Jessurun ER, Theuns D, Jordaens L. Pulmonary vein isolation using an occluding cryoballoon for circumferential ablation: feasibility, complications, and short-term outcome. Eur Heart J. 2007;28(18):2231-2237.

11. Van Belle $Y$, Janse $P$, Theuns D, Szili-Torok T, Jordaens L. One year follow-up after cryoballoon isolation of the pulmonary veins in patients with paroxysmal atrial fibrillation. Europace. 2008;10(11):1271-1276.

12. Ringelstein EB, Droste DW, Babikian VL, Evans DH, Grosset DG, Kaps M, Markus HS, Russell D, Siebler M. Consensus on microembolus detection by TCD. International Consensus Group on Microembolus Detection. Stroke. 1998;29(3):725-729.

13. Bruce GK, Bunch TJ, Milton MA, Sarabanda A, Johnson SB, Packer DL. Discrepancies between catheter tip and tissue temperature in cooled-tip ablation: relevance to guiding left atrial ablation. Circulation. 2005;112(7):954-960.

14. Wood MA, Shaffer KM, Ellenbogen AL, Ownby ED. Microbubbles during radiofrequency catheter ablation: composition and formation. Heart Rhythm. 2005;2(4):397-403.

15. Gottesman RF, Wityk RJ. Brain injury from cardiac bypass procedures. Semin Neurol. 2006;26(4):432 439.

16. Sylivris S, Levi C, Matalanis G, Rosalion A, Buxton BF, Mitchell A, Fitt G, Harberts DB, Saling MM, Tonkin AM. Pattern and significance of cerebral microemboli during coronary artery bypass grafting. Ann Thorac Surg. 1998;66(5):1674-1678. 
17. Khairy P, Chauvet $P$, Lehmann J, Lambert J, Macle L, Tanguay JF, Sirois MG, Santoianni D, Dubuc M. Lower incidence of thrombus formation with cryoenergy versus radiofrequency catheter ablation. Circulation. 2003;107(15):2045-2050.

18. Lustgarten DL, Keane D, Ruskin J. Cryothermal ablation: mechanism of tissue injury and current experience in the treatment of tachyarrhythmias. Prog Cardiovasc Dis. 1999;41(6):481-498.

19. van Oeveren W, Crijns HJ, Korteling BJ, Wegereef EW, Haan J, Tigchelaar I, Hoekstra A. Blood damage, platelet and clotting activation during application of radiofrequency or cryoablation catheters: a comparative in vitro study. J Med Eng Technol. 1999;23(1):20-25.

20. Zhou L, Keane D, Reed G, Ruskin J. Thromboembolic complications of cardiac radiofrequency catheter ablation: a review of the reported incidence, pathogenesis and current research directions. J Cardiovasc Electrophysiol. 1999;10(4):611-620.

21. Lee DS, Dorian P, Downar E, Burns M, Yeo EL, Gold WL, Paquette M, Lau W, Newman DM. Thrombogenicity of radiofrequency ablation procedures: what factors influence thrombin generation? Europace. 2001;3(3):195-200.

22. Yokoyama K, Nakagawa H, Wittkampf FH, Pitha JV, Lazzara R, Jackman WM. Comparison of electrode cooling between internal and open irrigation in radiofrequency ablation lesion depth and incidence of thrombus and steam pop. Circulation. 2006;113(1):11-19.

23. Pinchuk LS, Kravtsov AG, Zotov SV. Thermally stimulated depolarization of human blood. Technical Physics. 2001;46(5):620-622.

24. Padanilam BJ. Cerebral microembolism during AF ablation: an innocent bystander or an accessory to brain injury? J Cardiovasc Electrophysiol. 2006;17(5):502-503.

25. Wazni OM, Rossillo A, Marrouche NF, Saad EB, Martin DO, Bhargava M, Bash D, Beheiry S, Wexman M, Potenza D, Pisano E, Fanelli R, Bonso A, Themistoclakis S, Erciyes D, Saliba WI, Schweikert RA, Brachmann J, Raviele A, Natale A. Embolic events and char formation during pulmonary vein isolation in patients with atrial fibrillation: impact of different anticoagulation regimens and importance of intracardiac echo imaging. J Cardiovasc Electrophysiol. 2005;16(6):576-581.

26. Dittrich R, Ritter MA, Kaps M, Siebler M, Lees K, Larrue V, Nabavi DG, Ringelstein EB, Markus HS, Droste DW. The use of embolic signal detection in multicenter trials to evaluate antiplatelet efficacy: signal analysis and quality control mechanisms in the CARESS (Clopidogrel and Aspirin for Reduction of Emboli in Symptomatic carotid Stenosis) trial. Stroke. 2006;37(4):1065-1069.

27. Markus HS, Ackerstaff R, Babikian V, Bladin C, Droste D, Grosset D, Levi C, Russell D, Siebler M, Tegeler C. Intercenter agreement in reading Doppler embolic signals. A multicenter international study. Stroke. 1997;28(7):1307-1310.

28. Lund C, Sundet K, Tennoe B, Hol PK, Rein KA, Fosse E, Russell D. Cerebral ischemic injury and cognitive impairment after off-pump and on-pump coronary artery bypass grafting surgery. Ann Thorac Surg. 2005;80(6):2126-2131. 


\section{CHAPTER 5}

\section{New-ultrasonic-radiation reduces \\ cerebral emboli during extracorporeal circulation}

Published in

Eur J Cardiothorac Surg. 2007 Aug;32(2):274-80.

Sauren LD, la Meir M, Palmen M, Severdija E, van der Veen FH, Mess WH, Maessen JG. 


\section{Abstract}

Introduction

Cardiac surgery is associated with intraoperative cerebral emboli, which can result in postoperative neurological complications. A new ultrasonic transducer (EmBlocker ${ }^{\mathrm{TM}}$ ) can be positioned on the ascending aorta and activation of the EmBlocker $^{\mathrm{TM}}$ is expected to divert emboli to the descending aorta, thereby decreasing emboli in the cerebral arteries. In this preliminary animal study, safety and efficiency of this technology were examined.

Methods

In 14 pigs $( \pm 70 \mathrm{~kg})$ a median sternotomy was performed and the EmBlocker ${ }^{\mathrm{TM}}$ was positioned on the aorta ascendens at the level of the bifurcation of the aorta and the innominate artery. In one animal temperature measurements were performed. During these measurements the EmBlocker ${ }^{\mathrm{TM}}$ was activated four periods 120 seconds of high power $\left(1.5 \mathrm{~W} / \mathrm{cm}^{2}\right)$ and four periods of 600 seconds of low power $\left(0.5 \mathrm{~W} / \mathrm{cm}^{2}\right)$. In the safety study $(\mathrm{n}=6)$, the EmBlocker ${ }^{\mathrm{TM}}$ was activated twice the expected clinical duration (eight periods of 120 seconds of high power and, subsequently one period of 20 minutes of low power). Tissue samples (control and sonicated) were collected after 1 week for histopathological evaluation (aorta, trachea, esophagus, vagus nerves). In the efficiency study $(n=7)$, extracorporeal circulation was installed. Emboli (air and solid (1200, size $500 \mu \mathrm{m}-750 \mu \mathrm{m})$ ) were introduced in the proximal ascending aorta and the EmBlocker ${ }^{\mathrm{TM}}$ was alternately activated with high power for solid emboli injections and low power for air emboli injections. Transcranial Doppler (TCD) was used to analyze middle cerebral artery blood flow for occurrence of embolic signals, which were manually counted offline.

Results

Histopathology revealed no difference between control and sonicated tissue. There is a rise in temperature during EmBlocker ${ }^{\mathrm{TM}}$ activation, but in all measured tissues it was within limits; less than $42^{\circ} \mathrm{C}$ for 2 minutes in the aorta wall directly under the EmBlocker $^{\mathrm{TM}}$. Use of the EmBlocker ${ }^{\mathrm{TM}}$ significantly reduced emboli in the cerebral arteries; air emboli with 65\% (left) and 69\% (right) and solid emboli with $49 \%$ (left) and $50 \%$ (right).

Conclusion

The new ultrasound technology can safely be applied and is capable of reducing emboli in the cerebral arteries during extracorporeal circulation. Use of the EmBlocker $^{\mathrm{TM}}$ in cardiac surgery bears the potential to lower the risk of postoperative neurological complications. Clinical feasibility studies are in progress. 


\section{Introduction}

Several interventions in cardiac surgery are associated with the occurrence of intraoperative cerebral emboli ${ }^{1-4}$. Transcranial Doppler (TCD) is a non-invasive method which permits intraoperatively visualization of these cerebral emboli. Using $T C D$, different causes of cerebral emboli have already been identified such as: cannulation, cardioplegia needle incision, cross-clamp placement, start and stop of cardiopulmonary bypass (CPB) and de-clamping ${ }^{2}$. The composition of the emboli can be either gaseous or solid (fat or calcified plaque) and is mostly related to the kind of intervention. Irrespective of the type of emboli composition, a correlation between the amount of emboli and neurological complications has been found ${ }^{2,4}$. The occurrence of neurological complications after cardiac surgery varies from $2 \%$ to $8 \%$ of stroke and $5 \%$ to $43 \%$ of cognitive decline ${ }^{1-5}$. By reducing the number of cerebral emboli, the neurological complications will most likely be reduced. In this study a new ultrasonic device is examined that has the potential to reduce the number of cerebral emboli. An ultrasonic transducer (EmBlocker ${ }^{\mathrm{TM}}$ ) is positioned on the distal ascending aorta and by activating the ultrasonic power emboli are expected to divert into to the aorta descendens and thereby reducing the emboli entering the innominate artery and left common carotid artery. The aim of this preliminary animal study was to investigate the safety and the efficiency of this new ultrasonic technology.

\section{Methods}

Three different protocols were part of this study. In one animal the temperature was measured at different locations during activation of the EmBlocker ${ }^{\mathrm{TM}}$. In 6 animals a safety study was performed. Following EmBlocker ${ }^{\mathrm{TM}}$ activation the animals were kept for 1 week. After this week tissues were collected for histopathology. During follow-up blood samples were taken to examine the haematology. In the third group $(n=7)$ the efficiency of the EmBlocker ${ }^{\text {TM }}$ was assessed using TCD.

All animals received humane care in compliance with the "Guide for the care and use of laboratory animals" of the National Institutes of Health. The study was approved by the local animal ethics committee.

\section{The EmBlocker ${ }^{\mathrm{TM}}$}

The new ultrasonic device, the EmBlocker ${ }^{\mathrm{TM}}$ (Neurosonix, Or-Yehunda, Israel), consist of a round $2.2 \mathrm{MHz}$ transducer with a diameter of $36 \mathrm{~mm}$ which is developed 
for placement on the aorta ascendens at the level of the bifurcation of the aorta and the innominate artery after thoracotomy as shown in figure 1 and 2. The EmBlocker $^{\mathrm{TM}}$ was kept in position with an ESTECH stabilizer (ESTECH, San Ramon, United States of America).

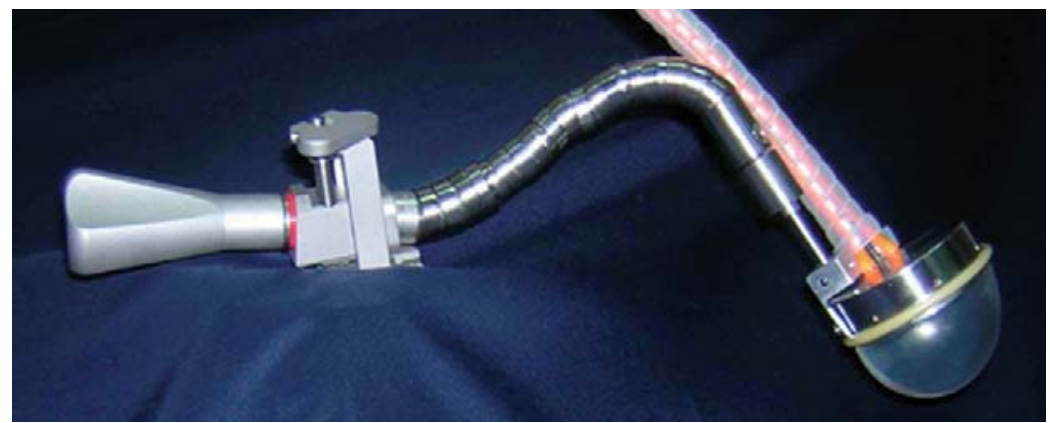

Figure 1:The EmBlocker ${ }^{T M}$ with the cooling system attached and connected to the ESTECH stabilizer.

The mechanism of the EmBlocker ${ }^{\mathrm{TM}}$ is based on the principle that an object with different acoustic impedance (density multiplied by sound speed) than its surroundings partly reflects and partly absorbs ultrasound energy. The acoustical energy which is absorbed by an object is also called the acoustic radiation force, and this energy is able to move an object or to change the direction of its path ${ }^{6,7}$.

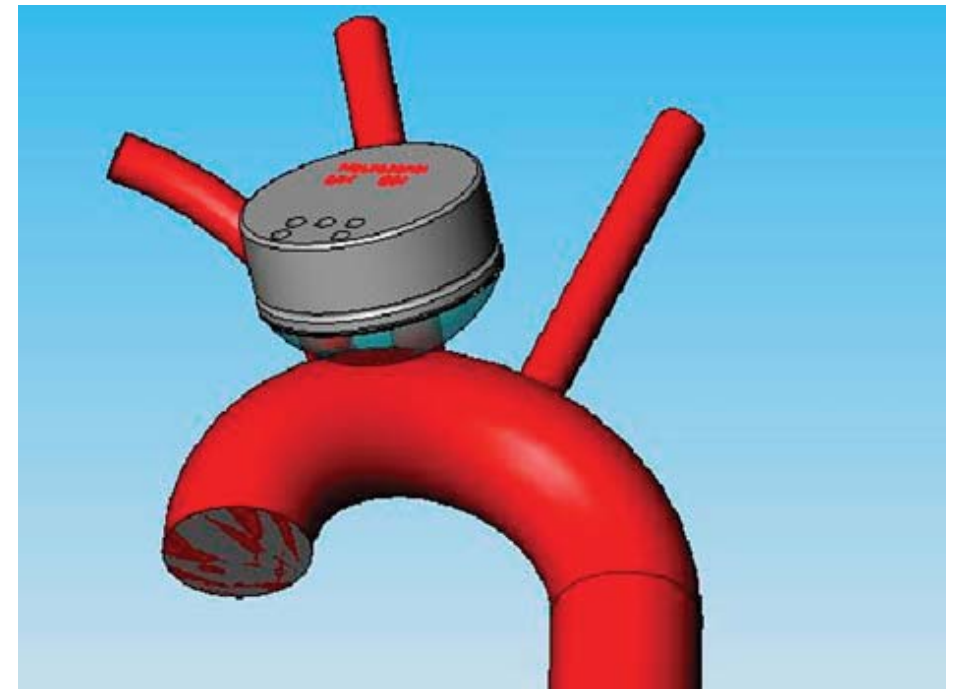

Figure 2:A schematic overview of the position of the EmBlocker ${ }^{\mathrm{TM}}$ on aorta arch.

The acoustic radiation force on an object depends on the extent of the difference between the acoustic impedance of the object and its surroundings; the greater the difference in acoustic impedance is, the higher the acoustical force on the object will be. Due to the fact that there is hardly an acoustic difference between red and white blood cells and its surroundings, the ultrasonic radiation power will not affect 
these cells. The acoustic impedance difference between gaseous emboli and its surroundings exceeds the acoustic impedance difference between solid emboli and its surrounding. ${ }^{8}$. For this matter a lower ultrasonic energy level of the EmBlocker ${ }^{\mathrm{TM}}$ can be sufficient to achieve the same acoustic radiation force on gaseous emboli as a higher ultrasonic level of the EmBlocker ${ }^{\mathrm{TM}}$ on solid emboli. Due to this knowledge and in-vitro testing, an intensity level of the EmBlocker ${ }^{\mathrm{TM}}$ of $0.5 \mathrm{~W} / \mathrm{cm}^{2}$ is chosen to divert gaseous emboli and an intensity level of the EmBlocker ${ }^{\mathrm{TM}}$ of $1.5 \mathrm{~W} / \mathrm{cm}^{2}$ is chosen to divert solid emboli.

\section{Animal preparation: temperature}

One pig $(70 \mathrm{~kg})$ was subcutaneous administrated with Xylazine, Diasepam and Ketamine $\mathrm{HCl} 30$ min prior to intubation. An endotracheal intubation was conducted and was followed by mechanical ventilation. Maintenance of general anaesthesia was performed with isoflurane during the whole procedure. After administration of the anaesthesia a mid sternotomy was performed. The Emblocker ${ }^{\mathrm{TM}}$ transducer was placed at the level of the bifurcation of the aorta and the innominate artery (figure 2). Temperature sensors were placed in the beam of the transducer in the esophagus, trachea, under aorta and on aorta. Also temperature sensors were positioned in control areas on the aorta and in the esophagus outside the ultrasonic beam of the transducer. All animals were exposed to twice the pretended clinical duration of sonication: 120 seconds of $1.5 \mathrm{~W} / \mathrm{cm}^{2}$ intensity of the EmBlocker ${ }^{\mathrm{TM}}$ and 600 seconds of $0.5 \mathrm{~W} / \mathrm{cm}^{2}$ intensity of the EmBlocker ${ }^{\mathrm{TM}}$. This protocol was repeated four times in the same animal.

\section{Animal preparation: histopathology and haematology}

Six female domestic pigs approximately $70 \mathrm{Kg}$ (about 4 months old) were subcutaneous administrated with Xylazine, Diasepam and Ketamine $\mathrm{HCl} 30 \mathrm{~min}$ prior to intubation. After the baseline blood sample was taken, endotracheal intubation was conducted and was followed by mechanical ventilation. Maintenance of general anaesthesia was performed with isoflurane during the whole procedure. After administration of the anaesthesia a mid sternotomy was performed using a sterile technique. The Emblocker ${ }^{\mathrm{TM}}$ transducer was placed at the level of the bifurcation of the aorta and the innominate artery. The position of the transducer was documented to allow identification of the sonicated tissues. Then all animals were exposed to a combination of 8 periods of 120 seconds of $1.5 \mathrm{~W} / \mathrm{cm}^{2}$ intensity of the EmBlocker ${ }^{\mathrm{TM}}$ and one period of 20 minutes of $0.5 \mathrm{~W} . \mathrm{cm}^{2}$ intensity of the EmBlocker ${ }^{\mathrm{TM}}$ (90 seconds on and 30 seconds off). After sonication the chest was surgically closed in layers and blood samples were taken. Each animal recovered from anaesthesia in the operating room, and then was transported to the step- 
down unit. Each animal received antibiotic (Cefazolin $30 \mathrm{mg} / \mathrm{kg}$ by IV, a single dose was given at the conclusion of the procedure. Bytril $1 \mathrm{ml} / 20 \mathrm{~kg}$ intramuscular injection once a day for 4 days) and analgesic agents (Morphine single dose was given at the conclusion of the procedure and Depirone in the first 24 hours, continued with Depirone for 3 days) in the postoperative period. After each clinical stage the animals were observed daily for signs of distress that would indicate the need for administration of analgesics. 72 hours post surgery a blood sample was taken. At day 7 postoperatively all animals were sacrificed. Blood samples were taken prior to euthanasia. Post euthanasia: A mid-re-sternotomy was performed. Tissues were taken from sonicated and non sonicated areas of the aorta, the innominate artery (or the junction of the innominate artery and aorta as a sonicated tissue), the trachea, the esophagus and the vagus nerve. The tissue samples were divided in two sections: back and front, whereby the front section is chosen as that which first comes into contact with the ultrasonic beam. The tissues were fixed in formalin for at least a one week and prepared routinely for histopathology.

Blood samples were analysed for general chemistry, free haemoglobin and haematology variables. Blood samples were taken from the animal at four different points of time: At baseline (prior to any surgical intervention), at the end of the surgery, 72 hours after surgery and before sacrifice (after 1 week).

\section{Animal preparation: efficiency}

Seven pigs $(75 \pm 20 \mathrm{~kg}$ ) were premedicated with $0.07 \mathrm{ml} / \mathrm{kg}$ azaperone (stresnil $40 \mathrm{mg} / \mathrm{ml}$ ) intramuscularly. Anaesthesia was induced with a mask of $1.5 \%$ isoflurane and with help of xylocaine spray (10\%) the pigs were orally intubated. Anaesthesia was maintained with a mixture of $\mathrm{O} 2$ and isoflurane (1.5\%). After administration of analgesic buprenorfine (i.v. bolus $0.01 \mathrm{mg} / \mathrm{kg}$ ) and muscle relaxant suxamethonium (i.v bolus $0.1 \mathrm{mg} / \mathrm{kg}$ ), a mid sternotomy was performed. Heparin was administered (bolus $200 \mathrm{IU} / \mathrm{kg}$ i.v.). After the activated clotting time (ACT) reached 300 seconds, an extracorporeal circulation with central cannulation was installed. ACT was kept above 480 seconds during the experiment. After the extracorporeal circulation had been started anaesthesia was maintained with a propofol IV drip. Monitoring included ECG, blood pressure, oxygen saturation and capnography.

A cardioplegia needle was placed in the aortic root distal from the arterial cannula, which was used for emboli injections. Polystyrene DVB particles (Duke Scientific Corp) $(500 \mu \mathrm{m}-750 \mu \mathrm{m})$ were dissolved in a $10 \mathrm{ml}$ syringe filled with a mixture (1:33) of serum and ringer's lactate. Air emboli were created by mixing $1 \mathrm{ml}$ of air with $9 \mathrm{ml}$ of blood. Immediately after the mixture of air with blood the $10 \mathrm{ml}$ was injected. Each kind of injection was performed 10 times; 5 times without EmBlocker $^{\mathrm{TM}}$ activation (control) and 5 times with activation of the EmBlocker ${ }^{\mathrm{TM}}$ (sonicated). The applied power of the EmBlocker ${ }^{\mathrm{TM}}$ transducer is during air emboli 
injections $0.5 \mathrm{~W} / \mathrm{cm}^{2}$ and for solid emboli injections $1.5 \mathrm{~W} / \mathrm{cm}^{2}$. At the end of the experiment, all animals were sacrificed through a pentobarbital overdose (bolus 80 $\mathrm{mg} / \mathrm{kg}$ i.v.).

For cerebral monitoring, two transcranial transducers (Embodop DWL, Singen, Germany) were each placed on each eye of the pig. Through the opening of orbita of the eye, the ultrasound could pass the skull and penetrate into the white and gray matter of the brain and reach the cerebral blood vessels. A cerebral blood flow velocity spectrum from an intracranial artery could be obtained. Transcranial Doppler (TCD) recordings were saved and analyzed offline. One observer manually counted the number of emboli according to the golden standard ${ }^{9}$.

\section{Statistics}

Statistical comparison (Mixed model, two-tailed comparisons, $n=7$ ) was performed to compare emboli counts between On and Off stages, while taking into account the fact that all animals are different and that each animal provides a number of correlated replicates. Statistical analyses were conducted with SAS/STATA ${ }^{\oplus}$ statistical software. The number of cerebral emboli was averaged over all replicated emboli injections for each type of emboli and for left and right measurements in all animals and presented as mean and standard deviation.

\section{Results}

In the safety study, all animals survived the operation, showed a course of steady clinical improvement, gained weight as planned and reached their target sacrifice date in good health and without any signs of illness or adverse events.

\section{Temperature}

In table 1 the temperature values are shown from the esophagus, the trachea, under the aorta, on the aorta, control aorta and control esophagus at two time intervals during two different power settings of the EmBlocker ${ }^{\mathrm{Tm}}$. The high power application $\left(1.5 \mathrm{~W} / \mathrm{cm}^{2}\right)$ results in the highest temperature $\left(41.9^{\circ} \mathrm{C}\right)$ under the aorta after 2 minutes. At the low power application $\left(0.5 \mathrm{~W} / \mathrm{cm}^{2}\right)$ the highest temperature measured $\left(38.1^{\circ} \mathrm{C}\right)$ was observed under the aorta after 10 minutes. All sonicated areas showed a rise in temperature during high and low power EmBlocker ${ }^{\mathrm{TM}}$ activation, the 
Table 1: Temperature in and outside (control) the beam during activation of the EmBlocker ${ }^{\mathrm{TM}}$ are listed.

\begin{tabular}{|c|c|c|c|c|c|c|c|}
\hline & & Sonicated & & & & Contro & \\
\hline & & Esophagus & Trachea & Under aorta & On aorta & Aorta & Esophagus \\
\hline & & Mean & Mean & Mean & Mean & Mean & Mean \\
\hline & Time (sec) & SD & SD & SD & SD & SD & SD \\
\hline High power & 0 & 35.3 & 35.6 & 35.2 & 27 & 33.2 & 34.6 \\
\hline & & 0.3 & 0.2 & 0.3 & 2.7 & 2.1 & 0.3 \\
\hline & 60 & 36.7 & 38.3 & 40.7 & 33 & 33.5 & 34.8 \\
\hline & & 1 & 1 & 0.9 & 2.1 & 1.9 & 0.5 \\
\hline & 120 & 37.5 & 39.1 & 41.9 & 33.3 & 33.6 & 35.1 \\
\hline & & 1.3 & 1.2 & 1.1 & 2.1 & 1.9 & 0.6 \\
\hline Low power & 0 & 35.3 & 35.6 & 35.3 & 25.5 & 33.1 & 34.6 \\
\hline & & 0.2 & 0.3 & 0.3 & 0.2 & 0.9 & 0.3 \\
\hline & 300 & 36.5 & 37.3 & 38.1 & 28 & 33.2 & 34.6 \\
\hline & & 1 & 0.9 & 0.7 & 0.5 & 0.9 & 0.8 \\
\hline & 600 & 36.5 & 37.3 & 38.1 & 28 & 33.2 & 35.1 \\
\hline & & 1 & 0.9 & 0.8 & 0.5 & 0.9 & 0.4 \\
\hline
\end{tabular}

temperatures in the control areas, outside the ultrasound beam, remained constant during EmBlocker ${ }^{\mathrm{TM}}$ activation.

\section{Histopathology}

Table 2: The abnormalities of the histopathology results are shown per animal in the control and/or sonicated tissue. If the remark is shown in both second and third column, the abnormality was found in both control and sonicated tissue.

\begin{tabular}{|c|c|c|}
\hline & CONTROL & SONICATED \\
\hline Animal 1 & Aorta & Aorta \\
\hline Remark & \multicolumn{2}{|c|}{$\begin{array}{l}\text { On the external surface of the adventitia is a focus of vascularised, inflamed granulation } \\
\text { tissue. }\end{array}$} \\
\hline Animal 2 & Aorta & Aorta \\
\hline Remark & \multicolumn{2}{|c|}{$\begin{array}{l}\text { On the external, adventitial surface is a thick layer of heavily inflamed vascularised } \\
\text { granulation tissue including clumps of fibrin. }\end{array}$} \\
\hline Animal 3 & Aorta & Aorta \\
\hline Remark & \multicolumn{2}{|c|}{$\begin{array}{l}\text { In the adventitial adipose tissue is a large area of heavily inflamed vascularised } \\
\text { granulation tissue that includes fibrin on the surface and histiocytic giant cells. }\end{array}$} \\
\hline Animal 4 & Trachea & Trachea \\
\hline Remark & \multicolumn{2}{|c|}{$\begin{array}{l}\text { The lamina propria is mildly expanded by acute and chronic inflammatory cells indicating } \\
\text { a mild acute or chronic bronchitis. }\end{array}$} \\
\hline Animal 5 & Aorta & Aorta \\
\hline Remark 1 & \multicolumn{2}{|c|}{$\begin{array}{l}\text { Aorta: On the external surface of the adventitia is a focus of vascularised, inflamed } \\
\text { granulation tissue. }\end{array}$} \\
\hline Remark 2 & Trachea: no abnormalities & $\begin{array}{l}\text { Trachea: On the external surface of the } \\
\text { adventitia is vascularised, inflamed granulation } \\
\text { tissue, involving large areas of the adventitia. }\end{array}$ \\
\hline Animal 6 & & Aorta \\
\hline Remark & No abnormalities & $\begin{array}{l}\text { The adventitia is mildly vascularised and mildly } \\
\text { fibrotic but uninflamed. }\end{array}$ \\
\hline
\end{tabular}


Only the atypical findings of the histopathology results are schematic given in table 2. In 5 animals abnormalities in tissue from the aorta were determined. In four of these animals the abnormalities were established in control as in sonicated tissue. In one animal just the sonicated aorta tissue demonstrated abnormalities. In two animals an inflammation in tissue of the trachea was determined. These findings were determined in one of these two animals in both control and sonicated tissue and in the other animal just in the sonicated tissue.

\section{Haematology}

The analysed white blood cells (WBC), free haemoglobin (free $\mathrm{HB}$ ) and the creatine phosphokinase (CPK) are shown in table 3 at 4 periods in time (baseline, post closure, 72 hours after thoracotomy and before sacrifice). The white blood cells within normal limits during the entire follow-up period, but show a significant reduction between baseline and post closure. The free haemoglobin values are above the normal values at baseline, post closure and 72 hours after thoracotomy. In the period just before sacrifice the free $\mathrm{HB}$ is within range. Also, the CPK values are only within normal limits just before sacrifice and at all three other time points they are above the normal values. Although the first three values are higher than normal, there is a significant reduction immediately after the baseline values were obtained. Just before sacrifice the CPK values significantly reduced to values within the normal range.

Table 3: White blood cells (WBC), free haemoglobin (free $\mathrm{HB}$ ) and creatine phosphokinase (CPK) are shown at four time points.

\begin{tabular}{lllll}
\hline & $\begin{array}{l}\text { Baseline } \\
\text { Mean (SD) }\end{array}$ & $\begin{array}{l}\text { Post closure } \\
\text { Mean (SD) }\end{array}$ & $\begin{array}{l}\text { After 72h } \\
\text { Mean (SD) }\end{array}$ & $\begin{array}{l}\text { sacrifice } \\
\text { Mean (SD) }\end{array}$ \\
\hline WBC (10^3CMM) & $19.7(5.1)$ & $15.7(2.9) *$ & $18.4(3.7)$ & $16(2.3)$ \\
Free HB (\%) & $6.9(5.4)$ & $5.1(7.5)$ & $8.5(8.5)$ & $3.2(4.2)$ \\
CPK (IU/L) & $4606(224.2)$ & $3189(1769) *$ & $5109(2510)$ & $1228(589)^{*}$ \\
\hline
\end{tabular}

* = significantly changed compared to the last measured value before.

\section{Efficiency}

In all animals both left and right velocity spectra of the cerebral arteries could be visualized with TCD. The recorded signals in each animal were acceptable for the counting purposes. In table 4 the number of cerebral emboli for the left and the right cerebral arteries are shown for as well solid as air injections with and without activation of the EmBlocker ${ }^{\mathrm{TM}}$. The number of emboli is significantly reduced by use of the EmBlocker ${ }^{\mathrm{TM}}$. In the case of air emboli injections the number of emboli in the left middle cerebral artery is reduced from 155 emboli to 65 emboli and in the right middle cerebral artery from 182 emboli to 90 emboli, resulting in a reduction of 
respectively $58 \%$ and $51 \%$. The activation of the EmBlocker ${ }^{\mathrm{TM}}$ reduced the number of solid emboli with $42 \%$ from 67 emboli to 39 emboli in the left middle cerebral artery, and with $44 \%$ from 83 emboli to 46 emboli in the right middle cerebral artery.

Table 4: The average number of emboli counted in the left and the right middle cerebral artery with and without activation of the EmBlocker ${ }^{T M}$. The first two rows show the number of air emboli and the last two rows show the number of solid emboli. The percentage of reduction is shown in the column on the right.

\begin{tabular}{llll}
\hline & & EmBlocker ${ }^{\mathrm{TM}}$ & \\
& & Off & On \\
& & Mean (SD) & Mean (SD) \\
\hline Air & Left & $155(69)$ & $65(52)$ \\
& Right & $182(96)$ & $90(84)$ \\
Solid & Left & $67(34)$ & $39(26)$ \\
& Right & $82(38)$ & $46(29)$ \\
\hline
\end{tabular}

\section{Discussion}

\section{Temperature}

The absolute temperature in different regions in the body was examined in one animal. As stated by Goldstein et al ${ }^{10}$, the level of damage in a tissue as a result of thermal exposure is dependent upon both temperature and time. And no incidence of clinically detectable injury has been found for thermal exposures $\leq 43^{\circ} \mathrm{C}$ up to a couple of hours. In animals the most sensitive organs (testes and brain) did show some level of damage after a disposure of 20 minutes at a temperature of $43^{\circ} \mathrm{C}$. Other organs like skin, retina and prostate injury occurred in animals after 21 to 40 minutes at a temperature of $43^{\circ} \mathrm{C}$. All these findings are confirmed on a report by Miller et al ${ }^{11}$. In this study the temperature never came above $43^{\circ} \mathrm{C}$ and although under the aorta the temperature reached almost $42^{\circ} \mathrm{C}$, the time period was less than 2 minutes. In clinical use the period of activation is pretended to be half of the time period which were used in this temperature measurements, resulting in a temperature under the aorta of less than $41^{\circ} \mathrm{C}$. The temperature rise in the lower power application of the EmBlocker ${ }^{\mathrm{TM}}$ did not exceed the temperature value of $38.5^{\circ} \mathrm{C}$. This implies that the $0.5 \mathrm{~W} / \mathrm{cm}^{2}$ energy level of the EmBlocker ${ }^{\mathrm{TM}}$ produces less heat than the $1.5 \mathrm{~W} / \mathrm{cm}^{2}$ energy level, and can therefore be used for a longer time period. The high power application cannot be replaced clinically by the low power application because the high energy level is required to divert solid emboli. We can conclude from the temperature measurements (high and low energy level) that the device can be used safely. Although the temperature results did not show any values above the limit, there is a twosome temperature precautions made for clinical use. A condom will be placed over the transducer in which continuously cold 
water $\left(0^{\circ} \mathrm{C}\right.$ till $\left.5^{\circ} \mathrm{C}\right)$ will be circulating, as is shown in figure 1 . As a second precaution, a temperature sensor will be installed, which automatically shuts down the EmBlocker ${ }^{\mathrm{TM}}$ when the temperature level of the underlying aorta reaches $43^{\circ} \mathrm{C}$.

\section{Histopathology}

Intra-individual comparison of sonicated versus non-sonicated tissue, revealed no effect of sonication, except in two special cases. The inflammation in the aorta found in four animals (animal 1, 2, 3 and 5) was found as well in control as in sonicated tissue. As this inflammation is a typical reaction to a surgical procedure there can be concluded that these effects are not due to sonication of the EmBlocker ${ }^{\mathrm{TM}}$ per se. In one animal (animal 6) mildly vascularised and mildly fibrotic tissue of the adventitia of the external layer of the aorta was demonstrated in just the sonicated aorta. Probably these findings can be ascribed to the surgical procedure as well, in particular because in more animals even stronger reactions were found in control and in sonicated tissue. Tracheitis (which is a common infection in pigs) was found in two animals. In one animal tracheitis was also detected in the control tissues and in the other animal a mild tracheitis was detected in sonicated tissue at the back of the trachea which is in the far end of the ultrasonic beam and the actual estimated intensity on that area is close to zero. We can conclude that the inflammation and the tracheitis are not caused by sonication. Coagulation necrosis, which is considered to be a marker of damage caused by ultrasound induced hyperthermia, was not observed in any of the tissue samples.

\section{Haematology}

Blood analyses showed no specific effect of sonication (table 3 ). The high plasma CPK, which was already demonstrated in the baseline measurement, is most likely caused by transportation of the animals just prior to the surgical procedure. The reduction of the CPK value to a normal value in 7 days after the transportation, confirms the assumption that the high CPK values are due to transportation. Free haemoglobin values did not reveal significant red blood cell destruction due to the sonication procedure and remained within normal levels in time.

\section{Efficiency}

The efficiency results show significant reduction of cerebral emboli due to EmBlocker ${ }^{T M}$ activation. The ultrasonic wave of the EmBlocker ${ }^{T M}$ exerts a more pronounced diversion effect on gaseous emboli than on the solid emboli, which can be explained by the difference in acoustic impedance (as mentioned before) between the two types of emboli and their surroundings. 
However both gaseous and solid cerebral emboli were reduced by use of the EmBlocker $^{\mathrm{TM}}$, but despite the use of lower intensity of the EmBlocker ${ }^{\mathrm{TM}}$ for gaseous emboli, the reduction of emboli in the middle cerebral arteries is $10 \%$ higher for gaseous emboli than for solid emboli. The proof of principle was demonstrated by these preliminary results; however the final positioning, the final shape and size of the transducer could improve the efficiency. The EmBlocker ${ }^{\mathrm{TM}}$ seems to be an efficient device to reduce cerebral emboli during extracorporeal circulation and thereby could reduce postoperative neurological complications ${ }^{4,5,12}$.

\section{Clinical application}

Neurological complications after cardiac surgery are well recognized and can vary from cognitive decline, with an occurrence of $5 \%$ to $43 \%$, to stroke with an occurrence of $2 \%$ to $8 \%{ }^{1-5}$. A correlation between cerebral emboli and neurological complications has been described in the literature presuming that a reduction of cerebral emboli could reduce these neurological complications. Specific interventions during coronary bypass grafting (CABG) and open heart surgery were identified to generate most of the cerebral emboli; cannulation, cardioplegia needle incision, start and stop CPB, cross-clamping, cross-clamp release, side-clamping, side-clamp release, de-airing and decannulation ${ }^{2}$. According to the findings of this present study, the EmBlocker ${ }^{\mathrm{TM}}$ is able to divert solid as well as gaseous emboli to the descending aorta and reduce the number of emboli in the cerebral vessels. The EmBlocker ${ }^{\mathrm{TM}}$ should be placed after thoracotomy on the aorta ascendens above the bifurcation of the aorta and the innominate artery (figure 2). One minute of activation of the EmBlocker ${ }^{\mathrm{TM}}$ during the interventions mentioned before, should be sufficient to divert the generated emboli. Because all interventions (except deairing) are associated with solid emboli the higher intensity $\left(1.5 \mathrm{~W} / \mathrm{cm}^{2}\right)$ of the EmBlocker ${ }^{\mathrm{TM}}$ is recommended. In open-heart surgery there is an extra procedure in which cerebral gaseous emboli are expected. This time period is from the moment the heart starts making output and can continue for approximately 5 to 10 minutes . Due to the fact that the emboli in this period are mainly gaseous emboli the lower intensity level for 5 minutes is recommended. In this present, study twice the clinical activation time was examined as a result of which can be concluded that the recommended clinical activation times could be used safely.

Although this animal study already demonstrates a diversion effect, a possible change in intensities or design of the EmBlocker ${ }^{\mathrm{TM}}$ could improve the efficiency.

\section{Limitations}

The high standard deviation of the number of emboli in the control injections could be due to the high standard deviation of the weight of the animals. The anatomy 
difference, particularly in innominate and in right common carotid artery, could cause a difference in absolute flow to the cerebral vessels. No flow measurements were done to confirm this hypothesis.

In this preliminary study a surrogate marker (number of emboli) was used to examine the efficiency of the EmBlocker ${ }^{\mathrm{TM}}$, no brain MRI or brain pathology has been performed to examine the cerebral damage of the emboli (gas and solid) injections.

\section{Conclusion}

Temperature, haematological and histopathological results show no effect although twice the clinically pretended period of activation was used of the EmBlocker ${ }^{\mathrm{TM}}$. Efficiency measurements show a significant decrease in cerebral emboli during emboli injections during extracorporeal circulation. Use of the EmBlocker ${ }^{\mathrm{TM}}$ in cardiac surgery bears the potential to lower the risk of postoperative neurological complications.

\section{Acknowledgments}

We thank Neurosonix for financial support. The authors want to express their gratitude to Mr. T. van der Nagel and Ms. M. de Jong for their technical support and effort. 


\section{References}

1. Bucerius J, Gummert JF, Borger MA, Walther T, Doll N, Onnasch JF, Metz S, Falk V, Mohr FW. Stroke after cardiac surgery: a risk factor analysis of 16,184 consecutive adult patients. Ann Thorac Surg. 2003;75(2):472-478.

2. Fearn SJ, Pole R, Wesnes K, Faragher EB, Hooper TL, McCollum CN. Cerebral injury during cardiopulmonary bypass: emboli impair memory. J Thorac Cardiovasc Surg. 2001;121(6):1150-1160.

3. Naylor AR, Mehta Z, Rothwell PM, Bell PR. Carotid artery disease and stroke during coronary artery bypass: a critical review of the literature. Eur J Vasc Endovasc Surg. 2002;23(4):283-294.

4. Nollert G, Mohnle P, Tassani-Prell P, Uttner I, Borasio GD, Schmoeckel M, Reichart B. Postoperative neuropsychological dysfunction and cerebral oxygenation during cardiac surgery. Thorac Cardiovasc Surg. 1995;43(5):260-264.

5. Pugsley W, Klinger L, Paschalis C, Treasure T, Harrison M, Newman S. The impact of microemboli during cardiopulmonary bypass on neuropsychological functioning. Stroke. 1994;25(7):1393-1399.

6. Palanchon P, Tortoli P, Bouakaz A, Versluis M, de Jong N. Optical observations of acoustical radiation force effects on individual air bubbles. IEEE Trans Ultrason Ferroelectr Freq Control. 2005;52(1):104110.

7. Michishita K, Hasegawa $\mathrm{H}$, Kanai H. Ultrasonic measurement of minute displacement of object cyclically actuated by acoustic radiation force. The Japan Society of applied Physics. 2003;42:46084612.

8. Markus H. Transcranial Doppler detection of circulating cerebral emboli. A review. Stroke. 1993;24(8):1246-1250.

9. Van Zuilen EV, Mess WH, Jansen C, Van der Tweel I, Van Gijn J, Ackerstaff GA. Automatic embolus detection compared with human experts. A Doppler ultrasound study. Stroke. 1996;27(10):18401843.

10. Goldstein LS, Dewhirst MW, Repacholi M, Kheifets L. Summary, conclusions and recommendations: adverse temperature levels in the human body. Int J Hyperthermia. 2003;19(3):373-384.

11. Miller MW, Ziskin MC. Biological consequences of hyperthermia. Ultrasound Med Biol. 1989;15(8):707-722

12. Stump DA, Kon NA, Rogers AT, Hammon JW. Emboli and Neuropsychological Outcome Following Cardiopulmonary Bypass. Echocardiography. 1996;13(5):555-558. 


\section{CHAPTER 6}

\section{The EmBlocker ${ }^{\mathrm{TM}}$ : Efficiency and safety of a new ultrasonic embolic protection device adjunctive to heart valve surgery}

Published in

Ann Thorac Surg. 2009 Jul;88(1):253-7.

Sauren LD, la Meir M, Bolotin G, van der Veen FH, Heijmans JH, Mess WH, Maessen JG. 


\section{Abstract}

Introduction

Perioperative cerebral microemboli in cardiac surgery are associated with postoperative neurological complications. The EmBlocker ${ }^{\mathrm{TM}}$ (Neurosonix Ltd, Rehovot, Israel), a newly developed device should be positioned against the ascending aorta, and it produces an ultrasonic force expected to divert microemboli away from the cerebral vasculature and reduce cerebral emboli.

Methods

Twenty-one consecutive patients, undergoing a valve procedure, were enrolled into this nonrandomized pilot study. The EmBlocker ${ }^{\mathrm{TM}}$ (Neurosonix Ltd) was positioned in 11 consecutive patients and activated for 1 minute $\left(1.5 \mathrm{~W} / \mathrm{cm}^{2}\right)$ during seven selected aortic manipulations and for 10 minutes $\left(0.5 \mathrm{~W} / \mathrm{cm}^{2}\right)$ intermittently after cross-clamp removal. Transcranial Doppler-based quantification of micro embolic signals was performed in all patients.

Results

The use of the EmBlocker ${ }^{\mathrm{TM}}$ showed a significant overall reduction of the cerebral microembolic signals of $53 \%$.

Conclusion

The use of the EmBlocker ${ }^{\mathrm{TM}}$ during valve surgeries is associated with a reduction of perioperative cerebral microembolic signals. This new technology holds the potential to lower the risk of postoperative neurological complications. 


\section{Introduction}

Cardiac surgery is associated with the occurrence of intraoperative cerebral emboli, which are suggested to be correlated with the postoperative neurological complications, such as cognitive decline, transient ischemic attack and stroke ${ }^{1,2}$. The EmBlocker ${ }^{\mathrm{TM}}$ (Neurosonix Ltd, Rehovot, Israel) is a novel, ultrasonic cerebral embolic protection transducer.

\section{Technique}

The EmBlocker ${ }^{\mathrm{TM}}$ (Neurosonix Ltd) should be positioned on the ascending aorta after sternotomy. The emitted ultrasonic forces deflect emboli in the aortic arch away from the innominate and left common carotid arteries downstream to the descending aorta. In this pilot study, the effectiveness of the EmBlocker ${ }^{\mathrm{TM}}$ was evaluated during valve surgery by means of detection of cerebral micro embolic signals (MES).

\section{Methods}

\section{EmBlocker ${ }^{\mathrm{TM}}$}

The mechanism of the EmBlocker ${ }^{\mathrm{TM}}$ is based on the principle that an object with a different acoustic impedance partly absorbs ultrasound energy. This energy is the acoustic radiation force and is able to move an object or to change the direction of its path ${ }^{3-5}$. By virtue of this acoustic radiation force, emboli flowing in the ascending aorta and aortic arch may be re-routed downstream to the descending aorta away from the innominate artery and left common carotid artery to avoid their passage into the cerebral vasculature. Because the difference in acoustic impedance between red and white blood cells and its surroundings is very small, the EmBlocker ${ }^{\mathrm{TM}}$ activations are unlikely to affect these cells.

The disposable transducer The EmBlocker ${ }^{\mathrm{TM}}$ (Neurosonix Ltd) has an oval shape (maximum, $15.8 \mathrm{~mm} \times 25 \mathrm{~mm} \times 14 \mathrm{~mm}$ ) and has only transmitting capacity. No additional incision was required for the placement of the EmBlocker ${ }^{\mathrm{TM}}$, and all surgical manoeuvres were not affected by the presence of the EmBlocker ${ }^{\mathrm{TM}}$. A biocompatible dome filled with saline is placed over the transducer for cooling and also to prevent the presence of air between the transducer and the tissue (Fig 1). 


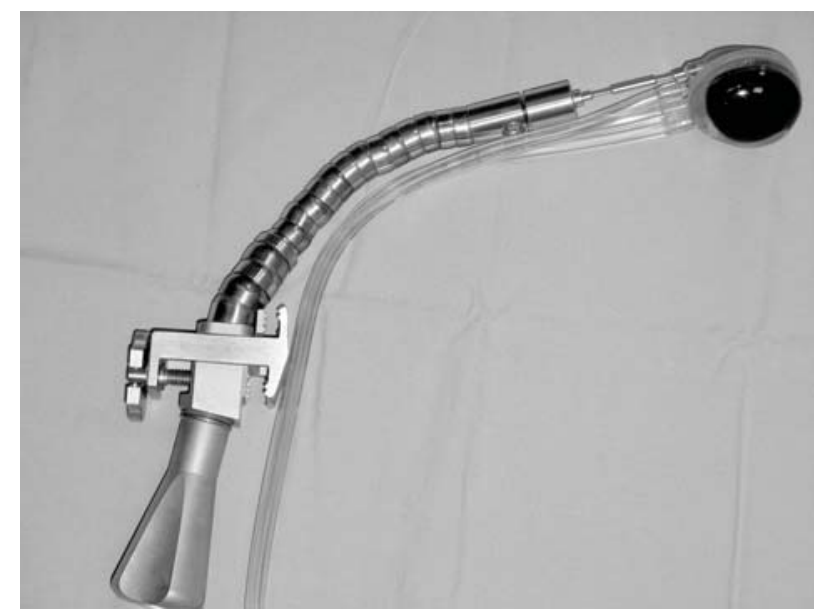

Fig 1: EmBlocker'm connected to ESTECH arm.

A temperature sensor monitors the temperature of the transducer, and this will shut down the activation when the temperature reaches a level which correlates with a tissue temperature of $43^{\circ} \mathrm{C}$. The EmBlocker ${ }^{\mathrm{TM}}$ was kept in position using an ESTECH stabilizer (ESTECH, San Ramon, CA, USA) as shown in Figures 1 and 2.

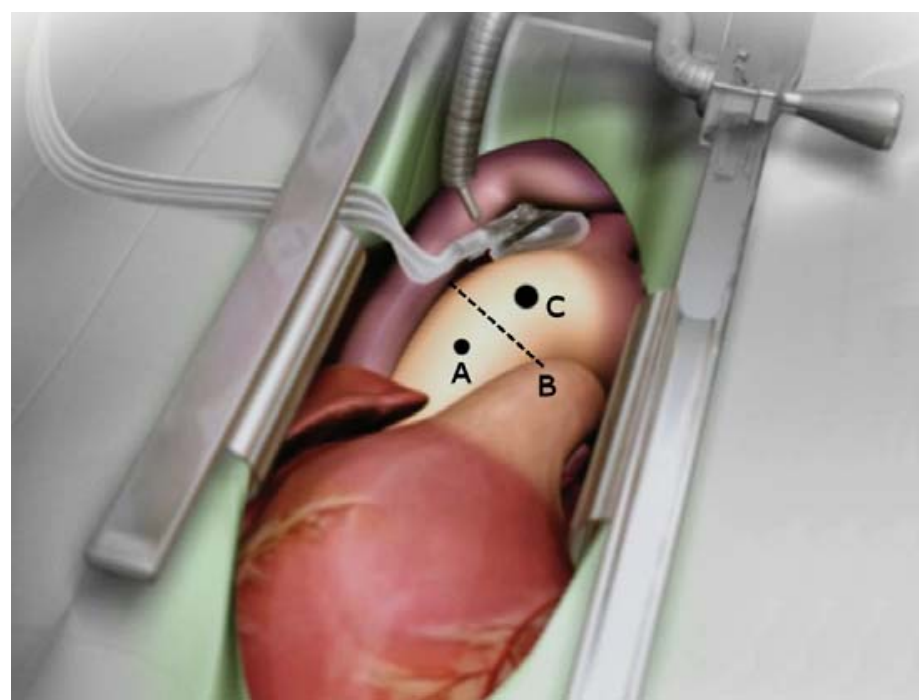

Fig2: Schematic view of the EmBlocker ${ }^{\mathrm{TM}}$ placement. Locations of $(\mathrm{A})$ the cardioplegia needle, (B) the cross clamp, and (C) the aortic cannula.

Due to different acoustical properties of gaseous and solid emboli, gaseous emboli experience a higher radiation force than solid emboli. Thus, lower energy levels can be applied when gaseous emboli are to be expected and result in an equivalent diverting effect. Therefore two intensity levels of the 2.2- $\mathrm{MHz}$ EmBlocker $^{\mathrm{TM}}$ were 
determined; for the air removal phase, a level of $0.5 \mathrm{~W} / \mathrm{cm}^{2}$ was determined, and for the aortic interventions, a level of $1.5 \mathrm{~W} / \mathrm{cm}^{2}$. Both intensity levels stayed within temperature safety ranges of all underlying tissues in animal experiments. For efficacy purposes, $0.5 \mathrm{~W} / \mathrm{cm}^{2}$ and $1.5 \mathrm{~W} / \mathrm{cm}^{2}$ energy levels proved to be efficient during injections of a mixture of air and saline (1:9) and injections of polystyrene particles (500micrometersm to 750 micrometers), respectively ${ }^{5}$.

The EmBlocker ${ }^{\mathrm{TM}}$ was activated by a trained physician at selected manipulations for 60 seconds: cannulation, cardioplegia needle placement, bypass on, cross-clamp placement, cross-clamp removal, bypass off and de-cannulation and for 10 minutes: the air removal phase (10 minutes after cross-clamp removal).

\section{Transcranial Doppler}

In both groups, transcranial Doppler (TCD) (Embodop DWL, Singen, Germany) examination was performed by bilateral insonation of the middle cerebral arteries. The moments of EmBlocker ${ }^{\mathrm{TM}}$ activation (or imitation activations in the control group) were marked and analyzed offline. Two blinded physicians manually, independently counted, according to the established consensus criteria ${ }^{6}$. All interventions were divided in 200ms segments. Each segment was categorized for the presence or absence of a MES by each observer. Only when an agreement of both observers was achieved, it was considered an MES.

The nature (gaseous or solid) and size of cerebral emboli is currently not possible to determine with use of transcranial Doppler ${ }^{7}$.

\section{Study design}

This single-centre nonrandomized, blinded trial was conducted from February 2006 until August 2007. A total of 21 patients were enrolled; 10 consecutive patients in the control group and 11 consecutive patients in the EmBlocker ${ }^{\mathrm{TM}}$ group.

\section{Patient selection}

Eligible patients for this study were men and women between the age of 50 and 75 undergoing a valve procedure with or without coronary bypass grafting. The exclusion criteria for this study were a carotid atheroma higher than grade II, protruding ascending aortic atheroma (atheroma grade $>\mathrm{III}$ ), previous cardiac operation, uncontrolled diabetes (i.e., fasting glucose $>250 \mathrm{mg} / \mathrm{dl}$ ), risk for surgery, euroscore $>8$, left ventricular ejection fraction $<40 \%$ (35\% for aortic stenosis), history of stroke, abnormal clotting activation with a prothrombin time $>60 \%$, and partial thromboplastin time $>2$ than the normal, emergency procedure, and life threatening disease other than cardiac. 


\section{Study procedure}

The TCD transducers were positioned on the head just after placement of the central venous pressure line. In the EmBlocker ${ }^{\mathrm{TM}}$ group, the EmBlocker ${ }^{\mathrm{TM}}$ was placed on the ascending aorta just proximal of the origin of the innominate artery after sternotomy (Fig 2). EmBlocker ${ }^{\mathrm{TM}}$ activations and de-activations were marked on the TCD recording. No EmBlocker ${ }^{\mathrm{TM}}$ was placed in the control group, but the control console of the EmBlocker ${ }^{\mathrm{TM}}$ was present to imitate EmBlocker ${ }^{\mathrm{TM}}$ activations. Each manipulation resulted in 1 minute of TCD recording, except the removal of air phase, which was a 10 minute TCD recording.

\section{EmBlocker ${ }^{\text {TM }}$ procedure}

In 11 patients the EmBlocker ${ }^{\mathrm{TM}}$ transducer was positioned as shown in Figure 2. Placement of the EmBlocker ${ }^{\text {TM }}$ did not have any impact on the valve procedure, and it was performed according to the standard protocol.

The EmBlocker ${ }^{\mathrm{TM}}$ was activated for 60 seconds (intensity of $1.5 \mathrm{~W} / \mathrm{cm} 2$ ) during the selected aortic manipulations. The start of activation of the EmBlocker ${ }^{\mathrm{TM}}$ and applying a marker in the TCD recording was synchronized with the surgeon and perfusionist. In the air removal phase the EmBlocker ${ }^{\mathrm{TM}}$ was activated for 90 seconds and switched off for 30 seconds (intensity of $0.5 \mathrm{~W} / \mathrm{cm} 2$ ). This sequence was repeated successively 5 times. Immediately after de-cannulation, the EmBlocker ${ }^{\mathrm{TM}}$ was removed.

\section{Statistical analysis}

Statistical comparisons (Mann-Whitney U signed-rank test; two-tailed comparisons) were made between the number of detected cerebral MES during the selected interventions in the control group and in the EmBlocker ${ }^{\mathrm{TM}}$ group. A p value $<0.05$ was considered statistically significant.

The investigation was approved by the Human Research and Ethics Committees of the Academic Hospital Maastricht, the Netherlands. All participating patients gave written informed consent

\section{Results}

One patient from the EmBlocker ${ }^{\mathrm{TM}}$ group was excluded from the efficacy study due to technical problems with the EmBlocker ${ }^{\mathrm{TM}}$ device. The temperature algorithm did terminate all the activations within 2 seconds, which appeared postoperatively, caused by a leaking biocompatible dome placed over the EmBlocker ${ }^{\mathrm{TM}}$. 
Table 1 represents the patient's characteristics of both groups $(n=20)$. Table 2 represents the number of cerebral MES in the left and right middle cerebral arteries in the control and EmBlocker ${ }^{\text {TM }}$ group during the selected manipulations.

\begin{tabular}{|c|c|c|c|c|c|}
\hline & \multicolumn{2}{|c|}{ Control $(n=10)$} & \multicolumn{2}{|c|}{ EmBlocker $^{\mathrm{TM}}(\mathrm{n}=10)$} & \multirow[t]{2}{*}{$p$-value } \\
\hline & mean & SD & mean & SD & \\
\hline Age & 68,7 & 5,4 & 61,2 & 7,8 & 0,0962 \\
\hline Gender & \multicolumn{2}{|c|}{$M=7, F=3$} & \multicolumn{2}{|c|}{$M=8, F=2$} & 0,739 \\
\hline AVR & \multicolumn{2}{|c|}{4} & \multicolumn{2}{|c|}{4} & \\
\hline$A V R+C A B G$ & \multicolumn{2}{|l|}{4} & \multicolumn{2}{|l|}{0} & \\
\hline MVR/MVP & \multicolumn{2}{|l|}{1} & \multicolumn{2}{|l|}{4} & \\
\hline$M V R+C A B G$ & \multicolumn{2}{|l|}{1} & \multicolumn{2}{|l|}{2} & \\
\hline Aortic non-protruding atheroma & \multicolumn{2}{|l|}{10} & \multicolumn{2}{|l|}{8} & \\
\hline Aortic protruding atheroma & \multicolumn{2}{|l|}{0} & \multicolumn{2}{|l|}{0} & \\
\hline Aortic atheroma grade not recorded & \multicolumn{2}{|l|}{0} & \multicolumn{2}{|l|}{2} & \\
\hline $\begin{array}{l}\text { IMTmax }<1.0 \mathrm{~mm} \text { (Normal Carotid } \\
\text { Arteries) }\end{array}$ & \multicolumn{2}{|l|}{4} & \multicolumn{2}{|l|}{6} & \\
\hline $\begin{array}{l}1.0 \mathrm{~mm}=<\mathrm{IMTmax}>1.3 \mathrm{~mm} \text { (Thickening } \\
\text { carotid Arteries) }\end{array}$ & \multicolumn{2}{|l|}{5} & \multicolumn{2}{|l|}{3} & \\
\hline IMT measurements not performed & \multicolumn{2}{|l|}{1} & \multicolumn{2}{|l|}{1} & \\
\hline Creatinine concentration (pre-operative) & 87 & 14 & 82 & 11 & 0,447 \\
\hline Creatinine concentration (postoperative) & 106 & 31 & 85 & 12 & 0,095 \\
\hline Creatinine concentration (leave hospital) & 84 & 12 & 81 & 12 & 0,604 \\
\hline Time on CPB (minutes) & 119 & 48 & 107 & 29 & 0,739 \\
\hline $\begin{array}{l}\text { Time between Cross-Clamp off and De- } \\
\text { cannulation (minutes) }\end{array}$ & 27 & 6.5 & 28 & 7.9 & 0,863 \\
\hline Length of operation (hours) & 3.35 & 0.51 & 3.37 & 0.38 & 0,813 \\
\hline Length of stay in ICU (hours) & 66.5 & 85.7 & 25.7 & 9.2 & 0,093 \\
\hline Length of stay in hospital (days) & 10.5 & 5.5 & 7.0 & 1.8 & 0,165 \\
\hline
\end{tabular}

\section{Efficacy}

In all selected manipulations, the number of cerebral MES was lower in the EmBlocker $^{\mathrm{TM}}$ group compared to the control group. A significant reduction of $63 \%$ of cerebral MES during the selected aortic manipulations was accomplished by use of the EmBlocker ${ }^{\mathrm{TM}}$. Due to activation of the EmBlocker ${ }^{\mathrm{TM}}$ the overall number of cerebral MES was significantly reduced by $53 \%$. No significant differences were found between the number of MES detected in the left and right middle cerebral artery in both groups.

\section{Discussion}

This study has demonstrated that the use of the EmBlocker ${ }^{\mathrm{TM}}$ is associated with a significant perioperatively reduction in cerebral MES. No difference in operation 
time, no difference in ICU time, and no difference in creatinine levels were caused to document between the control and EmBlocker ${ }^{\mathrm{TM}}$ group.

\section{Efficacy}

The lower number of cerebral MES demonstrated in the air removal phase of the EmBlocker ${ }^{\mathrm{TM}}$ group was not statistically significant, which could be due to the high standard deviation and the emboli counting method. The high standard deviation in the number of cerebral MES in the air removal phase in both groups could be originated from the variation in the time period between release of the cross clamp and de-cannulation. This time period difference could cause a variation of dissolving capability of the remaining air in the heart, which may contribute to a difference in number of MES entering the systemic circulation and explain the high standard deviation in the de-airing phase.

Table 2: The number of cerebral MES measured in the left and right middle cerebral artery in the control and in the EmBlocker ${ }^{\mathrm{TM}}$ group in all selected manipulation.

\begin{tabular}{|c|c|c|c|c|c|c|c|c|c|c|}
\hline & EmBlocker $^{\mathrm{TM}}$ & Contro & & & $\mathrm{EmB}$ & ocker & & & ntrol & \\
\hline & $\begin{array}{c}\text { mean } \\
\text { SD }\end{array}$ & $\begin{array}{c}\text { mean } \\
\text { SD }\end{array}$ & $\begin{array}{r}\text { pvalue EI } \\
\text { vs. CO }\end{array}$ & & $L$ & $\mathrm{R}$ & $\begin{array}{c}\text { pvalue L } \\
\text { vs. R }\end{array}$ & $\mathrm{L}$ & $\mathrm{R}$ & $\begin{array}{l}\text { pvalue } \\
\text { L vs. R }\end{array}$ \\
\hline \multirow[t]{2}{*}{ Cannulation } & 7 & 16 & 0.063 & & 3 & 4 & 0.529 & 9 & 7 & 0.28 \\
\hline & 10 & 14 & & & & & & & & \\
\hline \multirow[t]{2}{*}{ Cardioplegia needle } & 2 & 3 & 0.095 & & 1 & 1 & 0.971 & 2 & 1 & 1 \\
\hline & 5 & 3 & & & & & & & & \\
\hline \multirow[t]{2}{*}{ CPB on } & 3 & 4 & 0.962 & & 2 & 2 & 0.912 & 2 & 2 & 0.62 \\
\hline & 4 & 8 & & & & & & & & \\
\hline \multirow[t]{2}{*}{ Cross-clamp on } & 4 & 15 & 0.796 & & 2 & 2 & 0.796 & 12 & 3 & 0.796 \\
\hline & 4 & 37 & & & & & & & & \\
\hline \multirow[t]{2}{*}{ Cross-clamp off } & 20 & 21 & 0.631 & & 12 & 8 & 0.529 & 10 & 11 & 0.631 \\
\hline & 23 & 29 & & & & & & & & \\
\hline \multirow[t]{2}{*}{ CPB off } & 10 & 36 & 0.065 & & 5 & 5 & 0.971 & 20 & 16 & 0.931 \\
\hline & 10 & 36 & & & & & & & & \\
\hline \multirow[t]{2}{*}{$\mathrm{EE}$} & 252 & 519 & 0.218 & & 133 & 119 & 0.853 & 252 & 266 & 0.853 \\
\hline & 145 & 458 & & & & & & & & \\
\hline \multirow[t]{2}{*}{ De-cannulation } & 4 & 14 & 0.113 & & 2 & 2 & 0.258 & 7 & 6 & 0.796 \\
\hline & 4 & 15 & & & & & & & & \\
\hline \multirow[t]{2}{*}{ Total } & 303 & 622 & 0.043 & $*$ & 160 & 143 & 0.684 & 312 & 310 & 0.912 \\
\hline & 156 & 436 & & & & & & & & \\
\hline distribution ratio & & & & & 1.00 & 1.00 & & 1.12 & 1.00 & \\
\hline Aortic interventions & 51 & 103 & 0.019 & $*$ & 27 & 24 & 0.684 & 60 & 44 & 0.684 \\
\hline (total minus de-airing) & 26 & 55 & & & & & & & & \\
\hline
\end{tabular}


The cerebral MES counting method chosen in this study is a highly reproducible and reliable method, but the choice for segments of $200 \mathrm{~ms}$ restricts the counted number of MES in 1 second to 5 MES. A new developed algorithm could not be implemented yet, due to a maximum recording period of 3 seconds ${ }^{8}$. Underestimation of the counted MES will occur when the density of emboli is high and could underestimate the difference between the numbers of cerebral MES between both groups in the air removal phase.

No significant differences were found in the number of cerebral MES measured in the left and right middle cerebral artery. A slightly higher reduction of MES was demonstrated in the right middle cerebral artery (54\%) versus the left middle cerebral artery (49\%) by the use of the EmBlocker ${ }^{\mathrm{TM}}$, which could be an indication that some microemboli are diverted away from the innominate artery, which will end up in the left common carotid artery.

\section{Limitations}

In this preliminary study a surrogate marker (number of cerebral MES) was used to examine the efficacy of the EmBlocker ${ }^{\mathrm{TM}}$, but no brain MRI has been performed to examine the cerebral damage of the cerebral emboli.

No monitoring device is available to quantify the microemboli in the ascending or descending aorta. Therefore, no quantification of the generated or diverted emboli could be made in this study.

Although the physicians are blinded for the TCD data, the surgeons were not blinded due to no EmBlocker ${ }^{\mathrm{TM}}$ placement in the control group. The activation (or imitation activation) was in both groups synchronized with the surgeon to limit the bias introduced by the non-blinded operator.

\section{Conclusion}

In this pilot, clinical study, the activation of the EmBlocker ${ }^{\mathrm{TM}}$ during selected interventions that are prone for embolization (i.e., cannulation, cardioplegia needle placement, bypass on, cross-clamp placement, cross-clamp removal, 10 minute after cross-clamp removal (the air removal phase), bypass off and de-cannulation) resulted in a significant reduction of cerebral MES of averaging 53\%. Cerebral MES can be considered a surrogate marker for postoperative neurological complications. Therefore, these results suggest that the EmBlocker ${ }^{\mathrm{TM}}$ technology holds the potential to diminish the risk of the postoperative neurological complications. 


\section{References}

1. Pugsley W, Klinger L, Paschalis C, Treasure T, Harrison M, Newman S. The impact of microemboli during cardiopulmonary bypass on neuropsychological functioning. Stroke. 1994;25(7):1393-1399.

2. Abu-Omar Y, Cifelli A, Matthews PM, Taggart DP. The role of microembolisation in cerebral injury as defined by functional magnetic resonance imaging. Eur J Cardiothorac Surg. 2004;26(3):586-591.

3. Palanchon $\mathrm{P}$, Tortoli $\mathrm{P}$, Bouakaz A, Versluis $\mathrm{M}$, de Jong $\mathrm{N}$. Optical observations of acoustical radiation force effects on individual air bubbles. IEEE Trans Ultrason Ferroelectr Freq Control. 2005;52(1):104110.

4. Michishita K, Hasegawa $\mathrm{H}$, Kanai $\mathrm{H}$. Ultrasonic measurement of minute displacement of object cyclically actuated by acoustic radiation force. The Japan Society of applied Physics. 2003;42:46084612.

5. Sauren LD, la Meir M, Palmen M, Severdija E, van der Veen FH, Mess WH, Maessen JG. New ultrasonic radiation reduces cerebral emboli during extracorporeal circulation. Eur J Cardiothorac Surg. 2007;32(2):274-280.

6. Ringelstein EB, Droste DW, Babikian VL, Evans DH, Grosset DG, Kaps M, Markus HS, Russell D, Siebler M. Consensus on microembolus detection by TCD. International Consensus Group on Microembolus Detection. Stroke. 1998;29(3):725-729.

7. Evans DH. Embolus differentiation using multifrequency transcranial Doppler. Stroke. 2006;37(7):1641.

8. Lipperts MG, Sauren LD, Maessen JG, Hoeks AP, Mess WH. Quantification of Embolic Showers Using Radio-Frequency Based TCD Analysis. Ultrasound Med Biol. 2008. 


\section{CHAPTER 7}

\section{Quantification of embolic showers using radio-frequency based TCD analysis}

Published in

Ultrasound Med Biol. 2009 Mar;35(3):395-402.

Lipperts MG, Sauren LD, Maessen JG, Hoeks AP, Mess WH. 


\begin{abstract}
Introduction

During cardiac surgery and cardiology interventions, microemboli may be generated and disperse in the systemic circulation. The amount of microemboli that ends up in cerebral blood vessels is associated with postoperative neurological complications. During cardiac surgery a large amount of cerebral microemboli can occur at once and create so called "cerebral embolic showers". To correlate postoperative neurological outcome to cerebral embolic load, a quantitative evaluation of these embolic showers is necessary. The standard monitoring technology to visualize cerebral microemboli is transcranial Doppler (TCD). Although the conventional TCD systems are equipped with software claiming to detect microembolic signals (MES), none of the existing TCD systems is capable of an accurate estimation of the number of cerebral microemboli in embolic showers.

Methods

In this study, an algorithm with a high temporal resolution, based on the radiofrequency (RF) signal of a TCD system, has been designed to quantify these showers. Results

Evaluation by 3 independent observers of a training set demonstrates that the proposed method has a sensitivity of at least one order of magnitude better than the automatic detection algorithm on the existing Doppler device used.

Conclusion

RF based emboli detection can possibly become a standard addition to conventional Doppler methods, considering that accurate estimation of the embolic load supports quantification of neurological risk during various surgical procedures.
\end{abstract}




\section{Introduction}

Many reports suggest a correlation between cerebral embolic load during (cardiac) surgery and postoperative stroke and cognitive deficits ${ }^{1-3}$. The number of cerebral microemboli during these surgeries can be very large, and embolic densities during specific operations (aorta cross clamp release, removal of left-ventricular cannula) can be very high and can create so called "embolic showers". Transcranial Doppler (TCD) is a monitoring method in which microembolic signals (MES) can be visualised in both middle cerebral arteries (MCAs). Counting of MES in the recorded TCD signal is a very tedious task. Because current MES detection algorithms are not accurate, aural evaluation is still considered the golden standard for isolated MES. However, empirically we found it impossible to quantify high density embolic showers with emboli interspacing of less than 50 ms with aural evaluation. Commercial automatic MES detection algorithms fail here as well, since their temporal resolution is limited by a refractory period in the order of $0.1 \mathrm{~s}^{4}$.

Doppler processing involves demodulation of the received radio-frequency (RF) signal by multiplication by a reference signal and integration (low-pass filtering) over a given depth range, thereby disguising depth-specific phase information. Mess et al. ${ }^{5}$ showed that plots of the RF amplitude as a two-dimensional function of both depth and time directly visualize the path taken by emboli. This was corroborated by Cowe et al. ${ }^{6}$, who also demonstrated that with an automated detection algorithm applied to RF amplitude plots isolated MES can be detected and distinguished from artefacts. The shape of an embolus in 2 dimensional amplitude plots resembles generally a diamond and its predictability was incorporated in the detection algorithm. However, Cowe and Evans ${ }^{7}$ made no attempt to explore the algorithm for embolic showers. The predictability of embolic shapes in showers is less obvious than for isolated emboli. Furthermore during embolic showers, depth resolution is more important than information about blood flow, which calls for a short length of the emitted ultrasound bursts as demonstrated by Mess et al. ${ }^{5}$. who used a $2 \mu$ s burst, compared to the longer $13 \mu$ s burst used by Cowe et al. ${ }^{7}$.

In this study, an algorithm was designed for detection of emboli in showers, based on velocity, duration and depth range of MES. The proposed algorithm was tested on various recordings made during cardiac surgery to investigate its applicability for clinical practice. 


\section{Methods}

\section{Data Acquisition}

A regular Doppler unit (Pioneer TC8080, Nicolet Biomedical, Hongkong, or Multidop $X$ 4, DWL, Sipplingen, Germany) was used to send $2 \mathrm{MHz}$ ultrasound pulses at a given pulse repetition frequency (PRF) and to acquire the echo and Doppler (audio)signal from the middle cerebral artery (MCA). The RF echo signal, internal clock and pulse emission trigger were made available and connected to a 12-bit $A D$ converter of the acquisition computer. The signals were continuously fed to the $A D C$, with a sampling frequency (fs) of 8 or $16 \mathrm{MHz}$ depending on the Doppler unit used, and stored into a temporary buffer able to contain approximately $3 \mathrm{~s}$ of the signal. If an observer, listening to the Doppler audio signal, suspected that an embolus passed by the activated permanent storage of the contents of the buffer. The data is organized in an $\mathrm{m} \times \mathrm{n}$ matrix, each row containing the returned echo of one emitted pulse, where $m$ and $n$ are:

$$
\begin{aligned}
& m=T \cdot \mathrm{PRF} \\
& n=\frac{2 \Delta d \cdot f_{s}}{c}
\end{aligned}
$$

where $T$ is the length in $s$ of the acquisition, and $\Delta d[\mathrm{~m}]$ is the width of the acquisition window. Typically the PRF was $5 \mathrm{kHz}$ with an acquisition window width of $30 \mathrm{~mm}$, symmetrically around the depth setting of the TCD device. For TCD systems, the duration of emitted burst is varied with the sample volume setting. It was chosen as short possible with maintenance of reasonable signal intensity, to achieve a high depth resolution. The measurements were executed with a sample volume setting of $1.1 \mathrm{~mm}$, which corresponds to an ultrasound burst of approximately $2 \mu$ s and a system bandwidth of approximately $0.5 \mathrm{MHz}$.

The spatial resolution along the ultrasound beam depends on the pulse length and can be found from:

$$
d_{\min }=\frac{c t_{p}}{2}
$$

where dmin is the minimal distance along the ultrasound beam between two emboli for them to be detected as separate events. $t_{p}$ Is the effective pulse duration and $\mathrm{c}$ is the sound velocity in blood. The temporal resolution depends also on the velocity ( $v$ ) of the emboli along the beam and is given by:

$$
t_{\min }=\frac{d_{\min }}{v}
$$


Using a burst length of $2 \mu \mathrm{s}$ a spatial resolution of approximately $1.5 \mathrm{~mm}$ can be theoretically reached, and assuming a blood velocity of $30 \mathrm{~cm} / \mathrm{s}$ a temporal resolution of approximately $5 \mathrm{~ms}$.

\section{Clinical Data}

The investigation was approved by the Human Research and Ethics Committees of the University Hospital Maastricht, the Netherlands. All data were obtained from patients undergoing cardiac valve operations. Emboli showers occurring after release of the aorta cross clamp were recorded. These showers contain mostly MES from gaseous emboli, although it might be possible that some solid emboli were present as well. In total 11 patients were investigated, but two were eventually excluded due to an insufficient acoustic window. Of the remaining 9 patients 5 were randomly selected for a training set to optimize the parameters of the algorithm and the other 4 were used to test the algorithm with optimal parameters. On average 5 recordings were obtained per patient.

\section{Processing}

In Matlab (The MathWorks Inc., Natick, MA) the matrix is transposed to conform to the standard in literature with the depth dimension (fast time) along the $y$-axis ( $\mathrm{n}$ pixels) and the slow time dimension along the $x$-axis (m pixels). Now each column (depth or fast-time dimension), is high-pass filtered using a fourth order Butterworth filter with a cut-off frequency of $500 \mathrm{kHz}$, to eliminate any DC components caused by a misaligned coupling to the ADC. Then the instantaneous signal envelope $\mathrm{S}[\mathrm{n}]$ is obtained using a Hilbert transformation of each column (convolution with $1 /(\pi \mathrm{t})$ ): $S[n]=s[n]+i s[n]$, where $\mathrm{S}[\mathrm{n}]$ is the signal amplitude, and $\tilde{s}[n]$ is the Hilbert transform of the original signal. Brands et al. ${ }^{8}$ showed that the error in amplitude and phase of the Hilbert transform is negligible when the sampling rate is sufficiently high (at least four times the ultrasound frequency). To suppress the signal from stationary reflections, each row (slow-time dimension) is high-pass (clutter) filtered using a fourth order Butterworth filter with a cut-off frequency of $50 \mathrm{~Hz}$ (corresponding to a velocity of approximately $2 \mathrm{~cm} / \mathrm{s}$ ). 

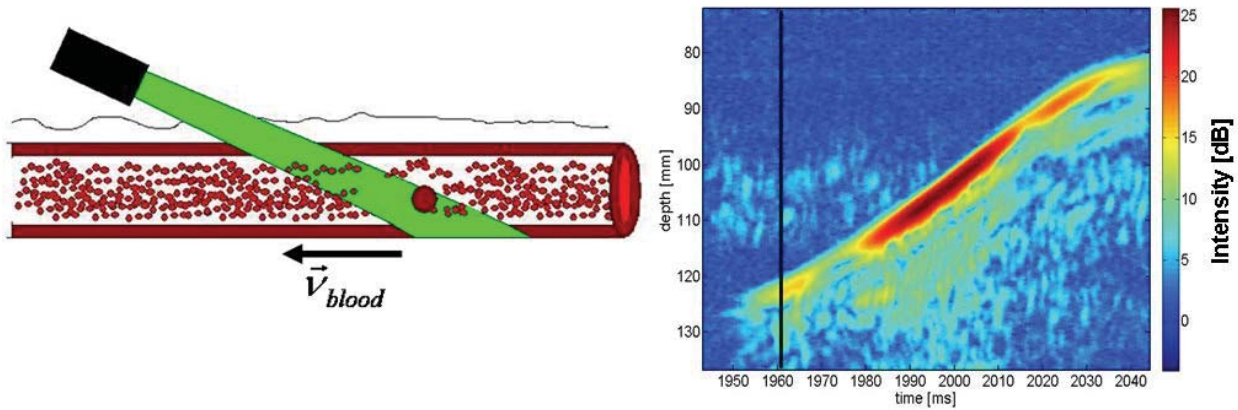

(A)
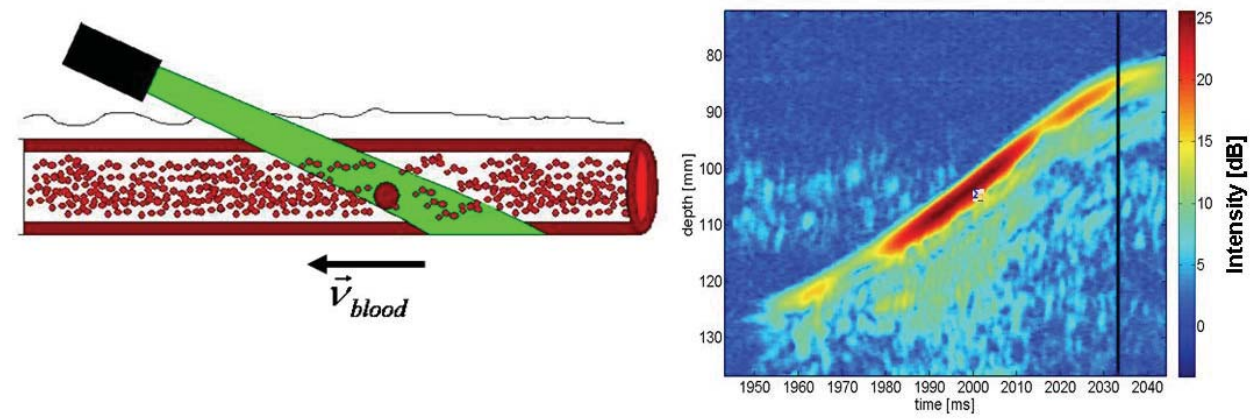

(B)

Figure 1: Schematic representation of an embolus travelling through a blood vessel with on the right the corresponding echo lines in the RF amplitude plot, (A) embolus just entering the ultrasound beam, (B) embolus just before leaving the ultrasound beam.

In the depth direction the intensity distribution of a single reflector attains the Gaussian shape of the spatial sensitivity function of the ultrasound system. In the case of an embolus travelling towards the probe, the depth of the reflection of the embolus decreases over time. As a consequence also the Gaussian intensity distribution shifts towards lower depths as time increases. This explains the typical 'comet' like shape as observed in figure 1. Because of the high amplitude of the reflection of a gaseous embolus compared to blood the MES appears to protrude outside the vessel. Instantaneous MES intensities are given in $\mathrm{dB}$, comparing the peak amplitude of the MES to the average amplitude over all depths of the matrix in a region without visual MES. To ensure that the selected region did not contain MES, usually a reference recording is made at the beginning of the surgery.

The standard way to classify the intensity of MES is the embolus to blood ratio (EBR) which can be extracted from the demodulated Doppler signal. For an RF amplitude matrix, the depth with a blood signal can be found exploiting the signal to noise ratio (SNR) as provided by a simply to apply cross-correlation model ${ }^{8}$. It 
should be $>1$ when blood (or any moving object) is present and $<1$ for other parts of the matrix. This is illustrated in figure 2, where blood signal is present between 48 and $57 \mathrm{~mm}$. The EBR is now calculated from:

$$
E B R=20 \cdot \log _{10}\left(\frac{\text { rms (with MES) }}{\text { rms (without MES) }}\right)
$$

where the rms SNR-values are calculated in a window with a width depending on the duration of the MES and a depth range corresponding to the region with blood flow. Averaging over depth and time is necessary to suppress random variations in blood signal amplitude caused by "speckle" 9 .

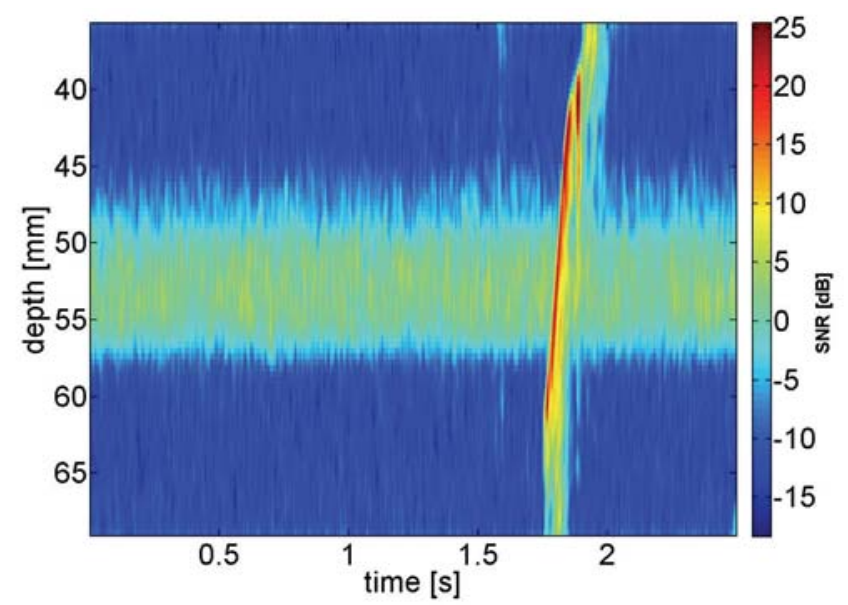

Figure 2: Signal to noise ratio (SNR) calculated by a cross correlation model. Blood (or a different moving object) is present at those positions where the SNR is higher than 1.

\section{Counting Algorithm}

The algorithm designed in this study to detect and count emboli bears some similarities to the algorithm proposed by Cowe and Evans ${ }^{7}$. To create a parallelogram around a MES in the 2-dimensional amplitude plot (figure 3), all local maxima above a certain amplitude threshold $\mathrm{T} 1$ (e.g. $15 \mathrm{~dB}$ ) within a certain depth range (e.g. $45-60 \mathrm{~mm}$ ) are located. A second threshold is defined as $T 2$, a certain value $V$ (e.g. $10 \mathrm{~dB}$ ) below the local maximum. It is reached, starting from the highest local maximum, by going back (P1) and forward (P3) in time (to the left or right in figure). The same is done for point $\mathrm{P} 2$ in upward direction. Along the slope $\mathrm{S}$ between points $\mathrm{P} 2$ and $\mathrm{P} 1$ in positive (up) and negative (down) direction from the local maximum, points $\mathrm{P} 4$ and $\mathrm{P} 5$ are obtained where again the threshold value $\mathrm{T} 2$ is reached. Now a parallelogram is constructed, its height being defined by points $\mathrm{P} 4$ 
and $\mathrm{P} 5$, its width by $\mathrm{P} 3$ and $\mathrm{P} 1$, and its slope by $\mathrm{S}$. All pixels within the parallelogram with an amplitude higher than $\mathrm{T} 2$ are given the amplitude value 0 , to indicate that they are part of the event. The event is further characterized by the slope of its diagonals.

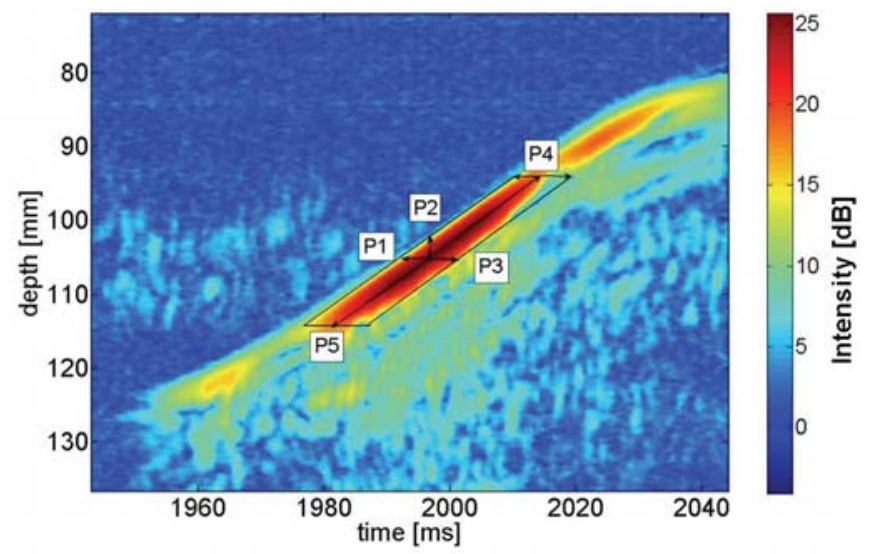

Figure 3: Steps to create a parallelogram around an event.

Based on our observation, the velocity of emboli in the MCA ranges from 5 to 90 $\mathrm{cm} / \mathrm{s}$ with a duration between 10 to $300 \mathrm{~ms}$, while the depth range varied from around 3 to $20 \mathrm{~mm}$, starting from the preset depth. These characteristics are used to establish criteria (slope, duration and depth range) for the characterisation of an event. An event is considered to be a MES when all criteria (see table 1) are satisfied. The procedure is repeated for all other local maxima in the amplitude plot. Double count of an event can occur when 2 or more local maxima are present in one single structure. This is prevented by disregarding events with a percentage of zero-pixels before actual classification higher than $3 \%$.

Table 1: Criteria for the characterization of possible embolic events

\begin{tabular}{lll}
\hline Criteria & lower boundary & upper boundary \\
\hline Velocity & $5 \mathrm{~cm} / \mathrm{s}$ & $90 \mathrm{~cm} / \mathrm{s}$ \\
Duration & $10 \mathrm{~ms}$ & $300 \mathrm{~ms}$ \\
Depth range & $3 \mathrm{~mm}$ & $20 \mathrm{~mm}$ \\
\% of zero pixels before classification & - & $3 \%$ \\
\hline
\end{tabular}

\section{Human Detection}

The processed RF matrices were read by 3 independent observers. The observers were instructed to classify an event based on their own intuition and experience, provided the event occurred within a pre-determined depth range and was completely within the RF plot. Finally an event was classified as MES when it was 
judged as being so by at least two of the three observers. Events classified as MES by the algorithm can now be classified as true positive (TP) or false positive (FP).

A training set consisting of 20 recordings taken from 5 different patients was used to determine the optimum values of the parameters $\mathrm{T} 1$ and $\mathrm{V}$, and to determine the inter observer-agreement of the three independent observers. The agreement was calculated using the proportion of specific agreement:

$$
p_{s}=\frac{3 a}{3 a+b+2 c},
$$

where $a$ is the proportion of events all three observers agreed to classify as MES, $c$ is the proportion of events two of the observers classified as embolus, and $b$ is the proportion of events only one of the observers classified as embolus. The sensitivity and positive predictive value (PPV) are monitored while varying parameters T1 and V. For T1 values of 15, 12 and $10 \mathrm{~dB}$ were taken, and for $V$ values of 10,8 and $6 \mathrm{~dB}$. The sensitivity was calculated by:

$$
S=\frac{\# \mathrm{TP}}{N_{\text {tot }}}
$$

where Ntot is the total number of events at least 2 observers classified as MES. The PPV was calculated by:

$$
\mathrm{PPV}=\frac{\# \mathrm{TP}}{\# \mathrm{TP}+\# \mathrm{FP}} \text {. }
$$

After the optimum values for parameters $T 1$ and $V$ are found, the algorithm is applied to the test set of 21 recordings taken from 4 different patients.

\section{Results}

\section{Sensitivity and PPV}

In the training set, the proportion of specific agreement between the three observers was 0.97 for a total of 207 events, while 201 events were classified as MES by at least two of the three observers. The sensitivity (figure 4) varied between 0.80 for $\mathrm{T} 1=15 \mathrm{~dB}$ and $\mathrm{V}=10 \mathrm{~dB}$ and 0.92 for $\mathrm{T} 1=10 \mathrm{~dB}$ and $\mathrm{V}=6 \mathrm{~dB}$. The PPV ranged from 0.63 for $T 1=10 \mathrm{~dB}$ and $\mathrm{V}=6 \mathrm{~dB}$ to 0.94 for $\mathrm{T} 1=15 \mathrm{~dB}$ and $\mathrm{V}=10 \mathrm{~dB}$. Lowering $\mathrm{T} 1$ and $V$ generally improves the sensitivity of the algorithm while sacrificing specificity. 


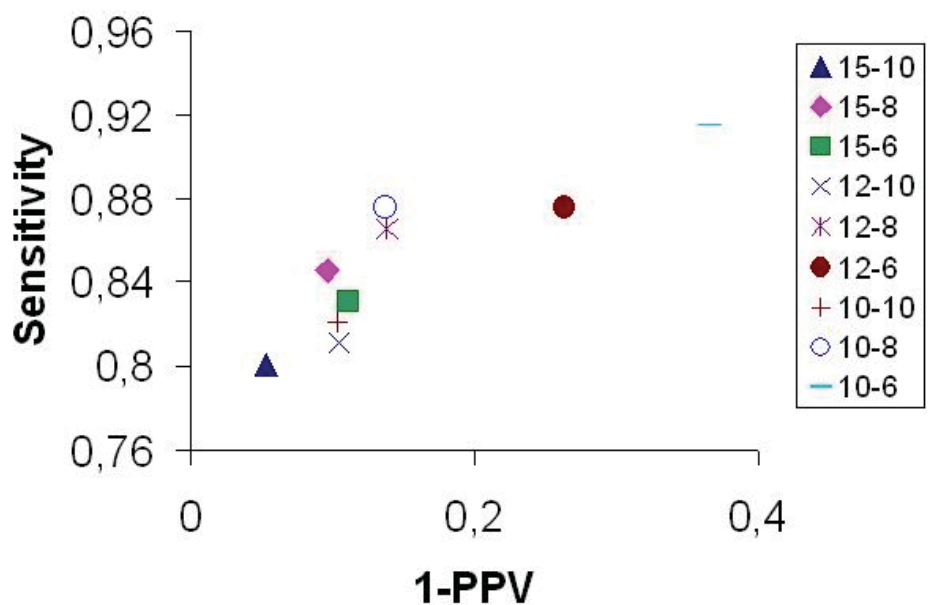

Figure 4: Receiver operating curve (ROC) showing results of the counting algorithm on a training set of 20 recordings. Positive Predictive Value (PPV) is used instead of specificity.

The optimum in the receiver operating characteristic (ROC) is the upper left point in the curve, which in this case (figure 4) corresponds to $T 1=10 \mathrm{~dB}$ and $\mathrm{V}=8 \mathrm{~dB}$, with a sensitivity and PPV of 0.88 and 0.86 , respectively. Using these parameters, the algorithm is applied to the test set of 21 recordings with a total of 388 MES by visual inspection. The number of MES per recording varied from 3 up to 71. A total of 277 events were correctly classified as MES by the algorithm, which yields a sensitivity of 0.71. Only 12 events were falsely classified as MES, which gives a PPV of 0.96 .

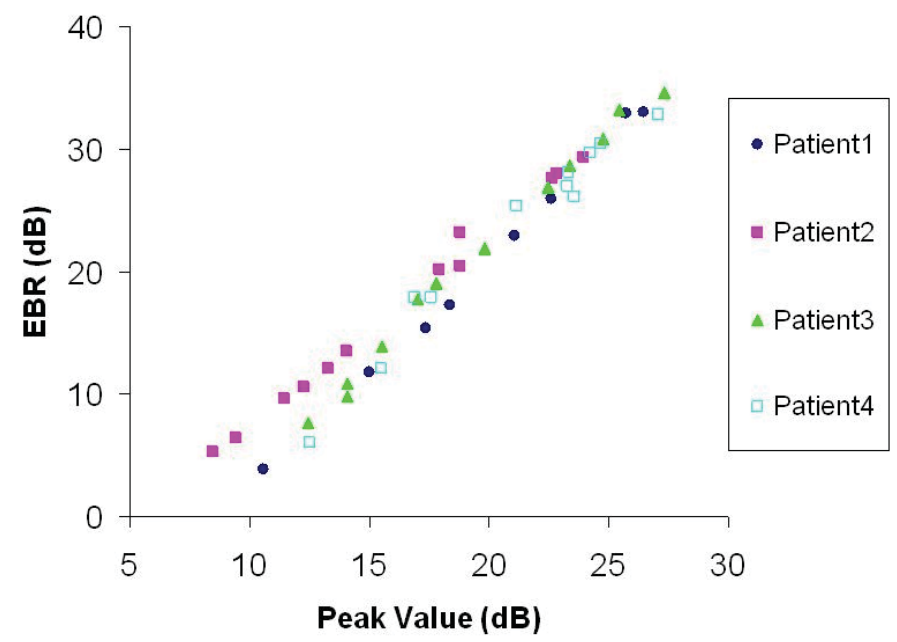

Figure 5: Mapping of calculated Embolus to Blood Ratio (EBR) versus RF peak amplitudes for 45 randomly chosen MES in 4 different patients. The EBR is calculated from the RF amplitude matrices. 


\section{EBR calculations}

For 45 randomly chosen MES in four patients the calculated EBR value is plotted against the peak value in the RF amplitude plot (figure 5), exhibiting a linear relationship for all patients. The parameter of interest is the EBR value at a peak MES amplitude of $10 \mathrm{~dB}$ (the detection threshold of the algorithm). From linear fits through the data points, the corresponding EBR value varies from approximately 2 $\mathrm{dB}$ for patient 1 to approximately $7 \mathrm{~dB}$ for patient 2 .

\section{Discussion}

The results demonstrate that the applied algorithm is able to estimate the number of emboli in embolic showers with a sensitivity of 0.71 and a PPV of 0.96 . This is a significant improvement compared to existing methods, which are not capable of providing an appropriate indication of the number of cerebral microemboli occurring during embolic showers. Due to the fact that embolic showers are mainly composed of gaseous microemboli an accurate estimation of the number of microemboli is sufficient to establish clinical relevance.

\section{Comparison to Doppler velocity spectra}

The conventional approach for MES detection based on evaluation of Doppler velocity spectra allows reliable discrimination of MES.

However, if two MES occur at approximately the same time at different depths the RF method is able to distinguish these signals. In figure 6 , the section between 1.5 and $1.6 \mathrm{~s}$ shows two MES, where the right part of the first MES occurs at the same time as the left part of the second but at a different depth. In the spectral Doppler plot (figure 6a) they appear as a continuous streak of increased intensity, while in the RF plot (figure 6b) both MES are clearly separated.

To estimate the incidence of overlapping emboli, the percentage of overlap time relative to the total time emboli are present is calculated as demonstrated in figure $6 \mathrm{~b}$. The test set consisted of 21 recordings of $2.5 \mathrm{~s}$, yielding a total time of $52.5 \mathrm{~s}$. Emboli were present during approximately $6 \mathrm{~s}$. The total time that 2 or more emboli were present within the predetermined depth range was $1.04 \mathrm{~s}$ which is $17 \%$ of the total time emboli were present. In total 151 of the 388 emboli are overlapping, of which 33 are even for our method too closely spaced to resolve. 


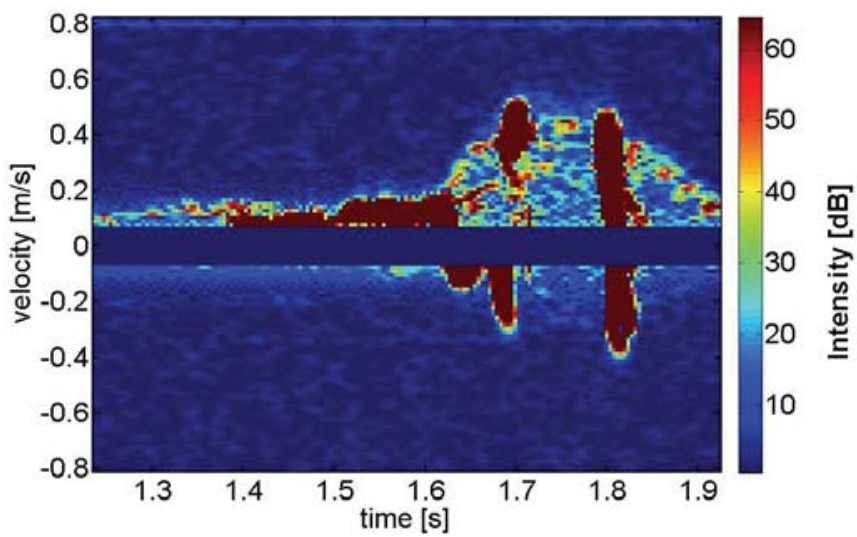

(A)

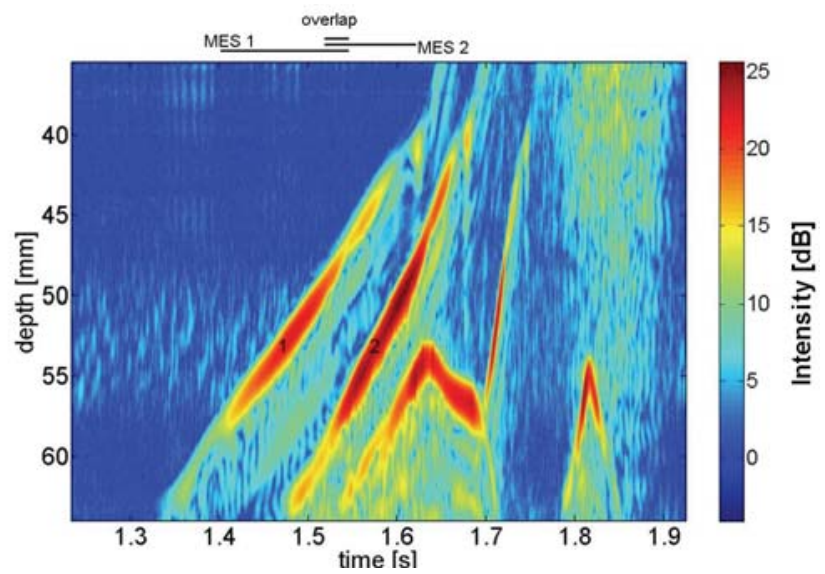

(B)

Figure 6: Doppler spectrum (A) and RF amplitude plot (B) of the same period in time. The Doppler spectrum was calculated based on the RF signal recorded from the 54 to $58 \mathrm{~mm}$ depth range. The time emboli are present and the time their signals are overlapping are indicated by black bars above the illustration.

When all the overlapping emboli would be detected as a single embolus, the sensitivity and PPV would degrade from 0.7 and 0.96 to 0.4 and 0.9 , respectively. This demonstrates the significant increase in sensitivity the proposed method yields in embolic showers.

Currently used algorithms, such as proposed by Cullinane et al. ${ }^{4}$, have a "refractory period" of >100 ms to allow amplitude comparison with the background level prior to the event. Our algorithm requires the average background value which can provided by a separate recording, because the background intensity variation is minimal during the short period after cross-clamp release in which embolic showers occur. This is corroborated by figure 5, showing an apparent linear correlation between EBR and embolic peak value. Due to the use of short ultrasound bursts and 
two-dimensional RF amplitude plots which retains depth and time information, the temporal resolution of the proposed algorithm is approximately $20 \mathrm{~ms}$. This is illustrated in figure 7 with 4 resolvable MES with an interspacing of less than $20 \mathrm{~ms}$ (7a) and possibly 2 MES that are too closely spaced to resolve (7b).

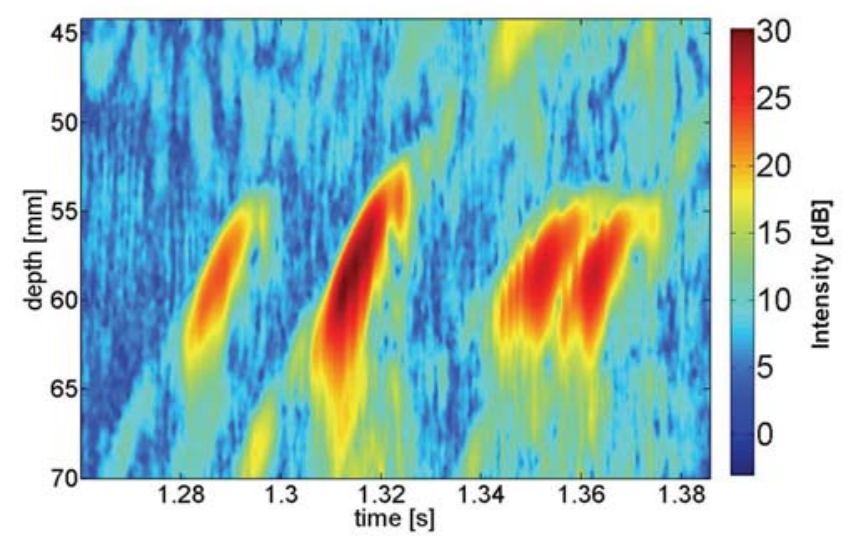

(A)

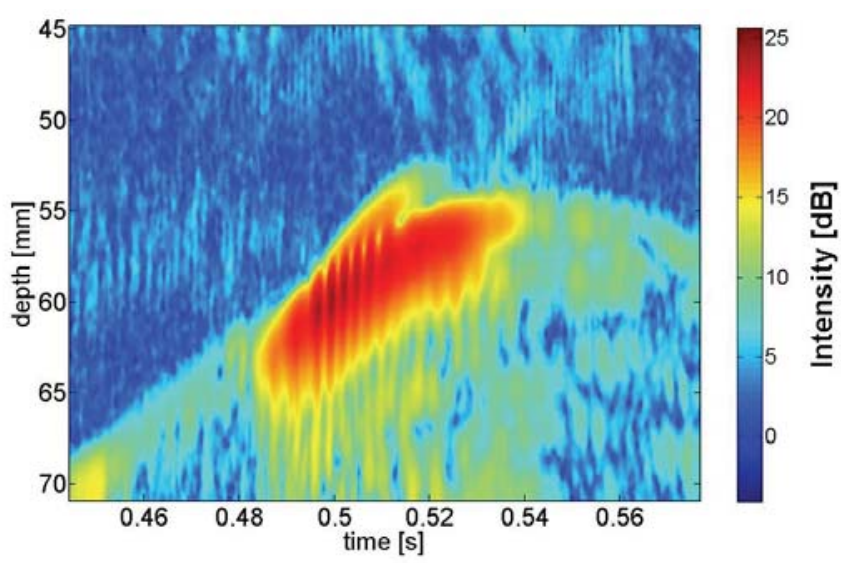

(B)

Figure 7: Four MES, all resolved by the algorithm $(A)$ and two MES too closely spaced in time for the algorithm to resolve them (B).

\section{RF Peak amplitude versus EBR}

Markus et al. ${ }^{10}$ showed that the inter-observer agreement on MES detection drops drastically for EBRs below $10 \mathrm{~dB}$. However, the detection threshold varies significantly with the phase of the cardiac cycle at which the embolus occurs ${ }^{11}$; during diastole even a detection threshold of $2 \mathrm{~dB}$ is feasible. However, the blood flow is still pump assisted when most showers occur, which makes a discussion about the cardiac phase irrelevant. 
In the present study, for a detection threshold of $10 \mathrm{~dB}$ peak value, the corresponding EBR value varies between 2 and $7 \mathrm{~dB}$, which indicates that with a threshold of $10 \mathrm{~dB}$ peak value, most emboli will be detected, especially considering that the majority of emboli occurring after cardiac surgery is gaseous and thus has a relatively high intensity. Only a very small percentage of all the emboli in our data sets had a peak intensity of less than $10 \mathrm{~dB}$, as shown in figure 8 .

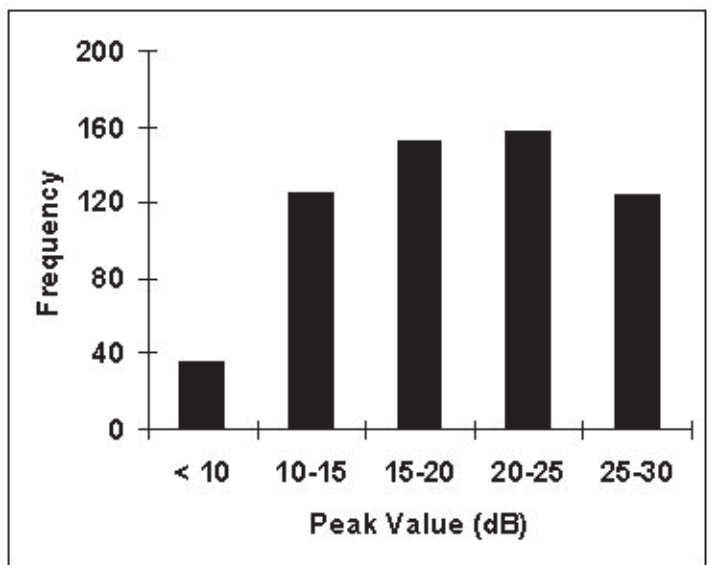

Figure 8: Histogram showing the distribution of peak amplitudes of the MES in our datasets.

It should be noted here that there is no unique definition of the EBR while the method of its calculation can have a significant influence, complicating direct comparison to literature values.

\section{Possible Improvements}

The errors made by the algorithm have been classified as False Positive (FP) or False Negative (FN). An increase in the number of FPs will yield a lower PPV, while an increase in the number of FNs will give a lower sensitivity. A source of false negatives is emboli with a temporal interspacing shorter than the temporal resolution of the algorithm. The theoretically achievable resolution for a pulse length of $2 \mu \mathrm{s}$ is a spacing of $5 \mathrm{~ms}$ between the local maxima of two MES with a typical velocity of $30 \mathrm{~cm} / \mathrm{s}$. In practice some broadening of the intensity distribution occurs (as shown in figure 9), and consequently the temporal resolution of the algorithm is around $20 \mathrm{~ms}$. This corresponds to a spatial resolution of $6 \mathrm{~mm}$. Emboli separated by such a small distance are prone to merge, and therefore such small interspacing rarely occur. As a consequence further improvement of the resolution has no priority.

To size gaseous emboli in cardiopulmonary bypass (CPB) systems, Lynch et al. ${ }^{12}$ use a novel technique based on broadband $4 \mathrm{MHz}$ pulses, providing an even better 
resolution. However, for TCD the maximum frequency is limited because of attenuation by the skull. Furthermore the bandwidth of most transducers is limited, restricting the effective pulse length.

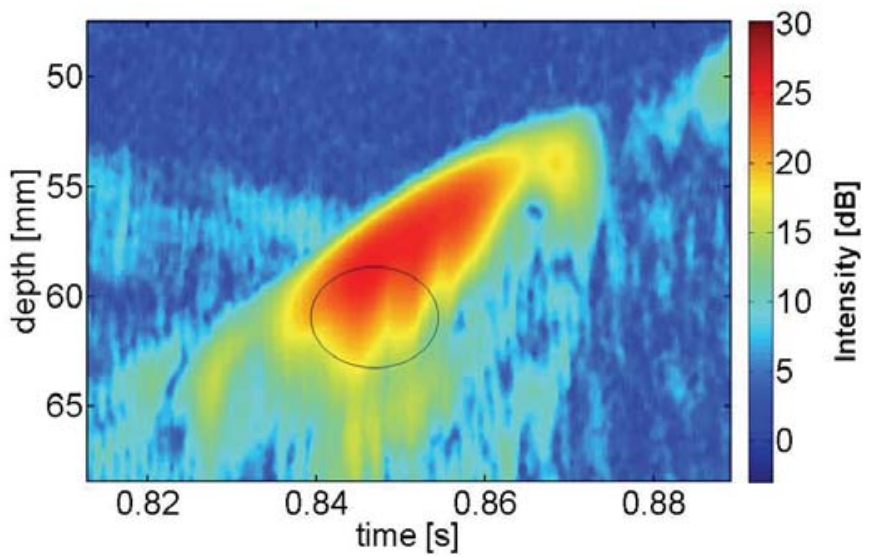

Figure 9: MES showing a broadened, irregularly shaped amplitude distribution (lower right part).

In one patient a significant number of MES had relative peak amplitudes of less than $10 \mathrm{~dB}$, which made them non-detectable and led to FNs. However, as discussed in a previous section, in most patients the $10 \mathrm{~dB}$ threshold is sufficient to detect almost all MES. To eliminate the effect of background intensity changes, which can possibly cause lower relative peak amplitudes, the reference recording can also be made just before cross-clamp release. One has to ensure in this case that no emboli are present in the interval of the recording. Possibly the detection threshold can also be adapted to the patient, using post-priori knowledge about the signal strength. Decreasing the threshold towards the speckle intensity, however, means sacrificing specificity and calculation speed.

Another source of FNs is a MES with an arced pathway. If the local maximum occurs in the downward part of the MES, it is often not classified as MES. These MES, however, rarely occurred in our data sets.

The two most important sources of false positives are artefacts and double counting of a single MES. Double counting can be prevented using a more sophisticated method of placing a contour around an event. Considering that the MES-shapes may vary between patients, the variations should be identified to implement an accurate contour method. Artefact rejection can be improved by using a velocity plot, where the velocity for each pixel is calculated using the complex cross-correlation velocity estimator described by Brands and Hoeks ${ }^{8}$. An example of the advantage of the RF velocity plot is shown in figure 10. In the RF amplitude plot (figure 10b) an obvious artefact is visible, which possibly can be misclassified as a MES. In the velocity plot (figure 10a) the pixels forming the 
artefact do not exhibit a well defined velocity, whereas MES consistently have a velocity higher than 0 . Unfortunately plots, obtained using the cross-correlation process, have a lower resolution than the amplitude plots. As a consequence we did not yet succeed to implement this method in the algorithm. Ideally, with future modifications, a detection algorithm can be created employing information about both the amplitude and velocity distribution.

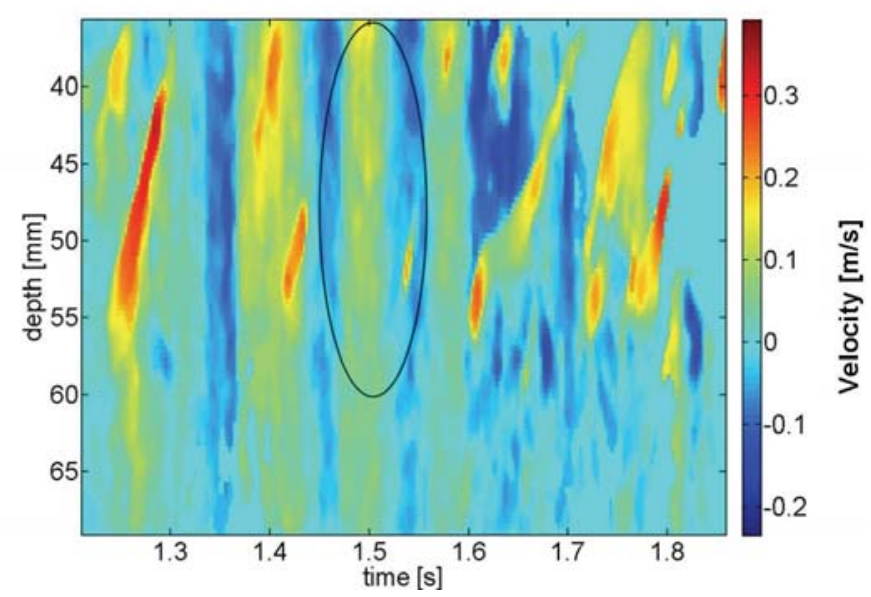

(A)

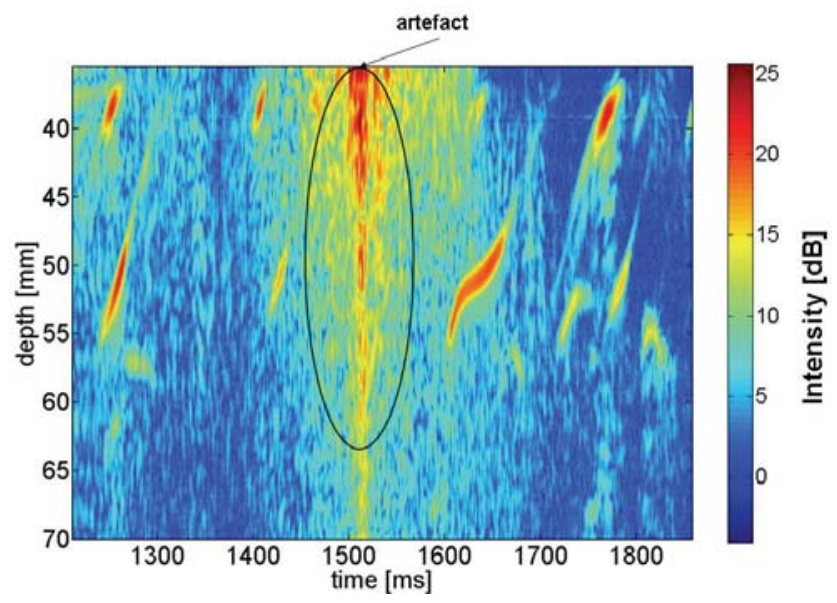

(B)

Figure 10: RF velocity plot calculated by a cross correlation model (A) and RF amplitude plot (B) showing an artefact at $1500 \mathrm{~ms}$. 


\section{Conclusion}

$\mathrm{RF}$ amplitude plots based on sample volumes with a short effective length of 1.1 $\mathrm{mm}$ visualise MES in embolic showers more evident than velocity spectra and Doppler audio signals of conventional TCD systems. The algorithm based on short pulsed RF amplitude plots provides quantitative information about large emboli densities ("showers") during cardiac surgery, because of its excellent temporal resolution. The results show that the algorithm is able to estimate the number of emboli in embolic showers with a sensitivity of 0.71 and a PPV of 0.96 . This is a significant improvement compared to existing methods, which tend to fail for embolic showers with emboli overlapping in time. Due to the fact that embolic showers mainly contain gaseous microemboli, a reliable estimate of the number of microemboli is sufficient to establish clinical relevance. Automated detection using $\mathrm{RF}$-amplitude plots seems to be a viable alternative to the golden standard of hours of manual counting. 


\section{References}

1. Muth CM, Shank ES. Gas embolism. N Engl J Med. 2000;342(7):476-482.

2. Neville MJ, Butterworth J, James RL, Hammon JW, Stump DA. Similar neurobehavioral outcome after valve or coronary artery operations despite differing carotid embolic counts. J Thorac Cardiovasc Surg. 2001;121(1):125-136.

3. Pugsley W, Klinger L, Paschalis C, Treasure T, Harrison M, Newman S. The impact of microemboli during cardiopulmonary bypass on neuropsychological functioning. Stroke. 1994;25(7):1393-1399.

4. Cullinane M, Reid G, Dittrich R, Kaposzta Z, Ackerstaff R, Babikian V, Droste DW, Grossett D, Siebler $M$, Valton L, Markus HS. Evaluation of new online automated embolic signal detection algorithm, including comparison with panel of international experts. Stroke. 2000;31(6):1335-1341.

5. Mess WH, Willigers JM, Ledoux LA, Ackerstaff RG, Hoeks AP. Microembolic signal description: a reappraisal based on a customized digital postprocessing system. Ultrasound Med Biol. 2002;28(1112):1447-1455.

6. Cowe J, Gittins J, Naylor AR, Evans DH. RF signals provide additional information on embolic events recorded during TCD monitoring. Ultrasound Med Biol. 2005;31(5):613-623.

7. Cowe J, Evans DH. Automatic detection of emboli in the TCD RF signal using principal component analysis. Ultrasound Med Biol. 2006;32(12):1853-1867.

8. Brands PJ, Hoeks AP, Ledoux LA, Reneman RS. A radio frequency domain complex cross-correlation model to estimate blood flow velocity and tissue motion by means of ultrasound. Ultrasound Med Biol. 1997;23(6):911-920.

9. Burckhardt CB. Speckle in ultrasound b-mode scans. IEEE Trans. Son. Ultrason. 1978;25(1):1-6.

10. Markus HS, Ackerstaff R, Babikian V, Bladin C, Droste D, Grosset D, Levi C, Russell D, Siebler M, Tegeler C. Intercenter agreement in reading Doppler embolic signals. A multicenter international study. Stroke. 1997;28(7):1307-1310.

11. Chung E, Fan L, Degg C, Evans DH. Detection of Doppler embolic signals: psychoacoustic considerations. Ultrasound Med Biol. 2005;31(9):1177-1184

12. Lynch JE, Pouch A, Sanders R, Hinders M, Rudd K, Sevick J. Gaseous microemboli sizing in extracorporeal circuits using ultrasound backscatter. Ultrasound Med Biol. 2007;33(10):1661-1675. 
CHAPTER 8

\author{
Discussion
}


Cerebral injury is one of the most feared complications after cardiac procedures. Embolisation is an important factor in this respect. Most emboli generated during cardiac procedures are relatively small and are therefore called microemboli. Nevertheless they can lead to neurological damage. Consequently measuring the number of microemboli entering the cerebral vasculature can be used as a surrogate marker for neurological impairment. In order to minimise the risk of neurological complications during cardiac procedures, not only the total amount of microemboli generated during the whole procedure is relevant. If the number of cerebral microemboli has to be reduced it is important to identify the specific moments of embolisation, in order to be able to adapt the actions taken, if possible. With Transcranial Doppler (TCD) it is possible to identify cerebral microemboli perioperatively.

This chapter will discuss the possible role of TCD monitoring during cardiac procedures in minimising the risk of neurological complications. Special attention will be paid at the question how accurate the cerebral embolic burden can be quantified. Finally, future perspectives in TCD monitoring during cardiac procedures will be discussed.

\section{TCD in cardiac procedures}

Measuring cerebral microemboli during cardiac procedures allows for estimating the risk of neurological complications due to embolisation that might stem from known and unknown sources. This has been outlined in Chapter 1 to 3 of this thesis. Rapidly evolving new cardiac equipment should not only be evaluated in terms of efficiency, but the risk of complications should also be considered. Cerebral emboli can serve as a surrogate marker for cerebral injury, avoiding large scale studies with clinical endpoints.

Furthermore, new types of cardiac procedures (for example percuteanous valve replacement) can readily be examined in terms of the generation of microemboli encompassing unrecognised embolic sources. Consequently, a thorough understanding of the procedural interventions generating emboli can be obtained, which in turn provides the opportunity to optimise the procedure in terms of emboligenicity.

Intraoperative TCD monitoring provides real time information regarding the occurrence of cerebral microembolic signals (MES), allowing for immediate feedback action in order to reduce the number of cerebral microemboli. The studies of Marrouche, Kilikisclan and Murkin ${ }^{1-3}$ illustrate this interaction during pulmonary vein isolation (PVI). In case cerebral MES occurred, the energy delivery was halted immediately, which in turn led to a reduced embolic load. Another example is demonstrated by Lunch et al ${ }^{4}$ in the context of coronary artery bypass grafting $(C A B G)$. The appearance of cerebral MES indicated an incorrect position of the 
venous cannula. Readjustment resulted in instant cessation of cerebral microemboli.

So, a TCD guided reduction of cerebral microemboli is feasible. However, in most cardiac procedures a complete elimination of cerebral microemboli is impossible. A method preventing emboli from entering into the cerebral vessels might reduce the cerebral embolic load.

Ultrasonic energy is able to reduce the number of cerebral MES during cardiac surgery by diverting emboli emerging in the ascending aorta towards the descending aorta. This has been demonstrated in chapter 4 and 5 of this thesis, which also showed that this method could be applied safely. Yet, important questions remain to be answered. Although the brain appears to be the most sensitive organ for embolic load other organs have not been proven harmless. Furthermore, the efficacy of this ultrasonic technology in terms of clinical endpoints still has to be shown. Since severe neurological complications occur in approximately 3-5\% of cardiac interventions, a considerably larger patient group has to be studied than was done in chapter 5 . Setting up a study with clinical endpoints, one has also to take into account that a stroke might not be related to embolism and that patients show a very large variation of the number of MES during the procedure. These two factors add to the need for large patient groups to be studied. An alternative, yet second choice, might be a study where pre and postoperative cerebral imaging is applied, allowing for detecting also clinically silent cerebral lesions that occurred perioperatively ${ }^{5-7}$.

\section{Pharmacological treatment for cerebral embolisation}

So far, methods are described that aim at decreasing the amount of cerebral microemboli during cardiac interventions. These range from identifying and adjustments of specific moments that are mainly responsible for the generation of emboli, to selecting the therapy approach with the least embolic burden and finally placing an embolic barrier by means of ultrasonic energy.

Yet, it is likely that not all emboli will be eliminated by the above mentioned approaches. So, the question arises whether there are other means of preventing neurological complications caused by embolisation. First, the emergence of emboli and second, their effect on brain function might be modified.

The formation of particulate emboli can be inhibited by antiplatelet and anticoagulation drugs like asparin, warfarin and heparin ${ }^{8}$, but the optimal antiplatelet/anticoagulation strategy is still undefined ${ }^{9}$. Fluorocarbons are carbonfluorine compounds characterised by a high gas dissolving capacity and addition of these compounds in the cardiopulmonary bypass prime solution leads to a reduction in the incidence and severity of neurologic injury in animals ${ }^{10}$. An alternative might be hyper-oxygen therapy, in which the patient breathes $100 \%$ 
oxygen to decrease the size of the gas bubble both by raising the ambient pressure and minimizing the partial pressure of nitrogen which accelerates bubble absorption 11

Several treatment options have been discussed if cerebral embolism has occurred. Within a few hours of the onset of stroke, administration of thrombolytic drugs can improve clinical outcome ${ }^{12-14}$. New concepts of application of ultrasound with or without simultaneous administration of microbubbles to thrombolytic therapy offers promising results to improve recanalisation of intracerebral vessels in animals ${ }^{13}$.

To increase the tolerance to ischemia barbiturates can also be given postoperatively to reduce cerebral oxygen consumption, intracranial pressure, the production of free radicals and the release of catecholamines to suppress the consequences of gas bubbles ${ }^{15,16}$. There is also evidence that prophylactic administration of heparin, decreases neurological impairment in animals after cerebral air embolism ${ }^{17}$.

Although the clinical value of these treatment options in the context of cardiac interventions has to be proven, they offer new approaches to achieve a better neurological outcome. The effects of the approaches aiming at diminishing the amount of emboli could be monitored with MES detection ${ }^{18}$

\section{MES as surrogate marker}

The amount of MES during cardiac interventions is related to the risk of neurological complications, yet, this relationship is complex, and there is no simple linear correlation. If MES are expected to be a surrogate marker for brain damage, several aspects have to be taken into account.

First, the incidence of asymptomatic lesions after cardiac interventions as measured with MRI is higher than clinically evident neurological complications. Hence, intraoperatively occurring cerebral MES can cause ischemic lesions that are not always clinically relevant. So, it is conceivable that the amount of cerebral MES shows a better correlation with postoperative MRI as compared to preoperative MRI rather than with clinically manifest neurological impairment.

Second, the estimation of the embolic load is not optimal. Even though counting the number of cerebral MES making use of the existing methodology can be considered as a potential risk marker for neurological impairment, it is likely that a more accurate estimation of the amount but also the composition of cerebral emboli will allow for a better correlation with cerebral damage.

Counting cerebral MES during cardiac interventions is hampered by at least factors. No commercially available automatic detection system is capable of counting MES accurately if the intensity of the MES varies widely, which is the case in these circumstances. Instead, the gold standard of counting cerebral MES is 
defined by human evaluation. Two trained observers use the audio and video signal to manually count the MES. When a consensus between the two observers is achieved an intensity increase within the Doppler signal is considered to be consistent with embolus. For a single embolus this counting method has been proven reliable ${ }^{19}$. Yet, it is obvious that a reliable counting of the number of MES during the interventional procedure is hardly feasible and quite time-consuming.

Additionally, in cardiac interventions embolic showers often do occur, i.e. emboli do not appear isolated but follow each other rapidly, so that they even might occur at the same time in the sample volume. With the conventional evaluation method as described above, it is not possible to discriminate between the individual MES anymore, which will inevitably lead to an inaccurate MES count.

So, a reliable automatic estimation of the number of MES is desirable in order to improve the correlation with neurological outcome. Chapter 6 provides a new method to quantify the number of cerebral MES even if they occur simultaneously, i.e. in embolic showers. The algorithm proposed could serve as a basis for an automatic detection algorithm.

To get an accurate estimation of the embolic burden to the brain the constitution of the microemboli plays an essential role as well. Particulate microemboli are prone to exert more damage than gaseous microemboli. This has been confirmed by several studies. Sylivris et $a^{20}$ found that the number of cerebral MES as detected during aortic manipulation showed a significant correlation with postoperative cerebral ischemic lesions by means of MRI. These MES are most likely to be of particulate nature. On the contrary, the total number of MES, which consists of not only of particulate but also of a large group of gaseous emboli, was not correlated with cerebral ischemic lesions. Omar et al ${ }^{21}$ examined catheterisation in patients with and without passage through the aortic valve in patients with valvular aortic stenosis. Crossing the aortic stenosed valve is associated with a potential risk of dislodgement of calcific valve particles and caused in $22 \%$ focal diffusion-imaging abnormalities versus none percent abnormalities in the patients without passage of the aortic valve. Clark et al found that the patients who underwent CABG and had postoperative complications had a higher percentage of emboli occurring while either the heart or the aortic arch where surgically manipulated ${ }^{22}$. Kotoh and Guerrieri Wolf ${ }^{23,24}$ demonstrated that partial side-clamping, i.e. manipulation of the aortic arch during off pump CABG, is an independent risk factor for cerebral infarction.

Abovementioned studies support the hypothesis that particulate emboli result in more cerebral damage as compared to gaseous emboli. Nevertheless, also gaseous emboli may be clinically relevant. The underlying pathophysiological mechanisms were described by Muth et el and Barak et al ${ }^{15,16}$. The vessel wall shows an inflammatory response due to stress and strain caused by contact of a 
gaseous bubble. Complement activation commences at the air-liquid interface. Micro bubbles induce clotting through both activating coagulation and inducing platelet aggregation. The bubble acts as a foreign substance and activates the coagulation cascade. Cerebral gas embolism initially induces the rapid development of cytoxic brain oedema, diminishing extracellular space and enlarging intracellular areas. Pugsley et al ${ }^{25}$ demonstrated that reducing the number of cerebral MES during CABG using an arterial line filter, contributes to a reduction in neurological deficit from $27 \%$ to $9 \%$. Emboli eliminated by an arterial filter are most likely gaseous, suggesting that gaseous emboli are able to cause neurological deficit. Large amounts of gaseous emboli may even be fatal ${ }^{15}$. However, as suggested by Stroobant et al, more studies are needed to correlate gaseous MES with neurological impairment as for example cognitive decline ${ }^{26}$.

The capability to discriminate between gaseous and particulate emboli would enable a more accurate estimation of the cerebral embolic burden during cardiac interventions and might result in a better correlation with neurological complications postprocedurally. The discrimination between particulate and gaseous emboli could contribute the debate on "on pump versus off-pump surgery". There is a controversy whether either of the approaches is favourable in terms of neurological outcome ${ }^{26-30}$. In spite of a lower number of MES during off pump CABG, a correlation with the number of MES and neurological outcome could not be established.

In this debate however, no accurate estimation of the embolic load was achieved, because the composition of the cerebral microemboli was unknown. Discrimination between particulate and gaseous emboli would allow for a more realistic comparison between different procedures or different equipment in terms of emoboligenic potential. Yet, a reliable discrimination between particulate and gaseous emboli is not feasible ${ }^{31,32}$.

\section{Future perspective}

The use of recently developed ultrasound techniques alike Power M-mode and the evaluation of RF signals might have the potential to accomplish a more realistic estimation of the embolic load also when the emboli appear in clusters. Automatic online counting of emboli based on the aforementioned techniques is likely to be only matter of time due to the ever-increasing capacity of personal computer systems. Although the relationship between cerebral emboli and neurological outcome has convincingly been shown, a large-scale introduction of TCD into daily practice is only likely to occur if in the future prospective clinical trials will bring up evidence that alterations of the surgical or endovascular procedures based on the results of the emboli detection will improve the neurological outcome of the patient. A reliably working automatic emboli detection system would be a 
prerequisite for conducting such studies. The results presented in this thesis add to our knowledge on the cerebral emboli during a variety of procedures, which is necessary to develop such an automatic system. One possibility to do so making use of the RF signal has been proposed. 


\section{References}

1. Kilicaslan F, Verma A, Saad E, Rossillo A, Davis DA, Prasad SK, Wazni O, Marrouche NF, Raber LN, Cummings JE, Beheiry S, Hao S, Burkhardt JD, Saliba W, Schweikert RA, Martin DO, Natale A. Transcranial Doppler detection of microembolic signals during pulmonary vein antrum isolation: implications for titration of radiofrequency energy. J Cardiovasc Electrophysiol. 2006;17(5):495-501.

2. Marrouche NF, Martin DO, Wazni O, Gillinov AM, Klein A, Bhargava M, Saad E, Bash D, Yamada H, Jaber W, Schweikert R, Tchou P, Abdul-Karim A, Saliba W, Natale A. Phased-array intracardiac echocardiography monitoring during pulmonary vein isolation in patients with atrial fibrillation: impact on outcome and complications. Circulation. 2003;107(21):2710-2716.

3. Murkin JM. Applied neuromonitoring and improving CNS outcomes. Semin Cardiothorac VasC Anesth. 2005;9(2):139-142.

4. Lynch JE, Riley JB. Microemboli detection on extracorporeal bypass circuits. Perfusion. 2008;23(1):23-32.

5. Lickfett L, Hackenbroch M, Lewalter T, Selbach S, Schwab JO, Yang A, Balta O, Schrickel J, Bitzen A Luderitz B, Sommer T. Cerebral diffusion-weighted magnetic resonance imaging: a tool to monitor the thrombogenicity of left atrial catheter ablation. J Cardiovasc Electrophysiol. 2006;17(1):1-7.

6. Moody DM, Brown WR, Challa VR, Stump DA, Reboussin DM, Legault C. Brain microemboli associated with cardiopulmonary bypass: a histologic and magnetic resonance imaging study. Ann Thorac Surg. 1995;59(5):1304-1307.

7. Restrepo L, Wityk RJ, Grega MA, Borowicz L, Jr., Barker PB, Jacobs MA, Beauchamp NJ, Hillis AE, McKhann GM. Diffusion- and perfusion-weighted magnetic resonance imaging of the brain before and after coronary artery bypass grafting surgery. Stroke. 2002;33(12):2909-2915.

8. Leys D, Balucani C, Cordonnier C. Antiplatelet drugs for ischemic stroke prevention. Cerebrovasc Dis. 2009;27 Suppl 1:120-125.

9. Halbfass P, Janko S, Dorwarth U, Riess G, Antoni D, Hoffmann E. Dilemma of antithrombotic therapy in anticoagulated atrial fibrillation patients squeezed between thrombosis and bleeding events: a single-centre experience. Europace. 2009.

10. Cochran RP, Kunzelman KS, Vocelka CR, Akimoto H, Thomas R, Soltow LO, Spiess BD. Perfluorocarbon emulsion in the cardiopulmonary bypass prime reduces neurologic injury. Ann Thorac Surg. 1997;63(5):1326-1332.

11. Ziser A, Adir Y, Lavon H, Shupak A. Hyperbaric oxygen therapy for massive arterial air embolism during cardiac operations. J Thorac Cardiovasc Surg. 1999;117(4):818-821.

12. Tissue plasminogen activator for acute ischemic stroke. The National Institute of Neurological Disorders and Stroke rt-PA Stroke Study Group. N Engl J Med. 1995;333(24):1581-1587.

13. Meairs S, Culp W. Microbubbles for thrombolysis of acute ischemic stroke. Cerebrovasc Dis. 2009;27 Suppl 2:55-65.

14. Hacke W, Kaste M, Bluhmki E, Brozman M, Davalos A, Guidetti D, Larrue V, Lees KR, Medeghri Z, Machnig T, Schneider D, von Kummer R, Wahlgren N, Toni D. Thrombolysis with alteplase 3 to 4.5 hours after acute ischemic stroke. N Engl J Med. 2008;359(13):1317-1329.

15. Barak M, Katz Y. Microbubbles: pathophysiology and clinical implications. Chest. 2005;128(4):29182932.

16. Muth CM, Shank ES. Gas embolism. N Engl J Med. 2000;342(7):476-482.

17. Ryu KH, Hindman BJ, Reasoner DK, Dexter F. Heparin reduces neurological impairment after cerebral arterial air embolism in the rabbit. Stroke. 1996;27(2):303-309; discussion 310 
18. Dittrich R, Ritter MA, Kaps M, Siebler M, Lees K, Larrue V, Nabavi DG, Ringelstein EB, Markus HS, Droste DW. The use of embolic signal detection in multicenter trials to evaluate antiplatelet efficacy: signal analysis and quality control mechanisms in the CARESS (Clopidogrel and Aspirin for Reduction of Emboli in Symptomatic carotid Stenosis) trial. Stroke. 2006;37(4):1065-1069.

19. Markus HS, Ackerstaff R, Babikian V, Bladin C, Droste D, Grosset D, Levi C, Russell D, Siebler M, Tegeler $C$. Intercenter agreement in reading Doppler embolic signals. A multicenter international study. Stroke. 1997;28(7):1307-1310.

20. Sylivris S, Levi C, Matalanis G, Rosalion A, Buxton BF, Mitchell A, Fitt G, Harberts DB, Saling MM, Tonkin AM. Pattern and significance of cerebral microemboli during coronary artery bypass grafting. Ann Thorac Surg. 1998;66(5):1674-1678.

21. Omran $H$, Schmidt $H$, Hackenbroch $M$, Illien S, Bernhardt $P$, von der Recke G, Fimmers R, Flacke $S$, Layer G, Pohl C, Luderitz B, Schild H, Sommer T. Silent and apparent cerebral embolism after retrograde catheterisation of the aortic valve in valvular stenosis: a prospective, randomised study. Lancet. 2003;361(9365):1241-1246.

22. Clark RE, Brillman J, Davis DA, Lovell MR, Price TR, Magovern GJ. Microemboli during coronary artery bypass grafting. Genesis and effect on outcome. J Thorac Cardiovasc Surg. 1995;109(2):249-257; discussion 257-248.

23. Kotoh K, Fukahara K, Doi T, Nagura S, Misaki T. Predictors of early postoperative cerebral infarction after isolated off-pump coronary artery bypass grafting. Ann Thorac Surg. 2007;83(5):1679-1683.

24. Guerrieri Wolf L, Abu-Omar Y, Choudhary BP, Pigott D, Taggart DP. Gaseous and solid cerebral microembolization during proximal aortic anastomoses in off-pump coronary surgery: the effect of an aortic side-biting clamp and two clampless devices. J Thorac Cardiovasc Surg. 2007;133(2):485493.

25. Pugsley W, Klinger L, Paschalis C, Treasure T, Harrison M, Newman S. The impact of microemboli during cardiopulmonary bypass on neuropsychological functioning. Stroke. 1994;25(7):1393-1399.

26. Stroobant N, Van Nooten G, Van Belleghem Y, Vingerhoets G. Relation between neurocognitive impairment, embolic load, and cerebrovascular reactivity following on- and off-pump coronary artery bypass grafting. Chest. 2005;127(6):1967-1976.

27. Abu-Omar Y, Cader S, Guerrieri Wolf L, Pigott D, Matthews PM, Taggart DP. Short-term changes in cerebral activity in on-pump and off-pump cardiac surgery defined by functional magnetic resonance imaging and their relationship to microembolization. J Thorac Cardiovasc Surg. 2006;132(5):11191125.

28. Diegeler A, Hirsch R, Schneider F, Schilling LO, Falk V, Rauch T, Mohr FW. Neuromonitoring and neurocognitive outcome in off-pump versus conventional coronary bypass operation. Ann Thorac Surg. 2000;69(4):1162-1166.

29. Lee JD, Lee SJ, Tsushima WT, Yamauchi H, Lau WT, Popper J, Stein A, Johnson D, Lee D, Petrovitch H, Dang CR. Benefits of off-pump bypass on neurologic and clinical morbidity: a prospective randomized trial. Ann Thorac Surg. 2003;76(1):18-25; discussion 25-16.

30. Lund C, Hol PK, Lundblad R, Fosse E, Sundet K, Tennoe B, Brucher R, Russell D. Comparison of cerebral embolization during off-pump and on-pump coronary artery bypass surgery. Ann Thorac Surg. 2003;76(3):765-770; discussion 770.

31. Evans DH. Embolus differentiation using multifrequency transcranial Doppler. Stroke. 2006;37(7):1641.

32. Markus HS, Punter M. Can transcranial Doppler discriminate between solid and gaseous microemboli? Assessment of a dual-frequency transducer system. Stroke. 2005;36(8):1731-1734. 



\section{Summary}

The number of periprocedural cerebral microemboli in cardiac interventions is associated with the risk of postprocedural neurological complications. Transcranial Doppler (TCD) is a non-invasive ultrasound monitoring method which visualizes the cerebral blood flow by means of a velocity spectrum. Presence of microemboli in the monitored cerebral vessels can be detected in the velocity spectrum as microembolic signals (MES) and an estimation of the total cerebral embolic load for a patient undergoing a cardiac procedure can be provided. Reducing the cerebral embolic load bears the potential to reduce the risk of neurological complications during cardiac interventions. Therefore, the amount of periprocedural cerebral MES ( $\approx$ embolic load) may serve as a surrogate risk marker of postoperative neurological complications.

The occurrence of microemboli during perfusionist interventions, e.g. drug administration, or blood withdrawal, has been shown to be an important source of cerebral microemboli. In chapter 2 a new method of withdrawing blood samples by the perfusionist is examined on MES occurrence during cardiopulmonary bypass (CPB). In the new blood sampling method, a shunt line is implemented. In contrast to injecting blood directly into the venous line, blood is injected through the shunt line into a reservoir, which, in turn, is connected to the venous line. No MES were detected in the systemic circulation when acquiring blood samples using the shunt line. The generation of microemboli in the CPB could be limited by using an extra shunt line for returning blood into the circulation.

Not only during cardiac surgery, also after other cardiac interventions may neurological complications occur due to cerebral microemboli. Pulmonary veins isolation (PVI) is a therapy for atrial fibrillation. In this procedure, tissue with abnormal electrical activity is destroyed, which terminates atrial fibrillation. In $0.5 \%$ to $10 \%$ of patients undergoing a PVI procedure, postoperative neurological complications are documented.

In chapter 3 the occurrence of cerebral MES during a catheter-based percutaneous endocardial PVI procedure and a recently developed minimal invasive video-assisted thoracoscopic epicardial PVI procedure on a beating heart, is examined. The number of cerebral MES signals detected during the epicardial PVI approach is neglectable as compared to the number of cerebral MES occurring during the endocardial PVI approach. The epicardial PVI method might reduce the risk of postoperative neurological complications as compared to the endocardial PVI approach, and could, therefore, could be an alternative to endocardial catheter PVI procedures. 
Although the percutaneaous endocardial approach produces a significant amount of cerebral MES, the cerebral embolic load may vary when different ablation catheters are used. In chapter 4, three different catheter-based PVI approaches are compared regarding the generation of cerebral microemboli: (1) ostial isolation using of a conventional RF ablation catheter, (2) ostial isolation using of an irrigated RF tip ablation catheter, and (3) circular isolation of the ostia using a cryocoagulation catheter. The cryocoagulation catheter and the RF irrigated catheter generated significant less cerebral MES when compared to the conventional RF ablation catheter. Thus, the risk of postprocedural neurological complications may be lower when using an irrigated RF catheter or cryocoagulation catheter as compared to the standard RF catheter for a PVI procedure.

Cerebral MES can be reduced during cardiac interventions by modifying the standard method (chapter 2), by choosing a different procedure approach (chapter 3 ) and by changing the equipment (chapter 4 ).

Elimination of all cerebral microemboli by changing equipment or protocol may be impossible, however. A new device, which has the potential to prevent microemboli in the blood circulation to end up in the cerebral vessels, has been examined preclinically in chapter 5. This ultrasonic device $\left(E \mathrm{mBlocker}{ }^{\mathrm{TM}}\right.$ ) is positioned on the distal part of the ascending aorta; by activating the device, microemboli are expected to be diverted into the aorta descendens instead of entering the cerebral vessels. The animal study demonstrated that the EmBlocker ${ }^{\mathrm{TM}}$ is able to reduce the number of both solid and gaseous MES in the cerebral vessels.

In chapter 6 this ultrasonic technology has been examined in patients undergoing cardiac surgery. The Emblocker ${ }^{\mathrm{TM}}$ was activated during selected manipulations that are prone for embolization. This reduced the amount of cerebral MES by approximately $50 \%$. Thus, the use of the EmBlocker ${ }^{\mathrm{TM}}$ in cardiac surgery reduces peri-operative cerebral MES and bears the potential to lower the risk for postoperative neurological complications.

The number of cerebral microemboli occurring cardiac interventions varies from patient to patient as has been demonstrated in the previous chapters. During various time points or upon manipulations during cardiac interventions, the number of generated microemboli can be very high (e.g., "embolic showers"). Current methods to count the number of emboli only provide a rough estimation during embolic showers. The time interval between consecutive emboli must be large enough for accurate detection. In embolic showers, emboli are clustered together, resulting in an underestimation of embolic load. In chapter $\mathbf{7}$ an algorithm with a high temporal resolution, based on the radiofrequency (RF) signal of a TCD system, has been designed to improving detection of emboli in embolic showers. The 
algorithm was validated on various recordings made during cardiac surgery and provided a RF-amplitude plot with quantitative information about large emboli densities. These amplitude plots visualise microemboli in embolic showers more clearly compared to velocity spectra and Doppler audio signals of conventional TCD systems. This is a significant improvement compared to existing counting methods. Therefore, automated detection using RF-amplitude plots may be an alternative to the current counting methods.

In chapter 8 the usefulness of MES detection in the evaluation of cardiac interventions and their risk of inducing neurological complications is discussed. 



\section{Samenvatting}

Het aantal cerebrale micro-embolieën tijdens een hartchirurgische procedure is geassocieerd met het risico op neurologische complicaties na de procedure. Transcraniale Doppler (TCD) is een niet-invasieve, op ultrageluid gebaseerde methode, die de bloedstroming door de hersenen kan visualiseren met behulp van een snelheidsspectrum. De aanwezigheid van micro-embolieën in de bestudeerde hersenvaten kan worden gedetecteerd in het snelheidsspectrum als microembolische signalen (MES) en daarmee kan een schatting van de totale "embolic load" in de hersenen worden gemaakt voor een patiënt die een hartchirurgische procedure ondergaat. Het verlagen van de embolic load in de hersenen zou het risico op neurologische complicaties na de hartchirurgische procedure kunnen verminderen. Hierdoor, kan de hoeveelheid cerebrale MES ( $\approx$ embolic load) dienen als een surrogaat marker voor neurologische complicaties.

Handelingen van de perfusionist bv het geven van medicijnen of het nemen van een bloed-monster, zijn een belangrijke oorzaak van het ontstaan van microembolieën. In hoofdstuk $\mathbf{2}$ is een nieuwe methode van het nemen van bloed monsters door perfusionisten tijdens hart-long machine (CPB) ondersteuning onderzocht op het ontstaan van de hoeveelheid MES. In deze nieuwe methode van het nemen van een bloed monster is een shunt-lijn geïmplementeerd. In plaats van het teruggeven van bloed direct in de veneuze lijn, wordt bloed via de shunt-lijn in een reservoir geïnjecteerd dat vervolgens bevestigd is met de veneuze lijn. Bij het gebruik van de shunt-lijn tijdens het nemen van bloedmonsters door de perfusionist is er geen enkele MES waargenomen in de systemische circulatie. Het ontstaan van micro-embolieën in de CPB kan worden gelimiteerd door gebruik te maken van een extra shunt-lijn voor teruggave van bloed in de bloedcirculatie.

Niet alleen bij hartchirurgische, ook na cardiologische ingrepen kunnen er neurologische complicaties ontstaan door cerebrale micro-embolieën. Long venen isolatie (PVI) is een therapie voor atrium fibrilleren. Tijdens deze procedure wordt weefsel met abnormale elektrische activatie vernietigd, waardoor het atrium fibrilleren wordt beëindigd. In $0.5 \%$ tot $10 \%$ van de patiënten die een PVI procedure ondergaan, worden er postoperatief neurologische complicaties gevonden.

In hoofdstuk $\mathbf{3}$ is de hoeveelheid cerebrale MES bestudeerd tijdens een cardiologische endocardiale PVI procedure en tijdens een recent ontwikkelde minimaal invasieve chirurgische thoracoscopische epicardiale PVI procedure met een kloppend hart. Het aantal cerebrale MES tijdens de epicardiale PVI methode is verwaarloosbaar in vergelijking met het aantal cerebrale MES tijdens de endocardiale PVI methode. Daarom zou de epicardiale PVI methode mogelijkerwijs 
een lager risico hebben op postoperatieve neurologische complicaties dan de endocardiale PVI methode en om die reden misschien een goed alternatief zijn voor de endocardiale PVI methode.

De cardiologische endocardiale PVI methode produceert weliswaar een significante hoeveelheid cerebrale MES, maar die hoeveelheid blijkt te variëren bij gebruik van verschillende katheters. In hoofdstuk 4 zijn drie cardiologische endocardiale PVI methoden met elkaar vergeleken met betrekking tot de ontwikkeling van cerebrale micro-embolieën: (1) ostium isolatie met gebruik van een conventionele radiofrequente (RF) ablatie katheter, (2) ostium isolatie met gebruik van een gekoelde tip RF katheter, (3) cirkelvormige ostium isolatie met gebruik van een cryocoagulatie katheter. De cryocoagulatie katheter en de gekoelde tip RF katheter genereren significant minder cerebrale micro-embolieën dan de conventionele RF katheter. Hierdoor bestaat de kans dat het risico op neurologische complicaties na een PVI procedure lager is bij gebruik van een cryocoagulatie katheter of een gekoelde RF katheter dan bij gebruik een conventionele RF katheter.

Cerebrale MES kunnen worden verminderd tijdens hartchirurgische en cardiologische procedures door veranderingen aan de standaard methode (hoofdstuk 2), door een andere methode voor dezelfde therapie te verkiezen (hoofdstuk 3) en door ander instrumentarium te gebruiken (hoofdstuk 4).

Desondanks kunnen niet alle cerebrale micro-embolieën tijdens hartchirurgische en cardiologische procedures door verandering van instrumentarium of methode volledig worden voorkomen. Een nieuw apparaat, dat de potentie heeft om te voorkomen dat micro-embolieën, die zich in bloedstroom bevinden, in de hersenvaten terecht te komen, is preklinisch getest in hoofdstuk $\mathbf{5}$. Dit nieuwe, op ultrageluid gebaseerde apparaat (EmBlocker $\left.{ }^{\mathrm{TM}}\right)$, wordt distaal op de "aorta ascendens" geplaatst en zou bij activatie micro-embolieën moeten afbuigen richting de "aorta descendens" om zo te voorkomen dat ze in de hersenvaten terechtkomen. In de preklinische dierstudie is aangetoond dat zowel vaste als gasvormige cerebrale MES kunnen worden verminderd door activatie van de EmBlocker ${ }^{\mathrm{TM}}$.

In hoofdstuk 6 is deze op, ultrageluid gebaseerde techniek, getest bij patiënten die een hart operatie hebben ondergaan. De EmBlocker ${ }^{\mathrm{TM}}$ werd gedurende de operatie geactiveerd tijdens geselecteerde momenten waarvan bekend is dat er microembolieën kunnen ontstaan. Deze activaties reduceerden het aantal cerebrale MES met ongeveer $50 \%$. Dit resultaat laat zien dat het gebruik van de EmBlocker ${ }^{\mathrm{TM}}$ tijdens hartchirurgische procedure, het aantal cerebrale MES kan verminderen, en daardoor mogelijkerwijs het risico op postoperatieve neurologische complicaties kan verkleinen. 
Het aantal cerebrale micro-embolieën dat veroorzaakt wordt tijdens een hartchirurgische en cardiologische procedures, blijkt afhankelijk van de fase van de behandeling en afhankelijk van procedures en gebruikt instrumentarium, zoals is aangetoond in de genoemde hoofdstukken. Bij verschillende momenten of manipulaties tijdens hart procedures kan de hoeveelheid gegenereerde microembolieën erg hoog worden en kunnen de zogenaamde "embolic showers" ontstaan. De huidige methoden om de micro-embolieën te tellen kunnen alleen een schatting geven van het aantal MES in "embolic showers". Alleen als de micro-embolieën met een bepaalde tijdsperiode na elkaar verschijnen, kunnen ze accuraat geteld worden. In "embolic showers" verschijnen ze sneller dan de benodigde tijdsperiode, waardoor de totale hoeveelheid micro-embolieën wordt onderschat. In hoofdstuk $\mathbf{7}$ is een algoritme beschreven dat is gemaakt om microembolieën in "embolic showers" nauwkeuriger te tellen. Dit algoritme heeft een hoge temporele resolutie en is gebaseerd op het ruwe teruggekaatste RF signaal van de microemboli. Het algoritme was toegepast op verschillende opnames van "embolic showers" gedurende hartchirugische operaties, en levert amplitude figuren op die, kwantitatieve informatie bevatten. Deze amplitude figuren leveren een duidelijker visueel beeld van de micro-embolieën in een "embolic shower", dan de snelheidspectra van de bestaande TCD systemen. Dit is een beduidende verbetering. Daarom zou een automatisch detectie algoritme voor micro-embolieën gebaseerd op RF-amplitude figuren, een geschikt alternatief zijn voor de bestaande detectie methoden.

In hoofdstuk 8 tenslotte wordt de relevantie van cerebrale MES detectie voor de inschatting van het risico op neurologische complicaties tijdens hartchirurgische en cardiologische procedures bediscussieerd. 



\section{Publications}

\section{Papers}

Sauren LD, la Meir M, de Roy L, Pison L, van der Veen FH, Mess WH, Crijns HJ, Maessen JG. Increased number of cerebral emboli during percutaneous endocardial pulmonary vein isolation versus a thoracoscopic epicardial approach. Eur J Cardiothorac Surg. 2009 Jul 8. [Epub ahead of print]

Sauren LD, la Meir M, Bolotin G, van der Veen FH, Heijmans JH, Mess WH, Maessen JG. The EmBlocker: efficiency of a new ultrasonic embolic protection device adjunctive to heart valve surgery. Ann Thorac Surg. 2009 Jul;88(1):253-7.

Sauren LD, Van Belle Y, DE Roy L, Pison L, LA Meir M, VAN DER Veen FH, Crijns HJ, Jordaens L, Mess WH, Maessen JG. Transcranial Measurement of Cerebral Microembolic Signals During Endocardial Pulmonary Vein Isolation: Comparison of Three Different Ablation Techniques. J Cardiovasc Electrophysiol. 2009 Jun 22. [Epub ahead of print]

Sauren L, Mooren E, Severdija E, Weerwind P, Maessen J. Emboli occurrence during coronary artery bypass surgery: the influence of a new method of perfusionist blood sampling. Perfusion. 2008 Sep;23(5):261-5.

Lipperts MG, Sauren LD, Maessen JG, Hoeks AP, Mess WH. Quantification of embolic showers using radio-frequency based TCD analysis. Ultrasound Med Biol. 2009 Mar;35(3):395-402. Epub 2008 Dec 12.

Sauren LD, la Meir M, Palmen M, Severdija E, van der Veen FH, Mess WH, Maessen JG. New ultrasonic radiation reduces cerebral emboli during extracorporeal circulation. Eur J Cardiothorac Surg. 2007 Aug;32(2):274-80. Epub 2007 Apr 12.

Sauren LD, Accord RE, Hamzeh K, de Jong M, van der Nagel T, van der Veen FH, Maessen JG. Combined Impella and IABP support to improve both ventricular unloading and coronary blood flow for myocardial recovery; an experimental study. Artif Organs 2007 Nov;31(11):839-42.

Reesink KD, Sauren LD, Dekker AL, Severdija E, van der Nagel T, Geskes GG, van der Veen FH, Maessen JG. Synchronously counterpulsating extracorporeal life support enhances myocardial working conditions regardless of systemic perfusion pressure. Eur J Cardiothorac Surg. 2005;28(6):790-6.

Sauren LD, Reesink KD, Selder JL, Beghi C, Veen van der FD, Maessen JG. The acute effect of Intra-aortic Balloon counterpulsation during Extracorporeal Life Support: An experimental study. Artif Organs. 2007 Jan;31(1):31-8 


\section{Abstracts}

Sauren LDC Bsc, Reesink KD Msc, Dekker ALAJ PhD, Veen van der FH PhD, Nagel van der T, Ommen van V MD, Severdija E, Geskens GG MD, Soemers ACM MD, Maessen JG MD PhD. Analysis of synchronized pulsatile support. Nederlandse vereniging voor Thoraxchrirurgie (Netherlands association cardiothoracic surgery), najaarsvergadering 2003. (oral presentation)

Sauren LDC Msc, Reesink KD Msc, Dekker AL PhD, Nagel van der T, Severdija E, Soemers C MD, Geskens, GG MD, Veen van der FH PhD, Maessen JG MD PhD. Cardiac working conditions can be optimized by synchronized pulsatile Extra Corporeal Life Support. CHEST 2004: 70th Annual Meeting of the American College of Chest Physicians October 23 - 28, 2004, Seattle, Washington, USA. (poster presentation)

Sauren LDC Msc, Selder J Bsc, Reesink KD Msc, Nagel van de T, Veen van der FH, PhD, Maessen JG MD PhD. Optimalisation of combined IABP/ECLS therapy: Aortic arch vs. femoral artery arterial cannulation of ECLS. Heart Failure \& Rotary Blood Pump, October 7-10 2004, Cleveland, Ohio, USA. (poster presentation)

Sauren LDC Msc, Selder JL Bsc, Veen van der FH PhD, Nagel van der T, Reesink KD Msc, Jong de M, Beghi $C$, Maessen J. Extra haemodynamic support provided by IABP in combination with ECLS. European Society of Cardiology (Heart Failure), June 11-14 2005, Lissabon, Portugal. (poster presentation)

Sauren LDC, de Jong M, Severdija E, la Meir M, van der Veen FH, de Jong D, Mess W, Maessen JG. New ultrasonic radiation technology reduces cerebral emboli during extracorporeal circulation, an animal study. Nederlandse vereniging voor Thoraxchirurgie (Netherlands association cardio-thoracic surgery), najaarsvergadering 2006. (oral presentation)

Loes Sauren, Erwin Severdija, Leonid Sternik, Mark la Meir, Erik van der Veen, Dick de Jong, Werner Mess Jos Maessen. New ultrasonic radiation technology reduces cerebral microemboli during extracorporeal circulation. A multi center animal study. 5th EACTS/ESTS joint meeting 2006. (oral presentation)

Sauren L, la Meir M, Bolotin G, van der Veen E, Mess W, Maessen J. A novel intra-operative ultrasonic technology to reduce micro-emboli in cardiac operations. Neurosonology meeting 2007, 26-29 may Budapest, Hungary. (oral presentation)

L. Sauren, M. la Meir, T. Bodifee, E. Van der Veen, L. le Roy, W. Mess, H. Crijns J.Maessen. Endocardial atrial fibrillation ablation procedures are associated with profuse microembolic signals whereas epicardial ablation is not. European stroke conference, 29 may-1 june Glasgow, Scotland. (oral presentation)

Sauren, Loes, la Meir, Mark, De Roy, Luc , van der Veen, Erik, Mess, Werner, de Roy, Luc, Crijns, Harry, Maessen, Jos. Cerebral micro embolic signals burden during AF ablation; endocardial versus epicardial approach. ECAS, 1-4 june, Marseille, France. (oral presentation)

L. Sauren, M. la Meir, T. Bodifee, E. Van der Veen, W. Mess, L. le Roy, H. Crijns, J.Maessen. Epicardial pulmonary vein isolation significantly eliminates cerebral micro emboli compared to the endocardial approach. Nederlandse vereniging voor Thoraxchrirurgie (Netherlands association cardio-thoracic surgery), voorjaarsvergadering 2007. (oral presentation) 
L. Sauren, E.Mooren, E.Severdija, D.S.de Jong, J.Maessen.The Micro Embolic Signals in Open and Closed Cardiopulmonary Bypass Systems can be low despite numbers of MES mentioned in literature reports; Changes in the method of blood sampling can even cause a total elimination of micro emboli in the arterial line. FECECT 2007, 4-6 june Kiev, Ukrainian. (oral presentation)

L. Sauren, L. le Roy, M. la Meir, E. Van der Veen, W. Mess, H. Crijns, J.Maessen.RF ablation with an irrigated tip catheter reduces cerebral micro emboli during pulmonary vein isolation (PVI). European society of cardiology 2007, 1-5 September Vienna, Austria. (poster presentation)

Sauren L, la Meir M, Bolotin G, van der Veen E, Mess W, Maessen J. A novel intra-operative ultrasonic technology to reduce micro-emboli in cardiac operations. EACTS 2007, 15-19 September Geneva, Switserland. (oral presentation)

L. Sauren, L. le Roy, L.Pison, M. la Meir, E. Van der Veen, W. Mess, H. Crijns J.Maessen. Ablation of the pulmonary veins using an irrigated tip RF ablation catheter reduces cerebral microemboli versus a non-irrigated-tip RF ablation catheter. American heart 2007 2-8 november, Orloando, USA. (poster presentation)

L. Sauren, M. la Meir, L.Pison, F. van der Veen, W. Mess, L. le Roy, H. Crijns J.Maessen. Thoracoscopic epicardial pulmonary vein isolation is a realistic alternative for endocardial radiofrequency ablation: lower risk of arterial embolism and shorter procedure times. American heart 2007 2-8 November, Orlando, USA. (poster presentation)

L. Sauren, M. la Meir, L.Pison, F. van der Veen, W. Mess, L. le Roy, H. Crijns J.Maessen. Thoracoscopic epicardial pulmonary vein isolation is a realistic alternative for endocardial radiofrequency ablation: lower risk of arterial embolism. European society of cardiovascular surgery 2008 24-27 april 2008, Barcelona, Spain (oral presentation)

L. Sauren, L. De Roy, Y. van Belle, L.Pison, M. la Meir, E. Van der Veen, W. Mess, L. Jordaens, H. Crijns, J.Maessen. Atrial fibrillation: the risk of microembolism depends on method of pulmonary veins isolation. An irrigated-tip RF, standard RF and a Cryo balloon study. Heart Rhythm, May 14-16 2008, San Fransisco, USA. (poster presentation) 



\section{Curriculum vitae}

Loes Sauren was born on September 261978 in Weert, the Netherlands. After graduating from secondary school (VWO) SG St-Ursula, Horn in 1997, she started the master Biomedical Engineering education at the Eindhoven University of Technology. In 2003 she worked for a year at the research and development department at the medical device company, Terumo Cardiovascular Systems in Tustin, CA, USA. From 2005 to 2008 she worked as a PhD student at the departments of Cardiothoracic Surgery and Clinical Neurophysiology of the Maastricht University under supervision of Prof. dr. J.G. Maessen and Prof. dr. W.H. Mess. Since the beginning of 2009 she enrolled a clinical physicist training program in the Maastricht University Medical Centre at the Clinical Neurophysiology department. 